NBER WORKING PAPER SERIES

\title{
STOCHASTIC INFINITE HORIZON FORECASTS FOR SOCIAL SECURITY AND RELATED STUDIES
}

\author{
Ronald Lee \\ Timothy Miller \\ Michael Anderson \\ Working Paper 10917 \\ http://www.nber.org/papers/w10917 \\ NATIONAL BUREAU OF ECONOMIC RESEARCH \\ 1050 Massachusetts Avenue \\ Cambridge, MA 02138 \\ November 2004
}

This research was supported by the U.S. Social Security Administration through grant \#10-P-98363-1 to the National Bureau of Economic Research as part of the SSA Retirement Research Consortium. The opinions and conclusions expressed are solely those of the authors and do not represent the opinions or policy of SSA, any agency of the Federal Government, or the NBER. The authors also acknowledge support from Berkeley's NIA-funded Center for the Economics and Demography of Aging. The research funded here builds on basic research funded by NIA grant R37-AG11761. The views expressed herein are those of the authors and do not necessarily reflect the views of the National Bureau of Economic Research.

(C) 2004 by Ronald Lee, Timothy Miller, and Michael Anderson. All rights reserved. Short sections of text, not to exceed two paragraphs, may be quoted without explicit permission provided that full credit, including (C) notice, is given to the source. 
Stochastic Infinite Horizon Forecasts for Social Security and Related Studies

Ronald Lee, Timothy Miller, and Michael Anderson

NBER Working Paper No. 10917

November 2004

JEL No. H0, H5

\begin{abstract}
$\underline{\text { ABSTRACT }}$
This paper consists of three reports on stochastic forecasting for Social Security, on infinite horizons, immigration, and structural time series models. 1) In our preferred stochastic immigration forecast, total net immigration drops from current levels down to about one million by 2020 , then slowly rises to 1.2 million at the end of the century, with $95 \%$ probability bounds of 800,000 to 1.8 million at the century's end. Adding stochastic immigration makes little difference to the probability distribution of the old age dependency ratio. 2) We incorporate parameter uncertainty, stochastic trends, and uncertain ultimate levels in stochastic models of wage growth and fertility. These changes sometimes substantially affect the probability distributions of the individual input forecasts, but they make relatively little difference when embedded in the more fully stochastic Social Security projection. 3) Using a 500-year stochastic projection, we estimate an infinite horizon balance of $-5.15 \%$ of payroll, compared to the $-3.5 \%$ of the 2004 Trustees Report, probably reflecting different mortality projections. Our $95 \%$ probability interval bounds are -10.5 and $-1.3 \%$. Such forecasts, which reflect only "routine" uncertainty, have many problems but nonetheless seem worthwhile.

\begin{tabular}{|c|c|c|}
\hline Ronald Lee & Timothy Miller & Michael Anderson \\
\hline Demography and Economics & Center for the Economics an & Center for the Economics and \\
\hline University fo California & Demography of Aging & Demography of Aging \\
\hline 2232 Piedmont Avenue & University fo California & University fo California \\
\hline Berkeley, CA 94720 & 2232 Piedmont Avenue & 2232 Piedmont Avenue \\
\hline and NBER & Berkeley, CA 94720 & Berkeley, CA 94720 \\
\hline rlee@demog.berkeley.edu & tmiller@demog.berkeley.edu & mikeand1@pacbell.net \\
\hline
\end{tabular}
\end{abstract}


This report consists of three sub-reports, which are listed below, followed by brief summaries of the conclusions of each.

Report I. A Probabilistic Forecast of Net Migration to the United States. (Miller and $\underline{\text { Lee) }}$

Summary of Conclusions

1. Given the history of immigration to the US, a number of key assumptions must be made without a satisfactorily firm basis, such as whether to model numbers or rates, over what historical period to fit the model, and whether to include a trend in the forecast, or to impose central tendency based on expert opinion.

2. Experiments with a variety of approaches suggest that the probability distribution of the immigration forecast is not highly sensitive to these variations, although forecasts of the rate, with a trend, do lead to forecasts of higher numbers in the future.

3. Our preferred projection is based on numbers of immigrants rather than rates, and randomly samples trends between 0 and the historical average for each sample path. In this case, the projected number of net immigrants (legal and illegal) drops from current levels down to about one million in 2020, and then slowly rises to 1.2 million at the end of the century. The lower $2.5 \%$ probability bound is near 800,000 throughout the century, after the first decade or two. The upper $97.5 \%$ bound starts at 1.3 million, and rises quite linearly to 1.8 million at the end of the century.

4. With this range of models and forecasts, including immigration in the population forecasts makes little difference to the probability distribution of the old age dependency ratio, which is the item of prime importance for the Social Security forecasts.

Report II. Structural time series models and parameter uncertainty in Stochastic Projections of Social Security Finances. (Anderson and Lee) Summary of Conclusions

We have experimented with a variety of different specifications of the time series models for wage growth and fertility, which are two of the key inputs for the projections. The expectation was that introducing parameter uncertainty, stochastically varying trends terms, and uncertain ultimate levels, would make the projections more uncertain. We did indeed find this to be so in every case, although one version of Homer's model, in which fertility was first logged, then modeled, then exponentiated, turned out to give a narrower probability interval than our other models including the standard ones. In some cases, the change in probability intervals for the individual input series was very slight, for example when parameter uncertainty was introduced to the fertility model, or when we used structural methods for wage growth. The big differences come from using an uncertain ultimate level for wage growth, or a structural estimate for fertility.

Although some of these new models have a substantial effect on the estimated probability distributions for the forecasts of the inputs themselves, they seem to make much less difference when they are embedded in a more fully stochastic Social Security projection. This is good news for the stochastic projections, because it suggests that they are not so sensitive to the specifications of the input series as one might have feared. This is true in our stochastic forecasting model which has only four stochastic inputs. It would be even 
more true in the forecasting models of Social Security and $\mathrm{CBO}$ with their greater number of inputs. One would not want to push this argument too far, of course. Ultimately, the stochastic forecasts of Social Security are only as good as the stochastic forecasts of the key input series.

\section{Report III. Stochastic Infinite Horizon Forecasts of Social Security Sustainability. (Lee and Anderson). \\ Summary of Conclusions}

1) Many issues surround infinite horizon forecasts, and the whole enterprise can certainly be questioned. Nonetheless, we have found it useful simply to extend the range of the stochastic forecasting models to very distant horizons. We call these "routine" or "business as usual" stochastic forecasts, because their uncertainty does not reflect the possibility of structural shifts. They understate actual uncertainty.

2) Both the Flat Fund Ratio Tax measure and the Unstable measure are useful simple approximations to the deterministic or median infinite horizon open group imbalance measure. The Flat Fund Ratio is the immediate and permanent tax increase that would be needed to hold the ratio of the Trust Fund to Costs constant over the last two years of the 75-year projection. It is more intuitive and therefore easier to explain than the Unstable measure, but it underestimates the imbalance, whereas the Unstable measure (explained in the report) gives a very good approximation to the infinite horizon measure, at least under current circumstances.

3) The 2004 Trustees Report indicates an infinite horizon open group imbalance equal to $3.5 \%$ of payroll, consistent with Lee and Yamagata's (2003) calculation using SSA mortality assumptions. Based on our 500-year projection with our own mortality forecasts, we estimate it to be 5.15\%, substantially larger. Our two simple methods, based on our 75 year projections, indicate levels of $4.36 \%$ for the Flat Fund Ratio measure, and $5.21 \%$ for the Unstable measure.

4) Good estimates of the uncertainty of the simple measures cannot be derived from stochastic forecasts over the 75 year horizon, at least using the methods we have attempted. Therefore the simple measures are useful only for central tendency.

5) The "routine" uncertainty surrounding the infinite horizon estimates of Summary Actuarial Balance is about $40 \%$ greater than the uncertainty of the 75 year projections: the $95 \%$ probability interval is $9 \%$ wide versus $6.5 \%$ for the 75 -year horizon.

6) Raising tax rates immediately by an amount intended to achieve sustainability would imply substantial chances of huge Trust Fund accumulations that neither could nor should be realized in practice, at least not through holdings of government bonds. Adaptive policies that maintain the Trust Fund ratio at a desirable level seem more attractive, but have not yet been explored. 


\title{
Report I
}

\section{A Probabilistic Forecast of Net Migration to the United States}

\author{
Timothy Miller \\ and \\ Ronald Lee \\ Center for the Economics and Demography of Aging \\ University of California at Berkeley \\ 2232 Piedmont Avenue \\ Berkeley, CA 94720-2120 \\ tmiller@demog.berkeley.edu
}

October 8, 2004

The research reported herein was performed pursuant to a grant from the US Social Security Administration (SSA) as part of the Retirement Research Consortium. The opinions and conclusions expressed are solely those of the authors and do not represent the opinions or policy of SSA or any agency of the Federal Government. The authors also acknowledge support from Berkeley's NIA-funded Center for the Economics and Demography of Aging. The research funded here builds on basic research funded by NIA grant R37-AG11761. 


\section{Background}

The core engine of stochastic macro forecasting models for Social Security finances is a stochastic population model. The first such model was developed by Lee and Tuljapurkar (1994), henceforth LT94. This model treated fertility and mortality as stochastic, but took immigration as deterministically given at some specified rate. There were two reasons for doing this. One was that immigration could be viewed as a policy variable. A policy maker would not find it useful to be given a forecast in which a key policy level was treated as stochastic, and outside control. Another is that immigration appears to be more difficulty to forecast then either fertility or mortality, because its trend has been so problematic in the US. In this report we discuss the issues and options for forecasting immigration stochastically, and develop some different versions of stochastic forecasts of immigration. These are then incorporated in a LT style model for generating stochastic population forecasts, and the results are discussed.

Forecasts of net migration to the United States are issued by the U.S. Social Security Administration (SSA), the U.S. Census Bureau (CB), and the United Nations (UN). The different approaches of these agencies are discussed in the following paragraphs and summarized in Table 1.

\section{Social Security Administration}

SSA forecasts immigration as a separate component of their population forecast. The projection assumes that changes in population size, age structure, and composition have no impact on the annual flow of net immigrants. The SSA median forecast assumes no change in current law in which approximately 600,000 legal immigrants are admitted each year. Illegal immigration is assumed to continue at half the level of legal immigrants. In the short-run, owing in part of the effects of the recent amnesty, SSA forecasts 800,000 legal immigrants plus another 400,000 illegal immigrants for a total of 1.2 net immigrants per year. They project a decline in the total number of net immigrants toward a long-run average of 900,000 per year (600,000 legal plus 300,000 illegal). Their high cost variant envisions net immigration of 1.3 million per year and while the low cost variant sees a decline to 672,500 net immigrants per year. Recently, the Social Security Technical Panel on Assumptions and Methods (2003) recommended that the SSA Trustees change their forecast methodology and project using a net immigration rate, rather than numbers. We explore the implications of both methods in our projections discussed in the next section.

\section{Census Bureau}

The Census Bureau forecasts in-migrants separately from out-migrants. The number of out-migrants is based on an out-migration rate applied to the projected foreign-born population. In the baseline projection, the number of in-migrants in the short-run (thru 2020 ) is based on assumptions about trends in immigration by category: immediate relatives, numerically-limited categories, refugees, and illegal immigrants. From 2021 to 
2030 , the projection assumes the number of in-migrants rises in response to increases in the dependency ratio. From 2030 onward, the number of in-migrants is assumed to be fixed at the new limit of 1.45 million immigrants. While the number of in-migrants is constant since 2030, the number of out-migrants fluctuates over the period in response to shifts in the age composition of foreign-born. Net immigration reaches its peak in 2030 at 1.06 million and slowly decreases to 926,000 by 2100 . The long-run values of the baseline forecasts of SSA and CB are surprisingly close. In contrast, the high-low range of the Census Bureau is very large relative to SSA. By 2100, the CB high-low estimates differ by 3 million immigrants ( 3 million versus 113,000). This is about 6 times as wide as the SSA high-low estimates which differ by only half a million (1.3 million versus $672,000)$. Recently, the $\mathrm{CB}$ issued a new interim population forecast (CB, 2004). In this forecast their immigration assumptions is set equal 0.938 times the year 2000 middle forecast plus 0.62 times the year 2000 high forecast. This implies immigration will reach nearly 1.1 million per year by 2100 .

\section{United Nations}

The UN forecasts net immigrants for each country based on the policy stance of the country. In the case of their U.S., they forecast a decline from 1.25 million net immigrants per year in the late 1990 s to 1.1 million by 2010 , followed by a constant level of 1.1 million. The UN forecast is quite close to the middle forecast of both $\mathrm{CB}$ and SSA. The UN provides no alternative migration scenarios. Table 1 below summarizes the differences among the SSA, CB, and UN in their immigration forecasts. 
Table 1. Summary of Methods for Immigration Forecasts by the Social Security Administration, Census Bureau, and United Nations.

\begin{tabular}{|c|c|c|c|}
\hline & SSA & CB & UN \\
\hline What is forecast? & Net immigrants. & $\begin{array}{l}\text { In-migrants separately from out- } \\
\text { migrants. }\end{array}$ & Net immigrants \\
\hline $\begin{array}{l}\text { Alternative } \\
\text { migration } \\
\text { scenarios? }\end{array}$ & High and low cost. & High and low population sizes. & None. \\
\hline $\begin{array}{l}\text { Baseline forecast is } \\
\text { based on: }\end{array}$ & $\begin{array}{l}\text { Current law with } \\
\text { temporary high net } \\
\text { migration due to } \\
\text { amnesty. }\end{array}$ & $\begin{array}{l}\text { Slight increase in response to } \\
\text { increased in OADR in the decade of } \\
\text { the } 2020 \mathrm{~s} .\end{array}$ & $\begin{array}{l}\text { Policy stance of } \\
\text { county. }\end{array}$ \\
\hline Baseline numbers: & $\begin{array}{l}1,200,000 \text { (of } \\
\text { whom } 400,000 \text { are } \\
\text { illegal) declining to } \\
\text { long-run average of } \\
900,000 \text { (of whom } \\
300,000 \text { are illegal) } \\
\text { in } 2024 \text {. }\end{array}$ & $\begin{array}{l}964,000 \text { net immigrants }(1,251,000 \\
\text { in-migrants and } 287,000 \text { out- } \\
\text { migrants). Declines to } 713,000 \text { net } \\
\text { migrants in } 2010 \text {, then peaks at } \\
1,061,000 \text { net migrants in } 2030 \text {, } \\
\text { slowly declines reaching } 926,000 \\
\text { net migrants in } 2100 \text {. In } 2004, \mathrm{CB} \\
\text { issued new interim projections } \\
\text { which raised the median } \\
\text { immigration forecast to equal } 0.938 \\
\text { times the old median forecast plus } \\
0.062 \text { times the old high forecast. } \\
\text { This implies a } 2100 \text { forecast of } \\
\text { nearly } 1.1 \text { million net immigrants. }\end{array}$ & $\begin{array}{l}1,250,000 \text { declining to } \\
\text { long-run average of } \\
1,100,000 \text { in } 2010 .\end{array}$ \\
\hline $\begin{array}{l}\text { Alternative } \\
\text { scenarios: }\end{array}$ & $\begin{array}{l}\text { Low cost: } \\
1,300,000 \text { (of } \\
\text { whom } 450,000 \text { are } \\
\text { illegal). } \\
\text { High cost: } 672,500 \\
\text { (of whom } 200,000 \\
\text { are illegal) }\end{array}$ & $\begin{array}{l}\text { Low pop: } 624,000 \text { net migrants in } \\
2000 \text {, declining to } 113,000 \text { net } \\
\text { migrants in } 2100 \text {. } \\
\text { High pop: } 1,363,000 \text { net migrants in } \\
2000 \text {, increasing to } 3,047,000 \text { in } \\
2100 \text {. }\end{array}$ & $\begin{array}{l}\text { No alternative } \\
\text { migration scenarios } \\
\text { (only fertility } \\
\text { scenarios). }\end{array}$ \\
\hline Issued: & $\begin{array}{l}2004 \text { Trustees } \\
\text { Report }\end{array}$ & $\begin{array}{l}2000 \text { National Population } \\
\text { Projections. Since replaced with the } \\
2004 \text { National Population } \\
\text { Projections with higher immigration } \\
\text { levels. }\end{array}$ & $\begin{array}{l}\text { World Population } \\
\text { Prospects: The } 2000 \\
\text { Revision (2001). }\end{array}$ \\
\hline
\end{tabular}




\section{The Time Series Approach to Forecasting Net Immigration}

We develop a probabilistic forecast of immigration. Rather than examining three scenarios as done by SSA or CB, we develop thousands of possible sample paths based on both time series analysis of past variation and on expert opinion about the future course of immigration. There are several distinct advantages of modeling uncertainty based on an analysis of historical times series rather than the use of high-low scenarios. (For an extensive discussion see Lee (2004) and Lee and Tuljapurkar, (2000)). The timeseries approach deals with uncertainty in a probabilistic and consistent fashion. By contrast, in the scenario approach, the high-low range generally lacks any probabilistic interpretation, so the user has no sense of how likely they are to contain the true values. The scenario approach assumes perfect correlation of the component trajectories (e.g., fertility, mortality, and migration) with each other and across time. For example, high fertility is always high and is always coupled with high immigration. It is generally not clear whether the high-low range is meant to contain annual variations or long-run averages. The probability bands for long-run averages will be considerably narrower than bands for annual variations due to error cancellation over time.

Ideally, we would be able to estimate a plausible and appealing time series model of the stochastic process based entirely on historical data, which would then be sufficient to identify both the long run level or trend in the input series for forecasting purposes, as well as identifying the variances and covariances of interest. In the case of mortality forecasts, this ideal case holds quite well, using the Lee-Carter (1992). However, in the case of fertility, there are strong theoretical reasons to expect the central tendency to have changed over the course of the $20^{\text {th }}$ century, but not necessarily to continue to change in the future. Also, there is external information about the range of possible variation that should be taken into account (Lee, 1993). For fertility, then, the ideal conditions are not met, and the forecast model takes a long term expected value from expert opinion, and excludes certain stochastic realizations as impossible. The real interest rate and the rate of growth of covered wages are handled in a similar manner, so far as central tendencies are concerned. For immigration, it seems clear that the historical data does not provide a fully adequate basis for assessing the long term trend. Even more than fertility, the course of immigration in the $20^{\text {th }}$ century US was dominated by very long trend like movements, which might or might not reasonably be expected to continue in the future. Thus there are difficult strategic issues to be confronted before we begin modeling, as we now consider. These issues are not specific to probabilistic modeling, but rather are the same issues that anyone constructing a deterministic projection would also have to confront.

Here are some of the basic questions:

- Should we forecast the rate of immigration or the number of immigrants?

- Should we rely on the observed historical trend for our forecast?

- Should we use expert opinion to specify the likely trend?

- If relying on historical data, how far back in history should we go?

The National Research Council (2000) published a report assessing the projections methodology of the UN, the World Bank, and the International Division of the US 
Census Bureau. This report evaluated methods used for global projections, covering all countries of the world, which is not the same as preparing a projection for the US. Nonetheless, the chapter on immigration in the report does provide some useful insights for present purposes. Here are some of the relevant conclusions.

1) 1) Errors in projecting immigration lead to errors in population projections that are as important as those arising from errors in projecting fertility, and far more important than errors in projecting mortality, in the United Nations projections record since 1960 or so. However, the most important errors arise for countries that are subject to a demographic "quake", an unexpected political, military or environmental shock. Excluding these instances, the role of errors in forecasting immigration is only about half as great, comparable to mortality. We would not expect that "quakes" of this sort would be likely for the US.

2) It is useful to distinguish countries that have a long history as receiving countries for immigrants, since they are much more likely to continue in this role in the future. The US is a prime example. However, it is also important to realize that some long-time receiving countries such as Brazil and Argentina no longer receive many international immigrants, so reversals do occur and continuing status as a receiving nation cannot be taken for granted but must be assessed.

3) Although it is plausible that increasing globalization of markets will lead to increased international migratory flows in the coming decades, it is also possible that national policy will tend toward restricting immigration. It is also possible that other industrial nations will increasingly compete with the US for immigrants from the Third World as an antidote to population aging, as is much discussed these days.

4) Using UN data since 1950, experiments with different projection assumptions for immigration and emigration were carried out. For our purposes, the two most interesting possibilities were considered were a) assuming 0 net immigration in the future regardless of past levels or rates, and b) assuming that the most recent level of immigration (over a five year interval) continued constant in perpetuity. Forecasting errors were then assessed. It was found that for horizons up to ten years, the constant immigration flow assumption led to smaller errors than the zero assumption, but for horizons of 15 to 40 years, the constant immigration assumption led to larger errors. This was true for all countries considered together, and also true if countries experiencing "quakes" were considered separately.

The National Research Council (2000) report does not explicitly address any of the questions posed earlier, but it does provide some general ideas about how to proceed. In the US, we have had a fifty year history of constantly accelerating immigration. The report can be read as suggesting some caution in assuming that this long and impressive trend will continue.

\section{Forecasting the Rate or Level of Immigration?}

Typically, forecasts are made of the number of immigrants rather than the immigration rate. Forecasting numbers of immigrants is consistent with legislative-controls on 
immigration which focus on numbers of legal permanent residents admitted each year. For example, under current U.S. immigration law the number of legal permanent residents admitted each year is limited to 675,000 plus unlimited numbers of immediate relatives (spouses and unmarried children U.S. citizens and parents of adult U.S. citizens) and unlimited numbers of previously-admitted refugees and asylees who are adjusting their immigration status. For those admissions subject to the annual numerical cap, it is easy to observe the effects of these limits in the 5.3 million immigrant applications that are currently pending or in the average 10 year waiting time for admission of siblings of naturalized U.S. citizens.

Recently, the SSA Technical Advisory Panel recommended that the Trustees long-run target for intermediate forecast be based on a net migration rate rather than a net migration level. The Panel recommended the long-run target be set to a net migration rate of 3.2 per 1,000 (based on Wilmoth's estimate of the net migration rate for the period 1821-2002). The panel recommended that the high-cost scenario be based on the continuation of the current level of immigration (implying a declining net migration rate) and that the low-cost scenario be based on a continuation of the current net immigration rate (4.2 per 1000). The panel listed several factors which might lead to more restrictive immigration: economic slowdown, national security concerns, falling fertility in sending regions, the dissipation of the residual immigration effects of the IRCA legalization of the 1990 s, and the increased demand for immigrants in rapidly aging Europe and Japan.

They also listed several factors which might lead to increased immigration: demand for immigrant labor is likely to scale with the growth of population and the economy, the increased share of foreign born increases the network available for immigrants, there are large untapped pools of immigrants around the world, and the difficulty in immigration enforcement. On balance they argued: "Faced with these varied arguments, the Panel concluded that there is no strong reason to anticipate a sharp break with past trends in the near future" (Technical Panel 2003).

There is another point to consider when deciding to forecast rates versus levels. In the context of forecasting rates stochastically, we might ask whether we expect a positive or negative co-variation between net immigration rates and population size. On the one hand, we might expect positive co-variance arising as larger populations result from higher immigration rates. On the other hand, we might expect negative co-variance as slower population growth might lead to increased demand for immigration. This ambiguity is one reason why projecting the number of immigrants might be preferable, because the historical co-variations of the rate of immigration and the base population size to which it is applied are implicit in the projection of their product, the numbers of immigrants.

In the models and forecasts which follow, we analyze four combinations of assumptions: forecasts of the net immigration rate or level and use of the observed historical trend in the forecast or substitution of a constant rate or level in the forecast. In addition, we present a forecast in which we assume that the trend in levels of immigration are uniformly distributed over the interval between 0 -trend and the time series estimate of the trend. 


\section{Choice of a time period}

We begin by modeling stochastic immigration in a similar manner to the stochastic forecasts of fertility as in Lee (1993). We issue a probabilistic forecast of the level of net immigration based on a time-series analysis of the historical series of legal immigration to the United States. A similar method is used to generate a probabilistic forecast of the net immigration rate. The first question that arises in the context of immigration is the appropriate time period for the time-series estimation.

Figure 1.1 shows the gross legal immigration rate from 1820 to 2002 . Two distinct periods are evident in the series. The $19^{\text {th }}$ century is characterized by high and fluctuating rates, while the $20^{\text {th }}$ century shows much less variation with a distinct upward trend. For the time series estimation we chose the period following the Federal Immigration Act of 1924 which permanently established immigration limits via the quota system. Choice of a shorter or longer time-series would influence both the predicted variation and trend of the forecast.

The distinct peak in legal immigration in the early 1990s represents an immigrant amnesty. We chose not to model this in the simulation, since our forecast is most concerned with when people entered the country and not when they were legalized. So, rather than include amnesties as a periodic occurrence, we stochastically forecast legal immigration and assume that illegal immigrants represent a fixed proportion of legal entries. We use the SSA assumptions that illegal immigrant flows are $1 / 2$ that of legal flows and that $1 / 4$ of immigrants eventually emigrate. So, our forecast of legal immigrants is multiplied by $1.125(=3 / 2 * 3 / 4)$ to transform it into a forecast of net immigrants (legal plus illegal).

\section{Use of the historical trend}

The second question that arises is whether to allow the observed historical trend to influence our probabilistic forecasts or to replace this with a trend provided by expert opinion. On the one hand, previous studies of both mortality and fertility forecasts have found expert judgment to be unduly influenced by the recent past. On the other hand, if we have reason to believe there has been a structural shift or when there is doubt about the sustainability of current trends, then subjective expert opinion would be preferred. In the case of probabilistic forecast of fertility (Lee 1993), it was argued that the fertility transition had resulted in a structural shift. Therefore, the wiser course of action was to impose a lower level of fertility than that observed in the historical series. This was done via a mean constrained forecast such that the mean across all trajectories tended toward the long-run average deemed to be 1.9 births per woman.

Figure 1.2 presents the level of gross legal immigration to the U.S. from 1820 to 2002. This series is similar to that of the gross legal immigration rate seen in Figure 1.1. The $20^{\text {th }}$ century is characterized by a distinct upward trend in both the level and rate of immigration. 
Figure 1.3 presents data from the United Nations on net immigration flows from developing nations to developed ones from 1950-2000, along with the UN forecast for 2000-2500. The latter part of the $20^{\text {th }}$ century is characterized by a distinct upward trend in the net immigration rate to developed nations. Yet, as is evident here, the UN forecasts a distinct break with the past trend. It would be interesting to investigate whether previous UN forecasts also envisioned a distinct break which was subsequently shown to be inaccurate. The UN, SSA, and CB all forecast a leveling off of the immigration to the US - in sharp contrast to the experience of recent decades.

In our probabilistic simulations of immigration, we consider alternative forecasts in which the historical trend is replaced with a subjective assumption of no trend which is consistent with the opinions expressed by the UN, SSA, and CB.

\section{Fitting the Time Series Model}

Lacking data on flows of illegal immigrants and out-migrants, the time-series was fit to data on legal immigrants admitted to the U.S. from 1925-2002. Illegal immigrants who were granted legal permanent residence under the amnesty program of the 1990s (IRCA) were not included in this series. Auto-regressive and moving average time series models with a linear trend (in order to de-trend the series) were fit to the level of immigrants and the rate of legal immigrants. Based on Akaike information criterion, the AR(2) model with linear trend was found to have the best fit for both series. (Results in Tables 2 and 3). We also attempted to de-trend the data by taking first differences. However, in this case, the probability bounds of the resulting forecast widen very rapidly so as to reach quite extreme levels of immigration within a decade. We don't have a good justification for assuming the series is trend-stationary rather than difference-stationary, beyond the implications observed in the forecasts.

Table 2. Time-series estimate of Legal Immigrants to U.S. 1925-2002

Coefficients:

ar1 ar2 intercept $\operatorname{seq}(1925,2002)$

$\begin{array}{llll}1.0077 & -0.1373 & -21958445 & 11420.363\end{array}$

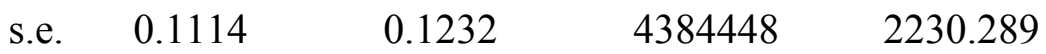

sigma $^{\wedge} 2$ estimated as $4.995 \mathrm{e}+09: \log$ likelihood $=-982.4$, aic $=1974.8$ 
Table 3. Time-series estimate of Legal Immigration Rate to U.S. 1925-2002

Coefficients:

ar1 ar2 intercept seq $(1925,2002)$

$1.0599 \quad-0.1721 \quad-50.4855 \quad 0.0268$

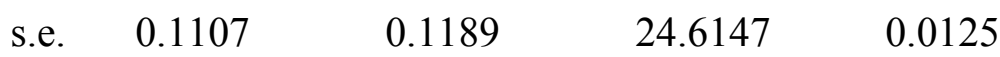

$\operatorname{sigma}^{\wedge} 2$ estimated as 0.1163: $\log$ likelihood $=-27.66$, aic $=65.31$

The point estimates of the AR coefficients imply a stationary forecast. However, in generating immigration trajectories, we sample from the joint distributions of the two AR coefficients. Therefore, it is possible that for some of our samples the AR coefficients imply a non-stationary path. we could have restricted the sampling so that such combinations were rejected. Instead, we have placed bounds on the resulting forecasts. In the forecasts of immigration rates, we established an upper bound of +15 per 1,000 (based on US historical experience) and a lower bound of -15 per 1000 (based on postwar experience in more developed countries). In the forecast of immigration level, we establish an upper bound of 4 million net immigrants per year.

\section{Previous Work}

In previous work, we stochastically forecast domestic and international migration to California for a probabilistic population forecast of the state (Miller, 2002). Net domestic immigration to California was based on a time series analysis of the net immigration rate. The rate was then applied to the population total in the previous year in order to derive a level of net immigration. The age/sex combination distribution of domestic immigrants was taken from the March CPS and was assumed to remain unchanged over the forecast. A similar approach has been taken in this paper. International migration to California was based on a time series analysis of the proportion of immigrants intending to reside in California. The forecast of this proportion was then multiplied by the Middle Series Forecast of Immigration to the U.S. from the Census Bureau in order to obtain the number of international migrants to California.

\section{Results}

Figure 1.4 compares our immigration forecasts to those of the UN, SSA, and CB. Our stochastic forecast of the level of immigration without the historical trend yields a median forecast nearly identical to that of Social Security. Our 95\% probability interval is about the same width as the high-low bounds of Social Security, but both our upper and lower bounds on the $95 \%$ probability interval lie above that of Social Security. The high-low bounds by Census Bureau are more than 4 times as wide as our 95\% probability interval.

Figure 1.5 shows our stochastic forecast of the level of immigration using the historical trend present in the time series. In this case, the baseline scenarios of both SSA and CB lie below our $95 \%$ probability interval. This reflects the fact that the baseline forecast of 
both agencies represents a distinct break with the past. The probability distribution for the cumulative average of the forecast looks odd in this figure. We would expect the distribution for the cumulative average to lie within the distribution for the forecasts for individual years, but this only need happen when there is no trend in the central forecast. When there is a rising trend, as in this version of the model, the cumulative average forecasts for longer horizons reflect the lower values of forecasts at shorter horizons, which pull down the whole distribution below the individual year forecasts.

The next set of figures compares the results of our stochastic forecast of the immigration rate to the forecasts of Census, SSA, and UN. A distinct narrowing of the high-low bounds of Census and SSA are evident in Figure 1.6. This is a by-product of the assumption of constant immigration levels with a growing population. In contrast, our probability intervals (based on rates) expand over time. By 2100, our probability intervals for the cumulative immigration rate are about as wide as those of the $\mathrm{CB}$, and many times wider than those of SSA.

Figure 1.7 shows the result of our stochastic forecast of the immigration rate using the trend present in the time series. In this case, our median forecast shows a slight increase in the net immigration rate from the current level of 4.2 , reaching 4.7 by 2100 . As the forecast horizon increases, the forecasts of $\mathrm{CB}, \mathrm{SSA}$, and UN fall below our $95 \%$ probability interval. Only CB's high population scenario lies within our 95\% probability interval at the end of the forecast.

In our view, the biggest uncertainty is in the choice of trend. We do not see a compelling reason to prefer either the trend extrapolation of the time series trend estimate or the expert opinion (expert opinion points in the direction of ignoring past trends). Therefore we created a mixed model in which we assume that the trend for an entire sample path is distributed uniformly between zero and the time series estimate of trend, for numbers of immigrants. In addition, there is the usual uncertainty due to innovations in the model. The results of this approach are plotted in the remaining diagrams with the label "uncertain trend". These are our preferred results. They generally lie midway between the forecasts with trend and without trend, for both central tendency and probability interval.

We will now consider the effects of modeling immigration stochastically rather than deterministically. We have used a stochastic population model we developed for use in an analysis of a probabilistic forecast of Medicare (Lee and Miller, 2002), which is similar to Lee and Tuljapurkar (1994). Figure 1.8 compares our alternative stochastic immigration forecasts with a deterministic immigration forecast. In terms of projected population size, there is little difference between the forecast based on stochastic level of immigration without a trend and the forecast based on deterministic immigration. Partly, this reflects the fact that we already have a lot of variance in the model from the two other stochastic components (TFR and $\mathrm{e}(0)$ ). In particular, forecast of the level of immigration adds relatively little variation to the forecast relative to that of the TFR. The $95 \%$ probability interval for the cumulative value of the TFR is about $+/-25 \%$ of the baseline TFR. In 2002, there were 4 million births in the US, a variation in TFR of $+/-$ $25 \%$ would translate into $+/-1$ million additional births. In contrast, our probability 
interval for immigration based on a model of immigration level without time series trend leads to differences of $+/-350,000$ immigrants. This is about $1 / 3$ as large an effect of variation as in the TFR. In addition, migrants contribute less to population size than do births, since the average age of migrants is near 30. So, the actual effect of an immigrant on population size might be only $5 / 8$ as large as a birth. The variation in population size introduced by modeling immigration level must be closer to $1 / 5$ as large an effect as modeling variation in TFR.

Figure 1.8 shows much larger upside uncertainty when rates of immigration are forecast rather than levels, because in this case upside uncertainty in rates interacts multiplicatively with upside uncertainty in population size, which does not happen when numbers of immigrants are directly projected. We are skeptical of these large upside probability ranges, because it seems likely to us that rates might be negatively correlated with population size, whereas our projections assume these to be independent. However, much of this is speculation and there are no compelling arguments that we see on either side.

Figure 1.9 shows the results of three stochastic forecasts: one in which only fertility and mortality are stochastically forecast, the second in which only immigration is stochastically forecast, and the third in which all 3 components are stochastically forecast. Here we see that the probability interval based on a stochastic forecast of immigration alone is about $1 / 4$ as wide as that of simulation based on stochastic fertility and mortality which is close to our admittedly crude approximation of $1 / 5$. In contrast to these results, the stochastic forecasts based on rates show wider probability intervals as these forecasts allow for more extreme population scenarios in which a high level of population can be matched with a high immigration rate and vice versa. As expected, the median of the forecasts based on rates are higher than those forecasts based on level of immigration.

Turning to a consideration of the old-age dependency rate in Figure 1.10, we find that forecasts based on immigration rate tend to produce younger populations than those based on levels. We also note that over the first 50 years of the forecast (see Table 4 below), the OADR in all these methods are surprisingly close - suggesting that uncertainty in immigration would contribute little to uncertainty in social security finances. 
Table 4. OADR in 2050. Simulation begins in 2003 with OADR at 216 per $1,000$.

\begin{tabular}{|l|c|c|c|c|c|}
\hline & \multicolumn{5}{|c|}{ Type of immigration forecast: } \\
\hline & Deterministic & $\begin{array}{c}\text { Level no } \\
\text { trend }\end{array}$ & $\begin{array}{c}\text { Level with } \\
\text { trend }\end{array}$ & $\begin{array}{c}\text { Rate no } \\
\text { trend }\end{array}$ & $\begin{array}{c}\text { Rate with } \\
\text { trend }\end{array}$ \\
\hline $\begin{array}{l}2.5 \\
\text { percentile }\end{array}$ & 312 & 310 & 304 & 299 & 288 \\
\hline $\begin{array}{l}50^{\text {th }} \\
\text { percentile }\end{array}$ & 382 & 382 & 370 & 372 & 363 \\
\hline $\begin{array}{l}97.5 \\
\text { percentile }\end{array}$ & 472 & 467 & 458 & 461 & 456 \\
\hline
\end{tabular}

\section{Foreign born population}

In a stationary population, we can calculate the percent of the population which is foreign-born based on the person-years lived of natives versus foreign-born. Assume that there is no difference in mortality between natives and foreign-born. In this case, the difference between the person-years lived in the U.S. by immigrants and by natives is simply $(\mathrm{T}(0)-\mathrm{T}(30)) / \mathrm{T}(0))$ where 30 is taken to be the average age of arrival of an immigrant. Using a recent life table, we can calculate this value as about $5 / 8$. So the steady state estimate of the percent foreign-born in the population is simply $\left(5 / 8^{*} \mathrm{I}\right) /(\mathrm{B}+$ $(5 / 8 * \mathrm{I})$, where I is the net immigration rate and B is the crude birth rate Currently, the US the net immigration rate is about $4 / 1000$ and the crude birth rate is about 14/1000. A steady-state calculation leads to a population of about $15 \%$ foreign-born.

Using Census data and the assumptions of the SSA forecasts, we have calculated the foreign born population as a percent of the working-age population and of the total population in Figure 1.11. We see that our crude estimate of $15 \%$ foreign-born from the preceding calculation is quite close to the projection for the US.

\section{Projected Net Immigrants}

Figure 12 shows the projected numbers and probability intervals of net immigrants, legal and illegal combined. Our preferred projection is based on the "uncertain trend" approach. The central forecast for this case shows the number of net immigrants dropping from current levels down to about one million in 2020, and then slowly rising to about 1.2 million at the end of the century. The lower $2.5 \%$ probability bound is near 800,000 throughout the century, after the first decade or two. The upper $97.5 \%$ bound starts at 1.3 million, and rises quite linearly to 1.8 million at the end of the century.

\section{Summary and Conclusions}

1. Given the history of immigration to the US, a number of key assumptions must be made without a satisfactorily firm basis, such as whether to model numbers or rates, over what historical period to fit the model, and whether to include a trend in the forecast, or to impose central tendency based on expert opinion. 
2. Experiments with a variety of approaches suggest that the probability distribution of the immigration forecast is not highly sensitive to these variations, although forecasts of the rate, with a trend, do lead to forecasts of higher numbers in the future.

3. Our preferred projection is based on numbers of immigrants rather than rates, and randomly samples trends between 0 and the historical average for each sample path. In this case, the projected number of net immigrants (legal and illegal) drops from current levels down to about one million in 2020, and then slowly rises to 1.2 million at the end of the century. The lower $2.5 \%$ probability bound is near 800,000 throughout the century, after the first decade or two. The upper $97.5 \%$ bound starts at 1.3 million, and rises quite linearly to 1.8 million at the end of the century.

4. With this range of models and forecasts, including immigration in the population forecasts makes little difference to the probability distribution of the old age dependency ratio, which is the item of prime importance for the Social Security forecasts. 


\section{References}

Burdick, Clark and Joyce Manchester (2003) "Stochastic Models of the Social Security Trust Funds" Office of Policy Office of Research, Evaluation, and Statistics, Research and Statistics Note No. 2003-01 (March)

Hollmann, Frederick W; Tammany J. Mulder and Jeffrey E. Kallan (2002). Methodology and Assumptions for the Population Projections of the United States: 1999 to 2100. Population Projections Branch, Population Division, Bureau of the Census. Population Division Working Paper No. 38. Available online: http://www.census.gov/population/www/documentation/twps0038.html

Lee, Ronald (1993). "Modeling and Forecasting the Time Series of US Fertility: Age Patterns, Range, and Ultimate Level," International Journal of Forecasting v.9, pp.187-202.

Lee, Ronald (2004). Quantifying Our Ignorance: Stochastic Forecasts of Population and Public Budgets. Paper prepared for the Rand Summer Institute Gala Celebration for the NIA Centers for the Demography and Economics of Aging. Available online: http://repositories.cdlib.org/iber/ceda/papers/2004-0001CL/

Lee, Ronald and Shripad Tuljapurkar (2000). "Population Forecasting for Fiscal Planning: Issues and Innovations" in Alan Auerbach and Ronald Lee, eds., Demography and Fiscal Policy, Cambridge: Cambridge University Press. Available online: http://repositories.cdlib.org/iber/ceda/papers/2000-0004CL/

Lee, Ronald and Tim Miller (2002). "An Approach to Forecasting Health Expenditures, with Application to the US Medicare System," Health Services Research, v. 37, n. 5, pp. 1365-1386 (October 2002).

Miller, Tim (2002). California's Uncertain Population Future. Technical Appendix. Available online: http://www.demog.berkeley.edu/ tmiller/papers/p2002.california.forecast.pdf

National Research Council (2000) Beyond Six Billion: Forecasting the World's Population. Panel on Population Projections. John Bongaarts and Rodolfo Bulatao, eds. Committee on Population, Commission on Behavioral and Social Sciences and Education. Washington, D.C.: National Academy Press.

Social Security Administration, Board of Trustees (2004). The 2004 Annual Report of the Board of Trustees of the Federal Old-Age and Survivors Insurance and Disability Insurance Trust Funds. Available online: http://www.ssa.gov/OACT/TR/TR04/index.html

Technical Panel on Assumptions and Methods (2003). Report to the Social Security Advisory Board. Washington, D.C., October 2003. Available online: http://www.ssab.gov/NEW/documents/2003TechnicalPanelRept.pdf 
United Nations, Population Division (2003). World Population Prospects: The 2002 Revision. Database available online: http://esa.un.org/unpp/ 
Figure 1. Legal Immigration Rate: US, 1820-2002

(Dashed spike indicates amnesty immigration)

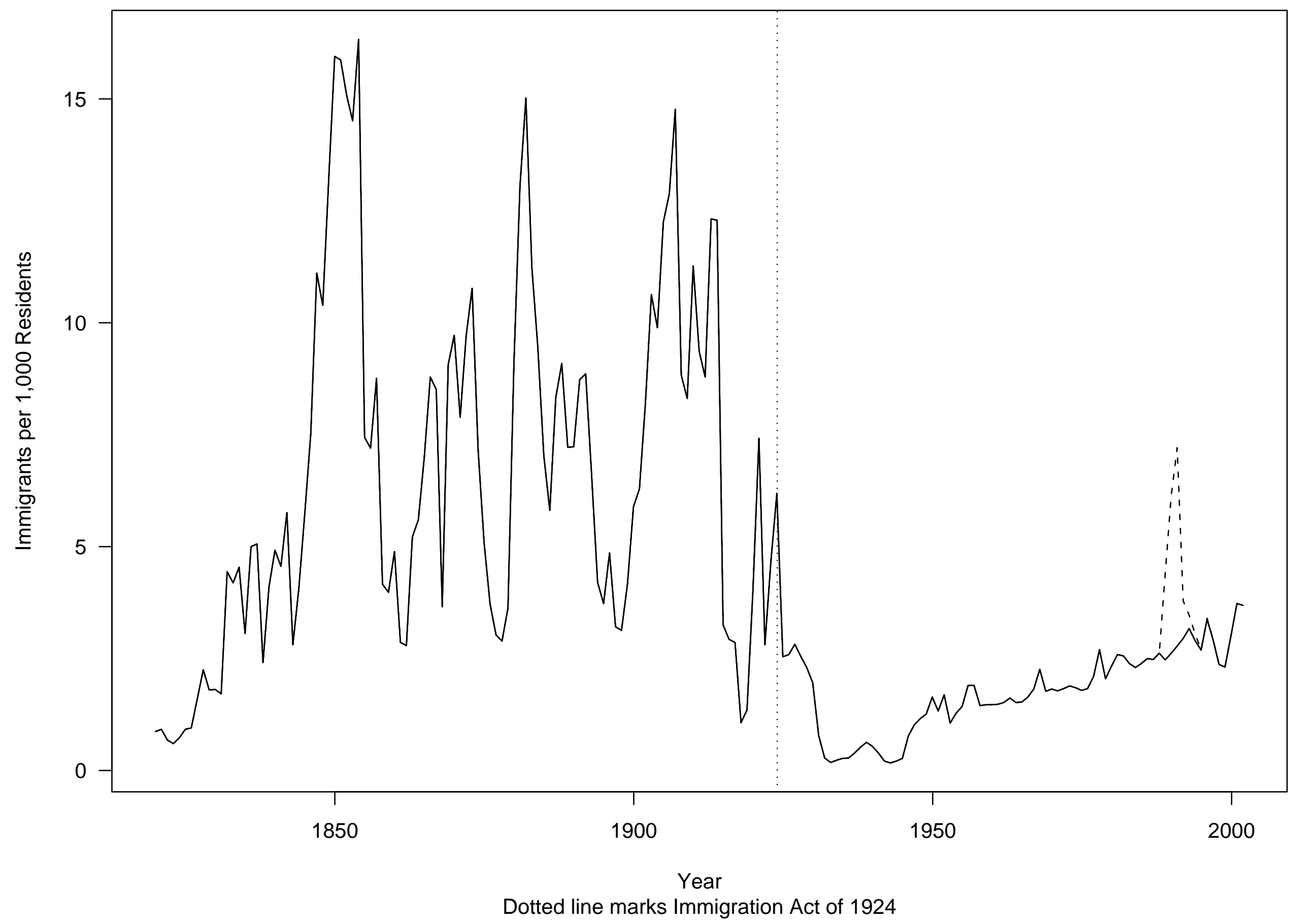


Figure 2. Legal Immigrants to U.S., 1820-2002

(Dashed spike indicates amnesty immigration)

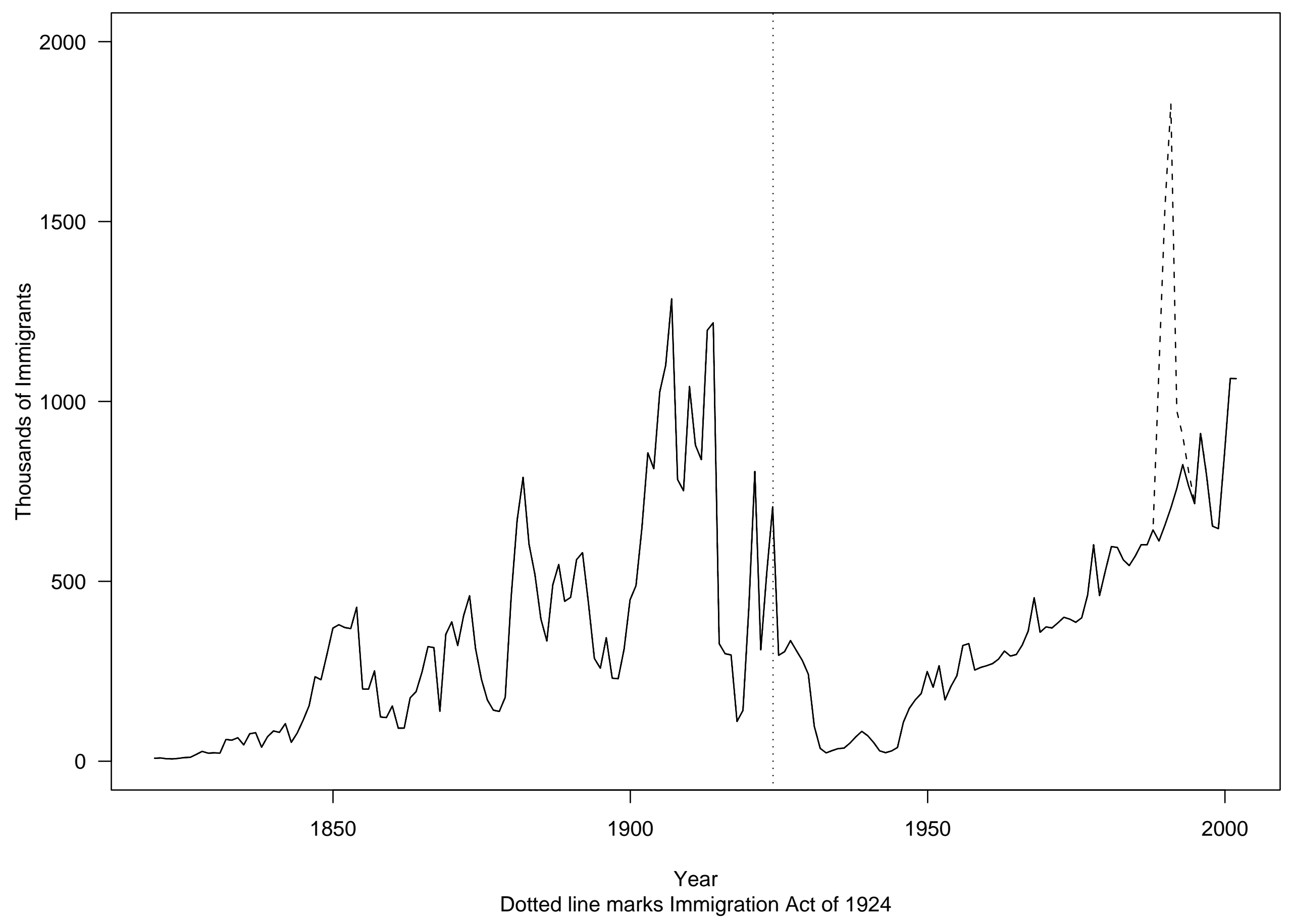


Figure 3. United Nations Estimate (1950-2000) and Forecast (2000-2050) of Net Immigration Rate to More Developed Region from Less Developed Region

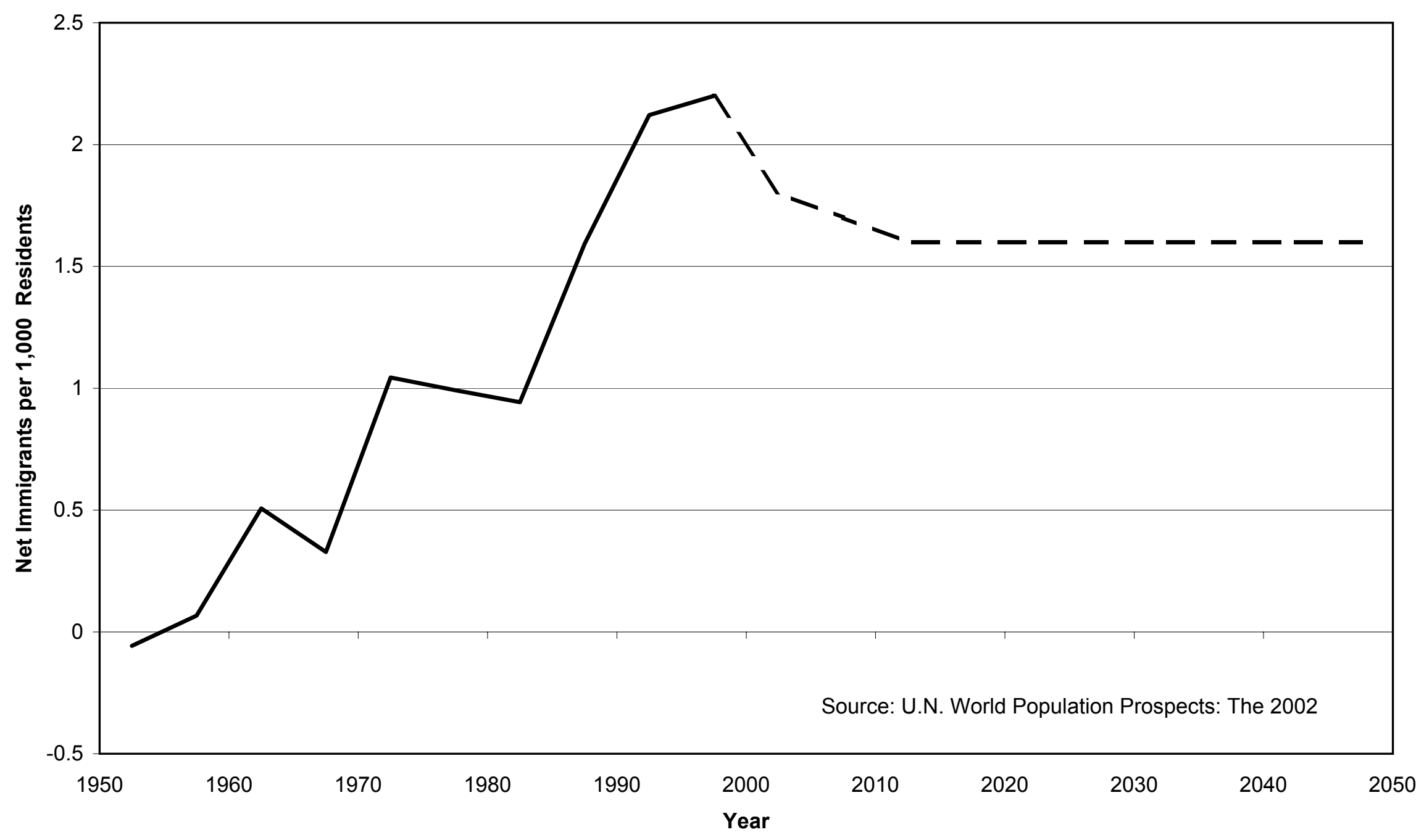


Figure 4. Gross Legal Immigrants, 1820-2002 with Forecast of Net Immigrants

Stochastic Forecast without historical trend

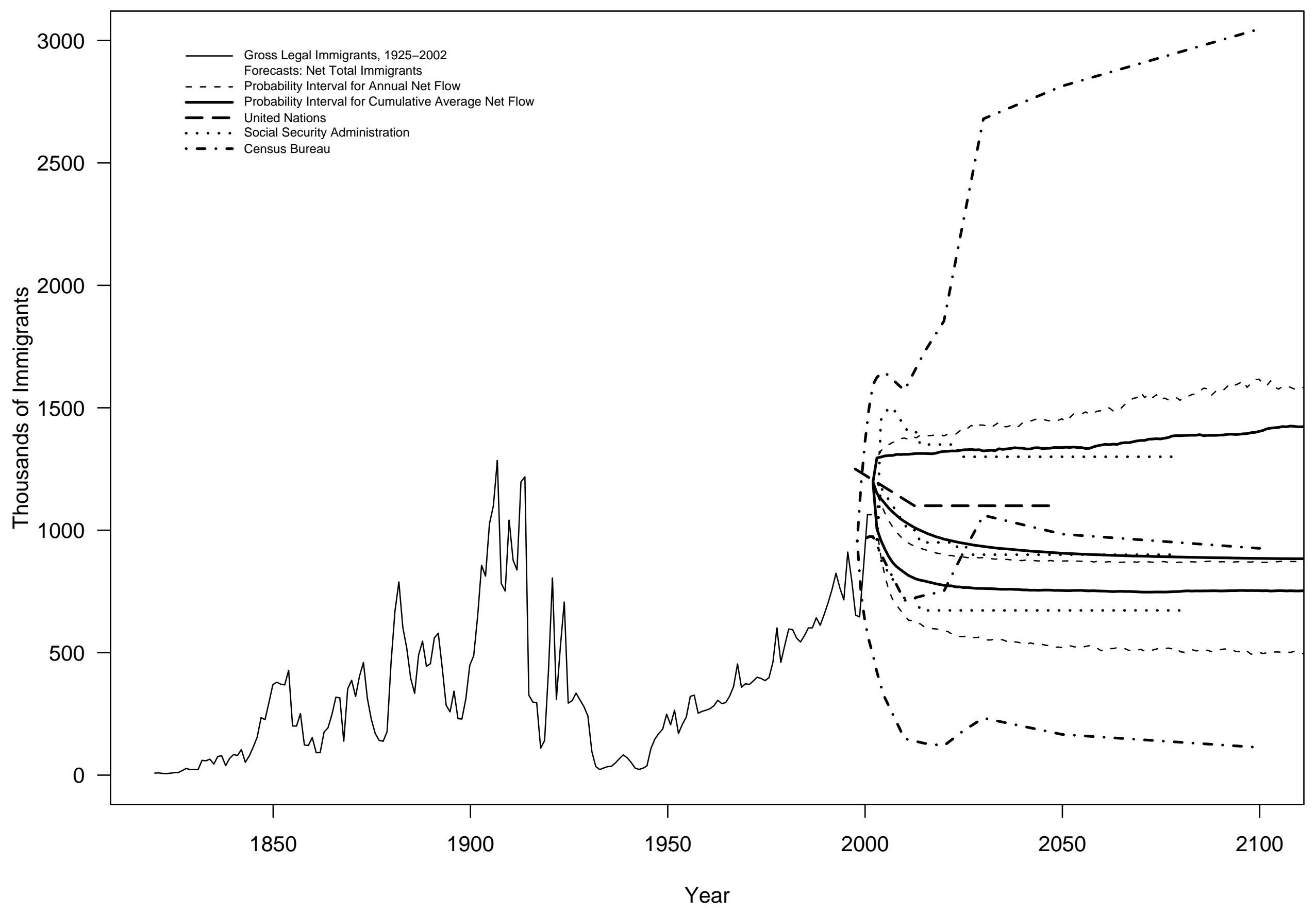


Figure 5. Gross Legal Immigrants, 1820-2002 with Forecast of Net Immigrants Stochastic Forecast with historical trend

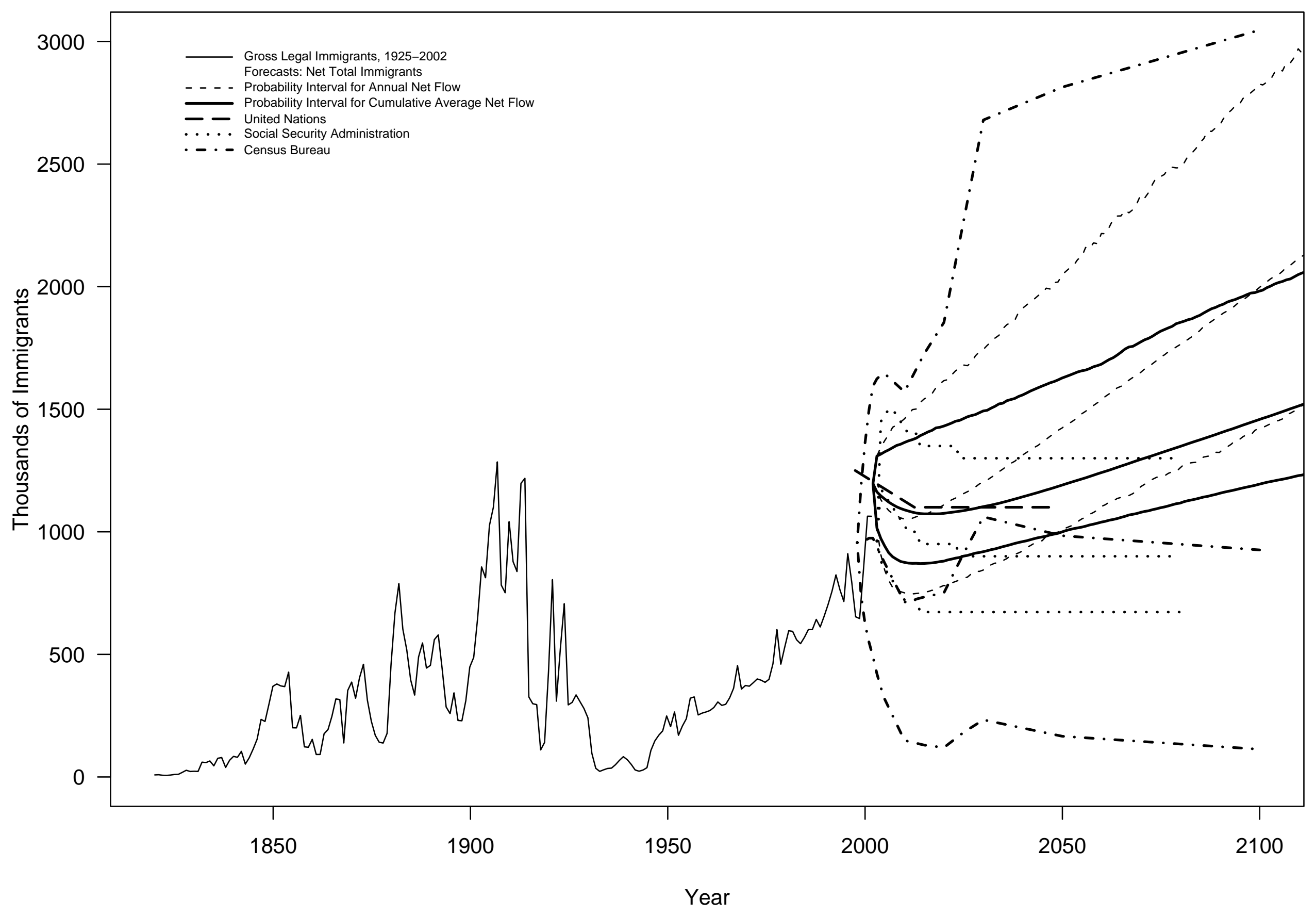


Figure 6. Gross Legal Immigration Rate, 1925-2002 with Forecasts of Net Immigration Rate Stochastic Forecast without historical trend

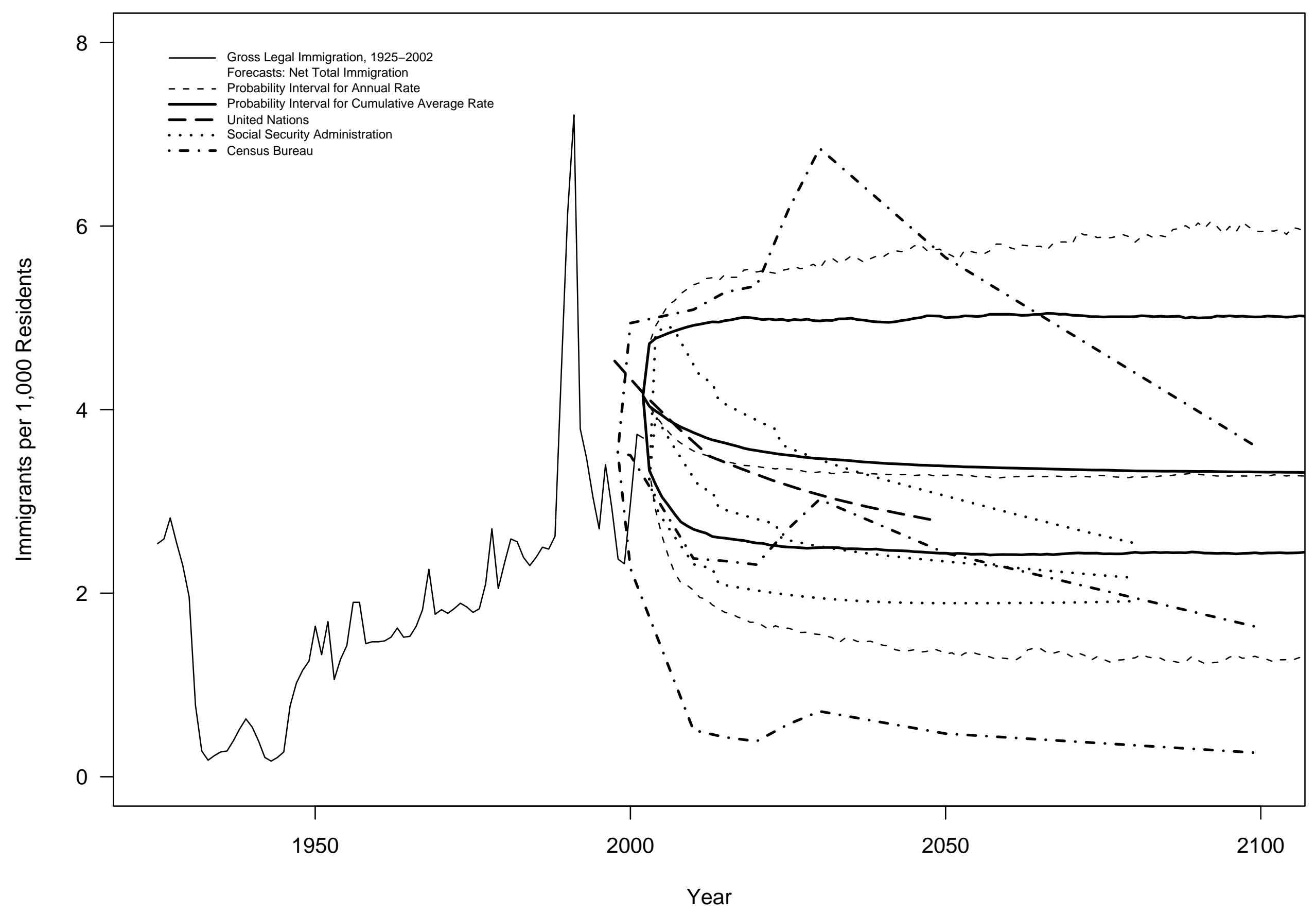


Figure 7. Gross Legal Immigration Rate, 1925-2002 with Forecasts of Net Immigration Rate Stochastic Forecast with historical trend

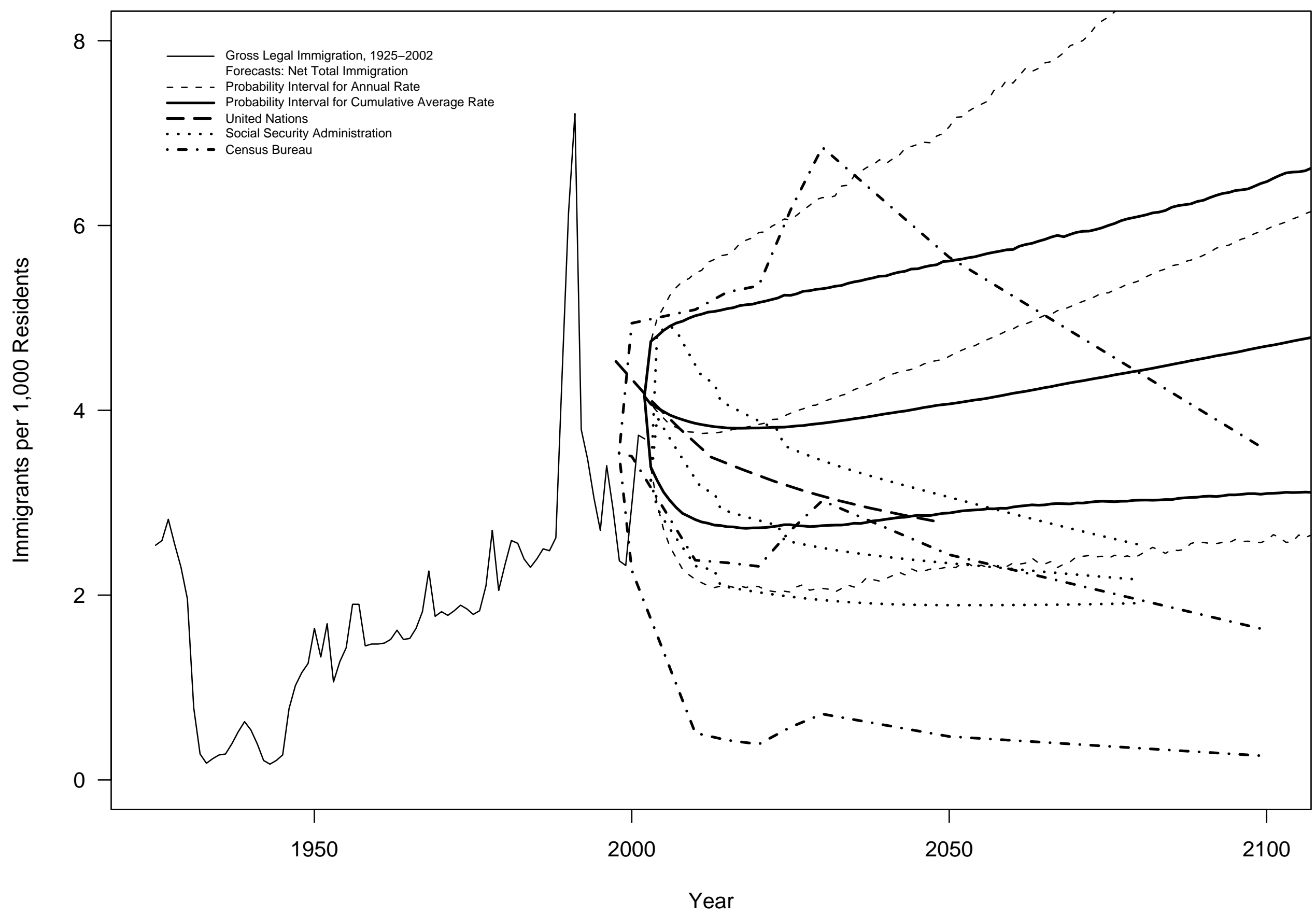


Figure 8. Population: median and $95 \%$ interval

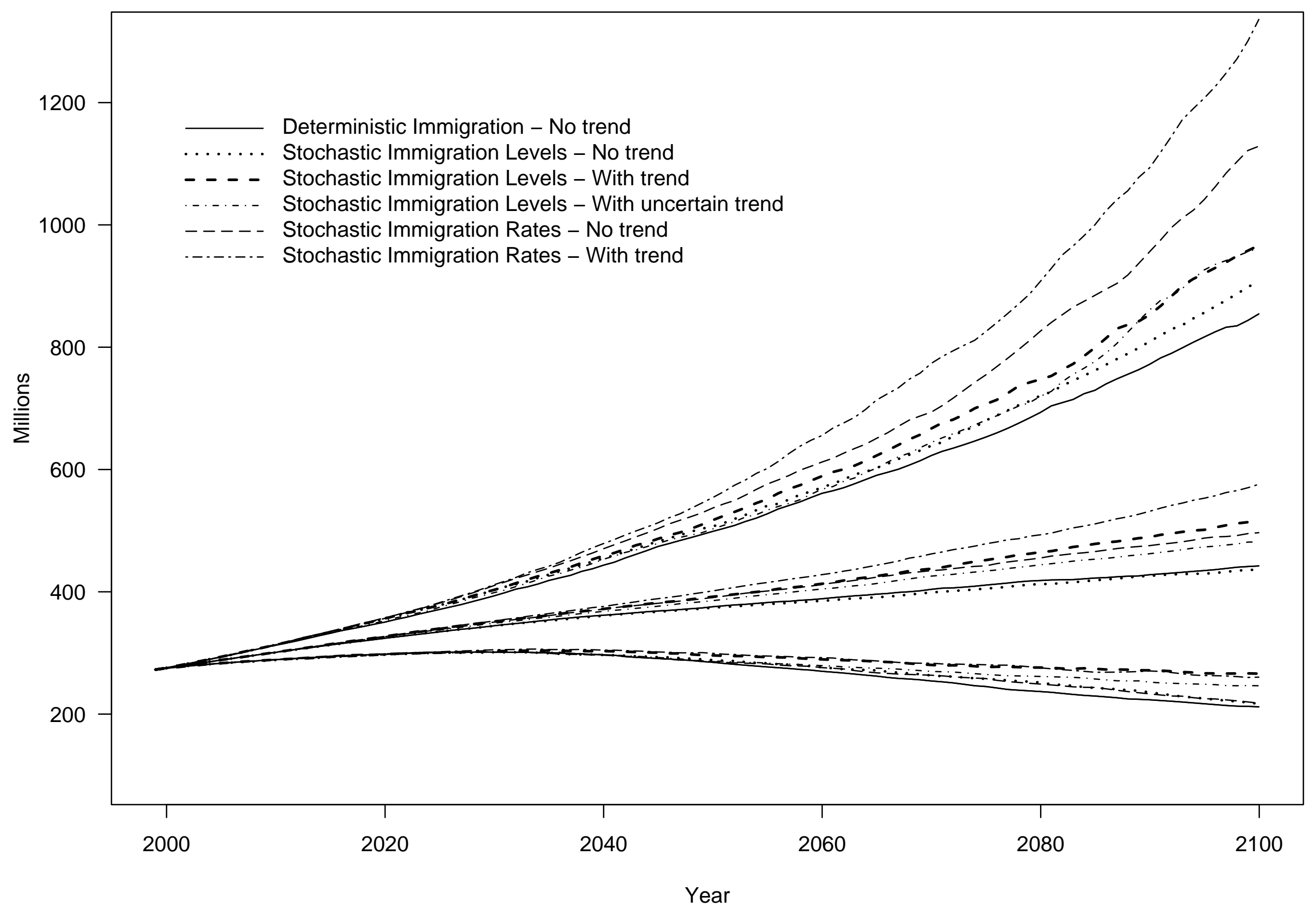


Figure 9. Effect of Stochastic Demographic Components on Population Forecast

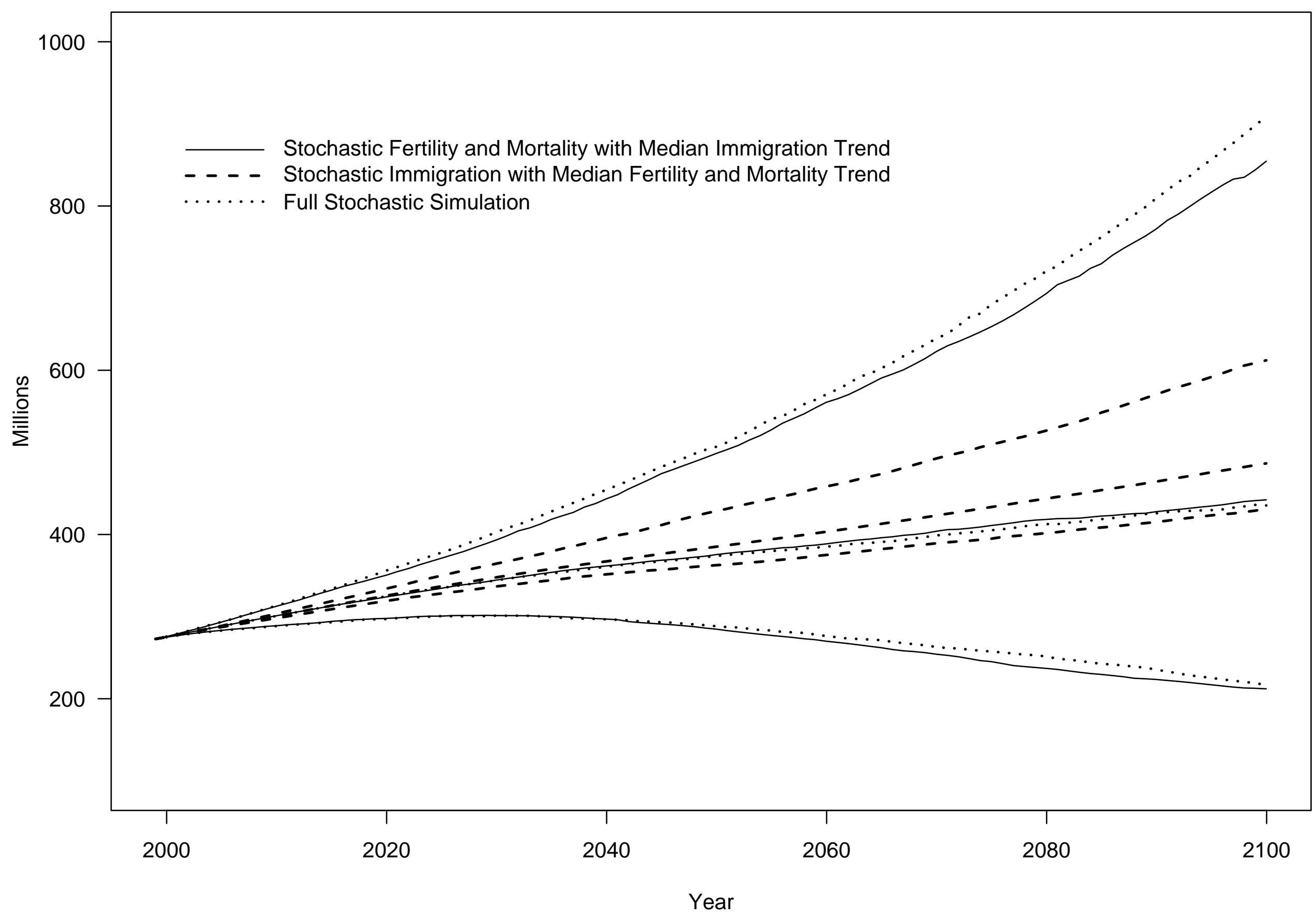


Figure 10. OADR: median and $95 \%$ interval

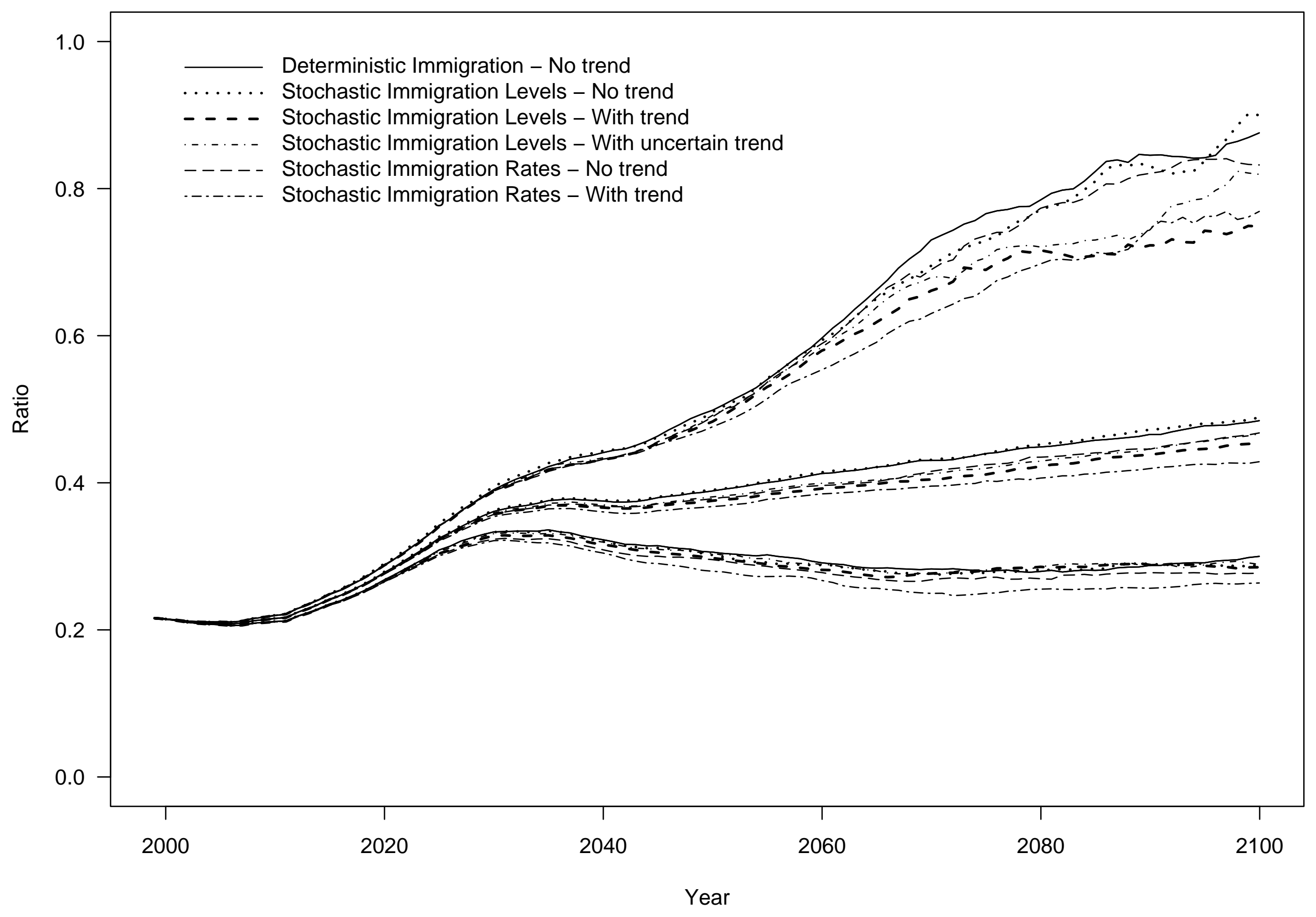


Figure 11. Foreign born as a Percent of Total and Working-age Population

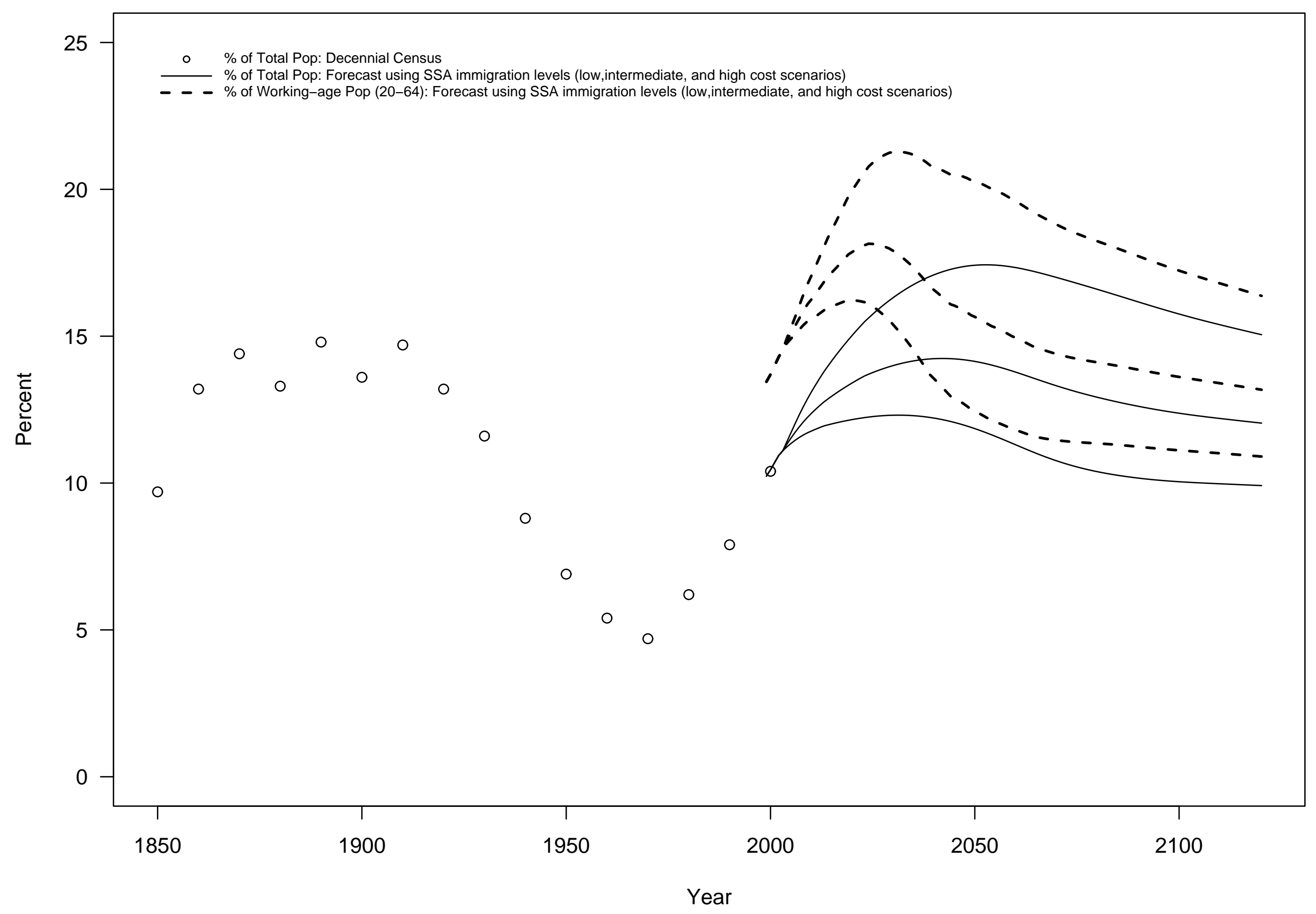


Figure 12. Gross Legal Immigrants, 1820-2002 with Forecast of Net Immigrants Stochastic Forecast with different assumptions about the trend

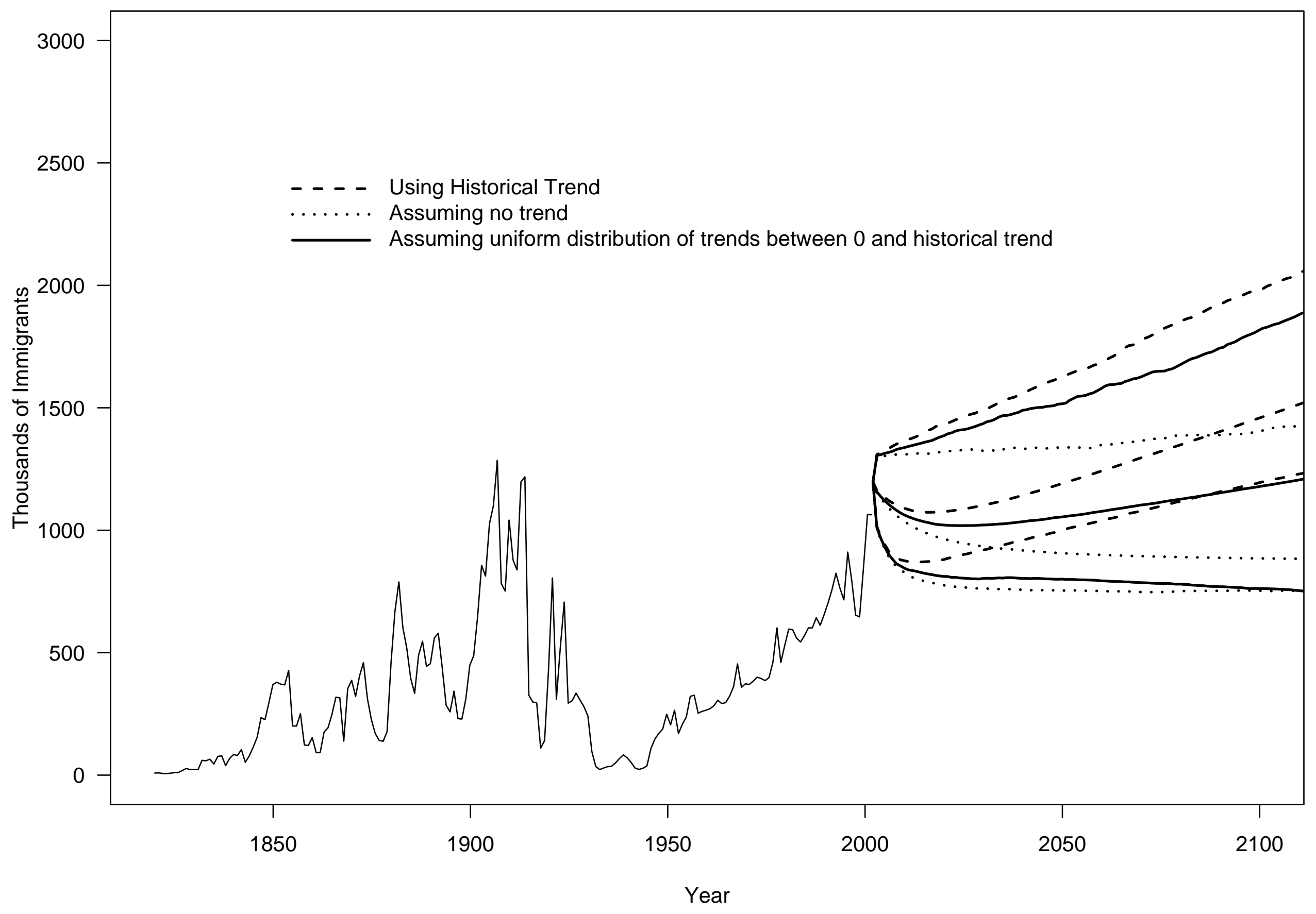




\title{
Report II
}

\section{Structural time series models and parameter uncertainty in Stochastic Projections of Social Security Finances}

\author{
Michael Anderson \\ mikeand1@pacbell.net \\ and \\ Ronald Lee \\ rlee@demog.berkeley.edu \\ Center for the Economics and Demography of Aging \\ University of California at Berkeley \\ 2232 Piedmont Avenue \\ Berkeley, CA 94720-2120
}

October 8, 2004

The research reported herein was performed pursuant to a grant from the US Social Security Administration (SSA) as part of the Retirement Research Consortium. The opinions and conclusions expressed are solely those of the authors and do not represent the opinions or policy of SSA or any agency of the Federal Government. The authors also acknowledge support from Berkeley's NIA-funded Center for the Economics and Demography of Aging. The research funded here builds on basic research funded by NIA grant R37-AG11761. 


\section{Background}

The strategy for constructing stochastic Social Security forecasts at the macro-level rests on developing stochastic time series models for a number of the key inputs. In the original Lee-Tuljapurkar implementation (Lee and Tuljapurkar, 1998a\&b, 2000; Tuljapurkar and Lee, 2000; Lee, Anderson and Tuljapurkar, 2003), these key inputs are fertility, mortality, real interest rates and the growth rate of covered real wages, with returns on equity sometimes included as well. This report also experiments with stochastic immigration.

However, using time series methods in this way goes well beyond their intended range of application, and poses special problems deriving from the length of the forecast horizon (typically 75 years) and, in the case of fertility, from special constraints on possible outcomes. There has been a certain amount of experimentation with different estimation strategies in the past. Lee (1993) constrained the expected value of the modeled fertility process to equal a prespecified value based on external evidence including expert opinion. Similarly, upper and lower bounds were imposed on the realized Total Fertility Rate in any year through a nonlinear transformation. Tuljapurkar found that this transformation imposed an implausible shape on the probability distribution of fertility outcomes. Consequently, Lee and Tuljapurkar (1994) instead constrained only the mean value, and then discarded stochastic sample paths that included outcomes deemed outside a prespecified range (e.g. paths with negative realizations for fertility were discarded). Tuljapurkar and Boe (1998b) experimented with various aspects of the specification, notably including uncertainty in the prespecified mean level of fertility. Lee, Carter and Tuljapurkar (1995) tried a structural time series model for mortality (with a random trend), and found that it made very little difference either to the central forecast or to its variance and uncertainty.

More recently, Holmer (2003) found that "the methods that have evolved for stochastic projection of trust fund finances are basically sound", but at the same time found that the time series methods currently in use for these stochastic Social Security forecasts had problems, and suggested that structural time series models and alternative Monte Carlo procedures might solve these problems. He found that replacing the usual ARIMA models with these new models altered the projections, particularly the assessment of uncertainty. Burdick and Manchester (2003) echoes interest in these new specifications, and concern that the usual ARIMA models may understate the uncertainty of the projections.

Holmer (2003) suggested and illustrated three alternative modeling strategies: a) the use of structural time series models for all inputs; b) the effects of uncertainty about the true values of estimated parameters, that is to "treat these estimated coefficients themselves as random, adding additional uncertainty to the stochastic models"; and c) "the ultimate rates to which the stochastic variables are calibrated can themselves be treated stochastically". 
In this report, we will investigate these suggestions, considering their effects both on the forecasts of the input series and their uncertainty, and also the effect of these new fitted models on the actual outcomes of the stochastic Social Security projections when all sources of variation are considered together. Stochastic forecasts of mortality have incorporated parameter uncertainty from the beginning, since Lee and Carter (1992) took uncertainty in the drift coefficient into account, and for the most part that practice has continued.

We will begin by considering new modeling approaches for real wage growth, and then incorporate the resulting models in a stochastic Social Security forecast in which all the other inputs are first treated deterministically, and then treated stochastically. We will next do the same for fertility.

\section{Remodeling Real Wage Growth}

\section{Structural time series models}

We estimated a structural model for productivity growth in an attempt to replicate Holmer's structural time series model; as reported later, we proceeded similarly for fertility. As did Holmer, we constructed state space representations for these models and fitted them through a combination of Kalman filter and maximum likelihood techniques. We used the publicly available $\mathrm{E}^{4}$ statistical package (available at http://www.ucm.es/info/icae/e4/e4download.htm) for parameter estimation and smoothing with the Kalman filter.

Holmer presented two structural models for productivity growth which we duplicate here. We first estimate a model which incorporates a time-varying mean displacement, and we then add to this model uncertainty in the long-term average of the simulated series (what Holmer calls the "ultimate value assumption.")

While Holmer fitted the productivity growth rate series, we fit the related real-wage growth series (the last column of Table V.B1 in the 2003 Trustees' Report) after adjusting the historical estimates for changes in the composition of the labor force. In our model of the Trust Fund, this latter series provides a more appropriate basis for adjusting payroll tax profiles by age and sex over time.

Holmer's first model fitted the productivity growth rate with a long run trend and a time varying mean displacement. He estimates the slope of long run trend to be zero, and thus simulates the series using only the remaining time-varying mean displacement.

We fit the model without a long run trend, using only the time-varying mean displacement equation. The equations for this model are:

$$
\begin{aligned}
& \mathrm{y}_{\mathrm{t}}=\gamma_{\mathrm{t}-1}+\varepsilon_{\mathrm{t}}, \varepsilon_{\mathrm{t}} \sim \mathrm{N}\left(0, \sigma_{\varepsilon}{ }^{2}\right) \\
& \gamma_{\mathrm{t}}=\lambda \gamma_{\mathrm{t}-1}+v_{\mathrm{t}}, \nu_{\mathrm{t}} \sim \mathrm{N}\left(0, \sigma_{v}{ }^{2}\right)
\end{aligned}
$$


where $\mathrm{y}_{\mathrm{t}}$ represents the observed growth in real wages at time $t$, and $\gamma_{\mathrm{t}}$ represents the time-varying mean displacement. We estimate $\lambda$ to be $0.758, \sigma_{\varepsilon}{ }^{2}$ to be 1.590 , and $\sigma_{v}{ }^{2}$ to be 0.7922 .

Figure 2.1 shows the result of simulating the model as compared with a simple AR(1) model as used in our past simulations, where it is the time series of real wage growth that is being simulated here, not its impact on the Trust Fund. For these simulations, we used a long run mean rate of real wage growth of $1.1 \%$, equal to the intermediate cost assumption from the 2003 Trustees' report. The solid line prior to 2002 shows the historical series, and the dashed line shows the smoothed estimate of the time-varying mean displacement. The outer solid lines after 2002 show the 95\% confidence interval from the AR(1) model, and the outer dotted lines show the $95 \%$ confidence interval for the structural model with time-varying mean displacement. The lines in the center show the median for each model, and the lines between the $95 \%$ confidence interval and the median show the $95 \%$ confidence interval for the cumulative mean. These cumulative mean plots, introduced by Lee (1993), are intended to capture a projection dispersion that is conceptually closer to the High-Medium-Low assumptions of traditional scenariobased projections, or in the case of Social Security, the High, Intermediate and Low-Cost projection assumptions. The plot shows that the uncertainty in the stochastic trajectories is only slightly greater for the structural model, but that the cumulative mean is somewhat more uncertain for the structural model.

\section{Uncertain Ultimate Rate of Wage Increase}

We then fit the model with uncertainty in the long run mean, or with an "uncertain ultimate value." We estimated uncertainty using Holmer's method, calculating the standard deviation of the ultimate value as the sum of the standard deviation for the historical mean plus the standard deviation for the projection deviation. This is represented by the equation:

$\sigma_{\mathrm{u}}^{2}=\sigma_{\mathrm{h}}^{2}+\sigma_{\mathrm{d}}^{2}$

where $\sigma_{\mathrm{u}}{ }^{2}$ represents the variance of the assumed ultimate value, $\sigma_{\mathrm{h}}{ }^{2}$ represents the variance of the historical mean, and $\sigma_{\mathrm{d}}^{2}$ represents the variance of the projection deviation. We estimated $\sigma_{\mathrm{h}}$ to be 0.2553 percent, using the usual equation for the sample mean, and set $\sigma_{d}$ equal to 1.1384 percent, that standard deviation such that there is a $20 \%$ chance of the long run mean exceeding the historical mean. According to these estimates, $\sigma_{u}$ is estimated to be 1.1667 percent, which is considerably larger than Holmer's estimate of 0.455 percent.

Figure 2.2 show the effect of incorporating uncertainty in the ultimate value. The solid lines past 2002 represent the projection of the structural model above, with no uncertain ultimate value, and the dashed lines show the projection of the model incorporating uncertainty in the ultimate value. The outer dashed lines show the $95 \%$ confidence interval for the model with an uncertain ultimate value, and the dashed lines in between represent the $95 \%$ confidence interval for the cumulative mean. The plot demonstrates that incorporating uncertainty into the mean results in a substantial increase in the uncertainty of the real wage growth rate forecast, just as Holmer found. 


\section{Social Security Projections with the New Wage Growth Models-Only Wage Growth Stochastic}

We then incorporated forecasts from the three real wage models above into our stochastic social security simulation to determine the effect of the increased uncertainty on fund forecasts. We first ran our simulation setting as deterministic all inputs except for the real wage growth rate forecast, using the 2003 Trustees' report intermediate forecasts. Figure 2.3 shows histograms of the 75-year actuarial balance ("AB75"), using each of the three models of real wage growth. The solid line represents the distribution of the AB75 using a simple AR(1) model, the dotted line represents the distribution of the AB75 using the structural model without uncertainty in the ultimate value, and the dashed line shows the distribution of the AB75 using the structural model with uncertainty in the ultimate value. The increase in uncertainty between the AR(1) model and the structural model is comparatively minor, as the width of the $95 \%$ confidence interval increases by a margin of only $0.30 \%$. However, a substantial increase in uncertainty results when uncertainty in the ultimate value is incorporated, as the width of the $95 \%$ confidence interval is increased by $2.54 \%$ as compared with the AR(1) model, and $2.24 \%$ as compared with the structural model absent uncertainty in the ultimate value. This is consistent with the results reported by Holmer.

\section{Social Security Projections with the New Wage Growth Models-All Inputs}

\section{Stochastic}

However, when we set as stochastic all inputs to the trust fund simulation (which includes uncertainty in fertility, mortality, and interest rates, in our usual simulation), the effect of using the three different real wage growth models is less dramatic. Figure 2.4 shows the distribution of AB75 for the three models when all inputs are forecasted stochastically. As above, the solid lines represent the distribution of AB75 when the AR(1) model for real wage growth is used, the dotted line represents the distribution of AB75 when the structural model is used, and the dashed line represents the distribution of AB75 when the structural model with uncertainty in the ultimate value is used. Here, the effect of the increase in uncertainty in AB75 under the three models for real wage growth is attenuated by the uncertainty in other inputs to the fund simulation. The width of the $95 \%$ confidence interval is increased by only $0.15 \%$ when the AR(1) model is compared with the simple structural model, and by $1.01 \%$ when the AR(1) model is compared with the structural model combined with uncertainty in the ultimate value.

Holmer did not report similar results for his simulation, as he compared only the effect of the models when all other inputs were forecasted deterministically.

\section{Discussion}

When we use the different models of wage growth in the Social Security projection with only wage growth stochastic, we found that the model specification had a large effect on the projection uncertainty, consistent with Homer's result. Specifically, we found that the uncertain ultimate level generated a probability interval three times wider than did either the ARMA or the structural models, which had very similar effects. However, when we use the different models in a stochastic Social Security simulation in which all our standard inputs are stochastic (mortality, fertility, real wage growth and real interest 
rates), we find that the difference in probability intervals is relatively small, differing by a factor of 1.16 in the $95 \%$ range (median values were similar).

These two results seem contradictory, but they are not. There are four random variates in our stochastic Social Security model, and if the variations are largely uncorrelated one with the other, then there will be a good deal of cancellation when they are summed by the projection process. A large effect on an individual series can get swamped in the aggregated uncertainty, as seems to be happening here. For the same reason, probability intervals are quite similar between our model with only four stochastic inputs, and the Social Security Administration version which has many more (Burdick and Manchester, 2003).

\section{Remodeling Fertility}

\section{The Baseline Fertility Model}

We take the Lee-Tuljapurkar fertility model as our baseline. We start by applying a singular value decomposition to a matrix of age-specific fertility rates over time, selecting out the first vectors along the time and age dimensions corresponding to the highest singular value. We then model the vector along the time dimension (which we denote $\mathrm{k}_{\mathrm{t}}$ ) using an ARMA $(1,1)$ model. Stochastic forecasts of the fertility series are generated by this model, with the added constraint that the long-term mean of the series yields a total fertility rate of 1.95 children per woman, corresponding to the Trustees' intermediate forecast in recent reports.

\section{Added Parameter Uncertainty}

Here we add parameter uncertainty to the model. Using the Splus function arima.mle(), we fit the model to the $\mathrm{k}_{\mathrm{t}}$ series and obtain the variance-covariance matrix of the maximum likelihood estimates for the moving average and autoregressive coefficients. We then stochastically generate 1,000 pairs of coefficients with the desired covariance structure. This is done by generating a $1000 \times 2$ matrix of standard normal variates, and postmultiplying this matrix with the Cholesky decomposition of the estimated variancecovariance matrix. Then for each pair of stochastic coefficients, we generate a trajectory using the corresponding ARMA $(1,1)$ model.

Figure 2.5 shows the result of incorporating parameter uncertainty into the model. The outer solid lines show the $95 \%$ confidence interval for the ARMA $(1,1)$ model without parameter uncertainty, and the outer dashed lines show the $95 \%$ confidence interval for the model with parameter uncertainty. The lines between the median and the outer lines show the $95 \%$ confidence intervals for the cumulative averages for each model. Uncertainty in the trajectories is only slightly greater when parameter uncertainty is incorporated into the model. Uncertainty in the cumulative average is slightly greater for the usual model over a horizon of twenty years or so, but greater for the model with parameter uncertainty past twenty years.

\section{Homer's Structural Model for Logged Fertility}

We begin by replicating Holmer's structural model, which is based on an initial log transform of fertility, in an attempt to determine the effect on Trust Fund forecasts of using his fitted model. As Holmer did, we started with the log of total fertility, and subtracted off the historical mean, resulting in a series which he denotes as $\mathrm{y}_{\mathrm{t}}$. Dropping 
the terms of the model that he estimates to be zero, we are left with the following equations:

$\mathrm{y}_{\mathrm{t}}=\varphi_{1} \mathrm{y}_{\mathrm{t}-1}+\varphi_{2} \mathrm{y}_{\mathrm{t}-2}+\mu_{\mathrm{t}-1}+\varepsilon_{\mathrm{t}}, \varepsilon_{\mathrm{t}} \sim \mathrm{N}\left(0, \sigma_{\varepsilon}^{2}\right)$

$\mu_{\mathrm{t}}=\rho \mu_{\mathrm{t}-1}+\gamma_{\mathrm{t}-1}$

$\gamma_{\mathrm{t}}=\lambda \gamma_{\mathrm{t}-1}+v_{\mathrm{t}}{ }^{\sim} \mathrm{N}\left(0, \sigma_{v}^{2}\right)$

The corresponding parameter estimates are taken from Holmer (2003).

Figure 2.6 shows the result of simulating the total fertility rate using Holmer's model, as compared with our usual ARMA $(1,1)$. The plot shows the unlogged total fertility rate series, after generating the stochastic trajectories using the model of the log of the total fertility rate. The solid lines show the result of simulating the ARMA $(1,1)$ model, and the dashed lines show the result of simulating Holmer's model.

As demonstrated by the plot, the uncertainty resulting from Holmer's structural model is substantially less than that implied by the ARIMA model. However, the plot also demonstrates a difficulty that arises by using the log of the total fertility rate as the series to be modeled. First, when the stochastic trajectories from the simulated logged series are transformed back into unlogged fertility rates, a substantial amount of asymmetry results in the uncertainty around the median. That is, uncertainty above the median is substantially greater than that below the median. Second, there is no natural way to determine the jump-off point for the stochastic simulation. When the $\mathrm{y}_{\mathrm{t}}$ series as described above is used, the jump off point is below 0 , and the generated trajectories immediately drop well below the natural jump-off point of TFR $=1.97$ (the most recently observed historical value). On the other hand, if the $y_{t}$ series is scaled after fitting the model, such that the jump-off point is near the most recently observed value, the generated trajectories fluctuate wildly for the first few years of the forecast. If the generated $\mathrm{y}_{\mathrm{t}}$ trajectories are instead generated, converted to unlogged rates, and a constant is then added to the trajectories to match the observed jump-off value of the TFR, then the amount of uncertainty is far too small.

In short, because any transformation of the model back to unlogged rates is a nonlinear one, there is no reasonable way to convert Holmer's model into a reasonable simulation of raw fertility rates. Unfortunately Holmer does not address this issue, as he plots only a simulation of the log of the TFR and does not explain how he converts the series into input for his model of the Trust Fund.

A structural model for unlogged fertility

We then fit a structural model for fertility rates, adopting a simplified version of Holmer's model. We started with the $\mathrm{k}_{\mathrm{t}}$ series as constructed above, and subtracted off the historical mean. We then modeled $\mathrm{k}_{\mathrm{t}}$ with an autoregressive term with a time varying mean, which itself is modeled as an autoregressive series. The equations for this model are: 
$\mathrm{k}_{\mathrm{t}}=\varphi \mathrm{k}_{\mathrm{t}-1}+\mu_{\mathrm{t}-1}+\varepsilon_{\mathrm{t}}, \varepsilon_{\mathrm{t}} \sim \mathrm{N}\left(0, \sigma_{\varepsilon}^{2}\right)$

$\mu_{\mathrm{t}}=\lambda \mu_{\mathrm{t}-1}+v_{\mathrm{t}}, v_{\mathrm{t}}{ }^{\sim} \mathrm{N}\left(0, \sigma_{v}^{2}\right)$

where $\mu_{\mathrm{t}}$ represents the time-varying mean displacement, and $\varepsilon_{\mathrm{t}}$ and $v_{\mathrm{t}}$ are independent normal random variates. Using the Kalman filter approach described above, we estimated the model parameters as follows:

$\varphi: 0.8812$

$\sigma_{\varepsilon}^{2}: 0.0078$

$\lambda: 0.9957$

$\sigma_{v}^{2}: 0.0010$

Figure 2.7 shows the result of using this model to forecast the total fertility rate. The outer solid lines show the $95 \%$ confidence interval for the usual ARMA $(1,1)$ model, and the dashed lines show the $95 \%$ confidence interval for the structural model. The lines between the $95 \%$ confidence intervals and the medians show the $95 \%$ confidence intervals for the cumulative averages. As the plot demonstrates, uncertainty is substantially greater for the structural model, largely reflecting the fact that the autoregressive coefficient for the time-varying mean displacement is very close to the unity.

For the ARMA fertility model, the $95 \%$ probability interval toward the end of the forecast period ranges from about .8 to 3.1 births per woman for the TFR, a span of 2.3 births. For the structural time series model, the $95 \%$ interval ranges from about .3 to 3.3 births per woman, or by about 3.0 births. One might question whether this broader range is appropriate, but in any case, it is clear that the structural time series model for fertility has substantially increased the uncertainty of the forecast.

\section{The Effect on Stochastic Projections of Alternative Fertility Models}

We used the above fertility forecasts from Holmer's structural model (see Figure 2.8) as input to our stochastic trust fund simulation. Figure 2.9 shows the distribution of AB75 when using Holmer's model as compared with our usual fund simulation using the LeeTuljapurkar ARMA(1,1) model. The $95 \%$ confidence interval using Holmer's model is ($5.55 \%, 0.002 \%)$, as compared with $(-5.88 \%, 0.25 \%)$ for the ARMA $(1,1)$ model, a difference of $0.578 \%$. Holmer's model also results in a slightly more pessimistic forecast, with a median $\mathrm{AB} 75$ of $-2.31 \%$ as compared with $-2.19 \%$ for our usual model.

\section{Discussion and Conclusions}

We have experimented with a variety of different specifications of the time series models for wage growth and fertility, which are two of the key inputs for the projections. The expectation was that introducing parameter uncertainty, stochastically varying trends terms, and uncertain ultimate levels, would make the projections more uncertain. We did indeed find this to be so in every case, although one version of Homer's model, in which fertility was first logged, then modeled, then exponentiated, turned out to give a narrower probability interval than our other models including the standard ones. In some cases, the change in probability intervals for the individual input series was very slight, for example 
when parameter uncertainty was introduced to the fertility model, or when we use structural methods for wage growth. The big differences come from using an uncertain ultimate level for wage growth, or a structural estimate for fertility.

Although some of these new models have a substantial effect on the estimated probability distributions for the forecasts of the inputs themselves, they seem to make much less difference when they are embedded in a more fully stochastic Social Security projection. This is good news for the stochastic projections, because it suggests that they are not so sensitive to the specifications of the input series. This is true in our stochastic forecasting model which has only four stochastic inputs. It would be even more true in the forecasting models of Social Security and CBO with their greater number of inputs. One would not want to push this argument too far, of course. Ultimately, the stochastic forecasts of Social Security are only as good as the stochastic forecasts of the key input series. 


\section{References}

Holmer, Martin R. 2003. Methods for Stochastic Trust Fund Projection. Report prepared for the Social Security Administration. January. Available at http://www.polsim.com/stochsim.pdf.

Lee, R.D. and Tuljapurkar, S. (1994) "Stochastic Population forecasts for the U.S.: Beyond High, Medium and Low," Journal of the American Statistical Association 87(419) pp. 659-671.

Lee, R.D. and S. Tuljapurkar (1998a) Stochastic forecasts for Social Security. D. Wise (ed.), Frontiers in the Economics of Aging, University of Chicago Press, pp. 393428.

Lee, R.D. and S. Tuljapurkar (1998b) Uncertain demographic futures and Social Security finances. American Economic Association Papers and Proceedings, Vol. 88, No. 2, 237-41.

Lee, Ronald and Shripad Tuljapurkar (2000) "Population Forecasting for Fiscal Planning: Issues and Innovations" in Alan Auerbach and Ronald Lee, eds., Demography and Fiscal Policy, Cambridge: Cambridge University Press.

Lee, Ronald (1993) "Modeling and Forecasting the Time Series of US Fertility: Age Patterns, Range, and Ultimate Level," International Journal of Forecasting v.9, pp.187-202.

Lee, Ronald and Timothy Miller (2001) "Evaluating the Performance of the Lee-Carter Approach to Modeling and Forecasting Mortality" Demography, v.38, n.4 (November 2001), pp. 537-549.

Lee, Ronald D. and Lawrence Carter (1992) "Modeling and Forecasting the Time Series of U.S. Mortality," Journal of the American Statistical Association 87(419) pp. 659-671.

Lee, Ronald, Lawrence Carter, and Shripad Tuljapurkar (1995) "Disaggregation in Population Forecasting: Do We Need It? and How To Do It Simply" Mathematical Population Studies v.5, n.3, pp.217-234.

Schieber, Sylvester J., Comment on: Lee, R.D. and S. Tuljapurkar (1998a) Stochastic forecasts for Social Security. D. Wise (ed.), Frontiers in the Economics of Aging, University of Chicago Press, pp. 393-428.

Tuljapurkar, S. and Boe, C.B. (1998a) "Mortality change and Forecasting: How Much and How Little Do We Know?" North American Actuarial Journal.

Tuljapurkar, S. and Boe, C. B. (1998b) "Validation, Probability-weighted priors, and information in stochastic forecasts." International Journal of Forecasting. 
Tuljapurkar, S and R. Lee, (2000) "Demographic uncertainty and the United States OASDI fund," in Sharing the Wealth: Demographic Change and Economic Transfers between Generations, in A. Mason. and. G. Tapinos, Eds. Oxford University Press.

Tuljapurkar, S. (1992) "Stochastic population forecasts and their uses." International Journal of Forecasting 8, pp. 285-391. 
Figure 2.1 Real wage growth, AR model and structural model

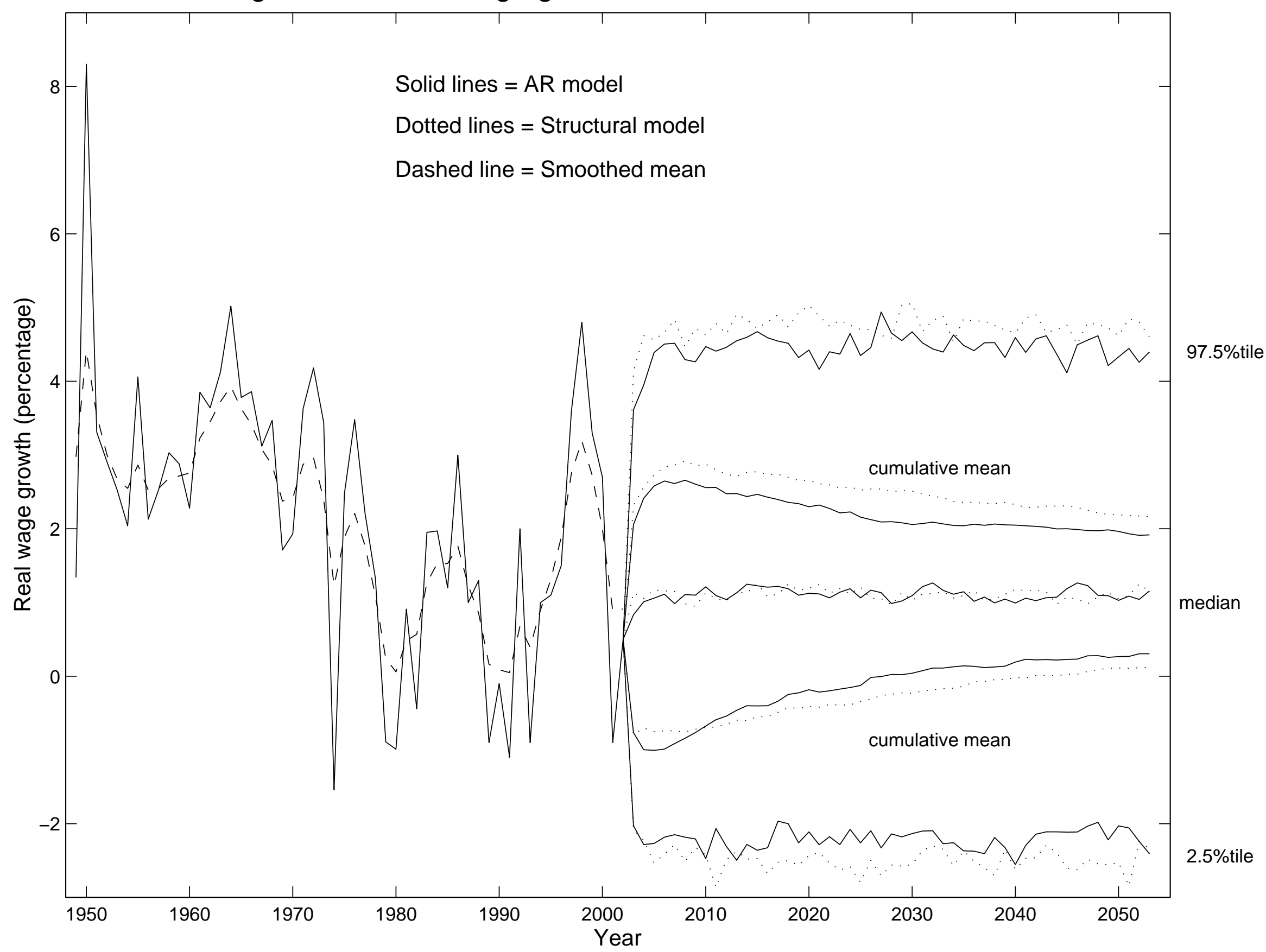

RealWageModels 16-Aug-2004 14:35:35 
Figure 2.2 Real wage growth, AR model and structural model with UUV

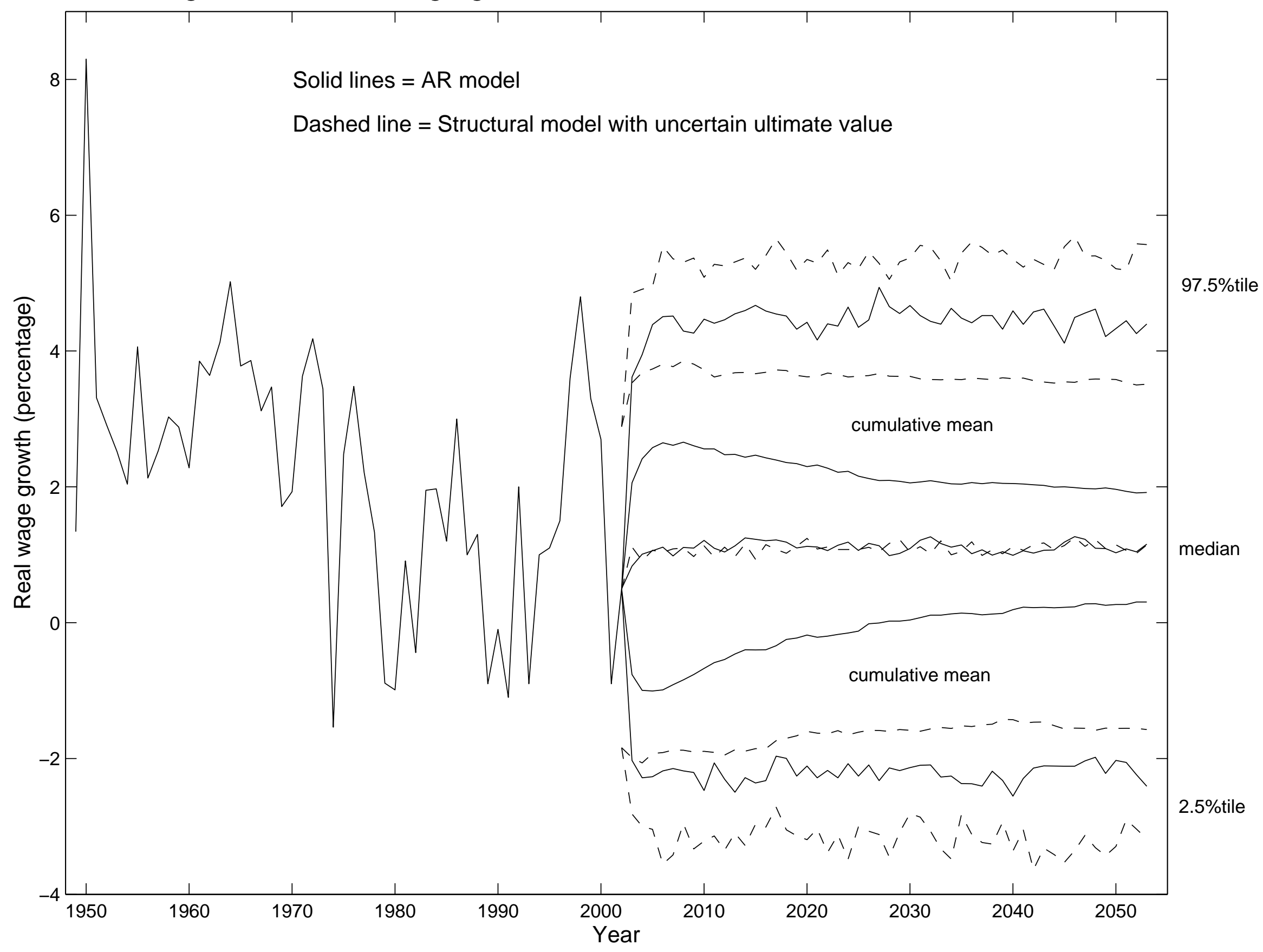

RealWageModelsUUV 17-Aug-2004 09:38:57 
Figure 2.3 Distribution of $A B 75$ for three real wage growth models, with only wage growth stochastic

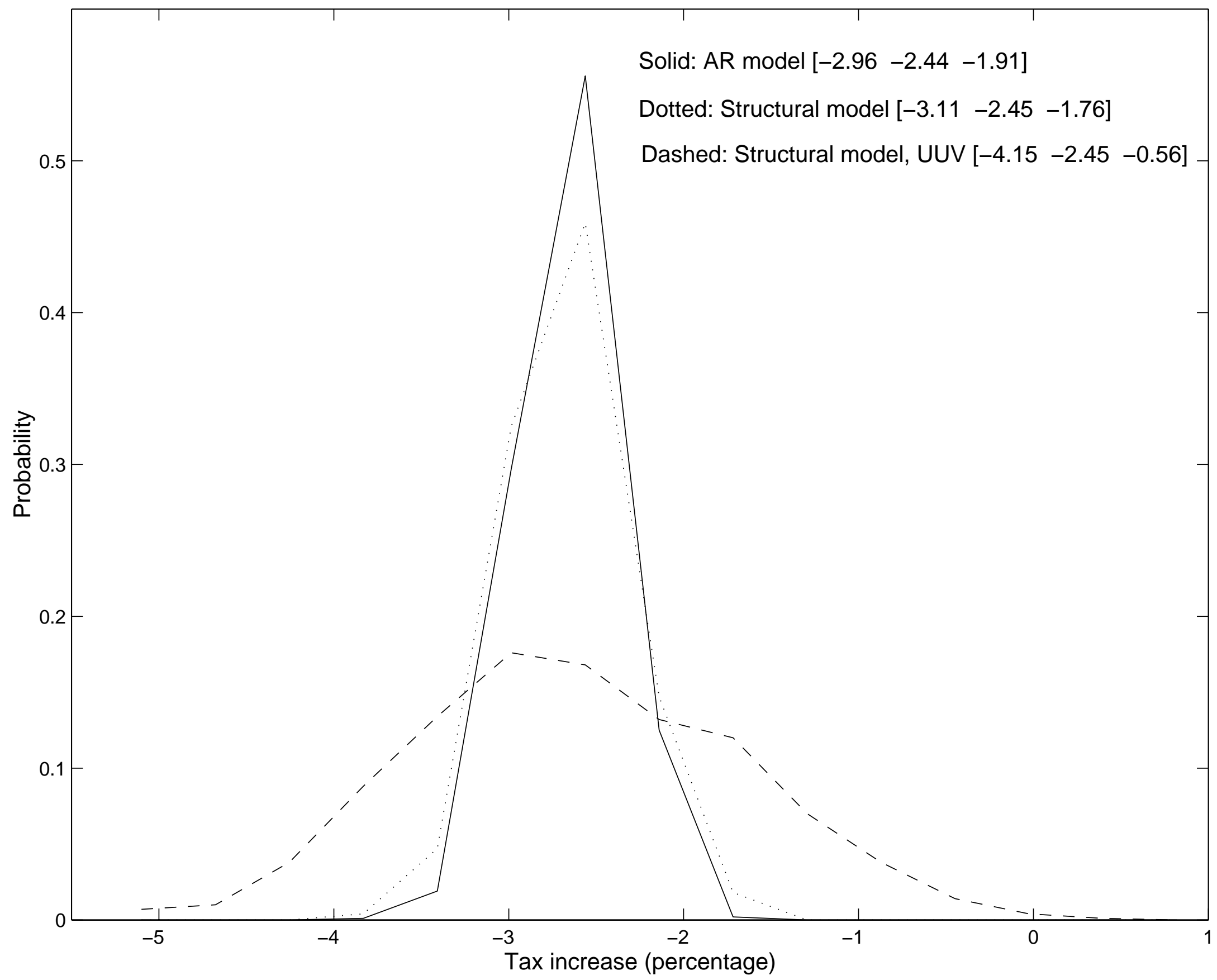

ThreeProdModABHist 17-Aug-2004 10:44:58 
Figure 2.4 Distribution of $A B 75$ for three real wage growth models

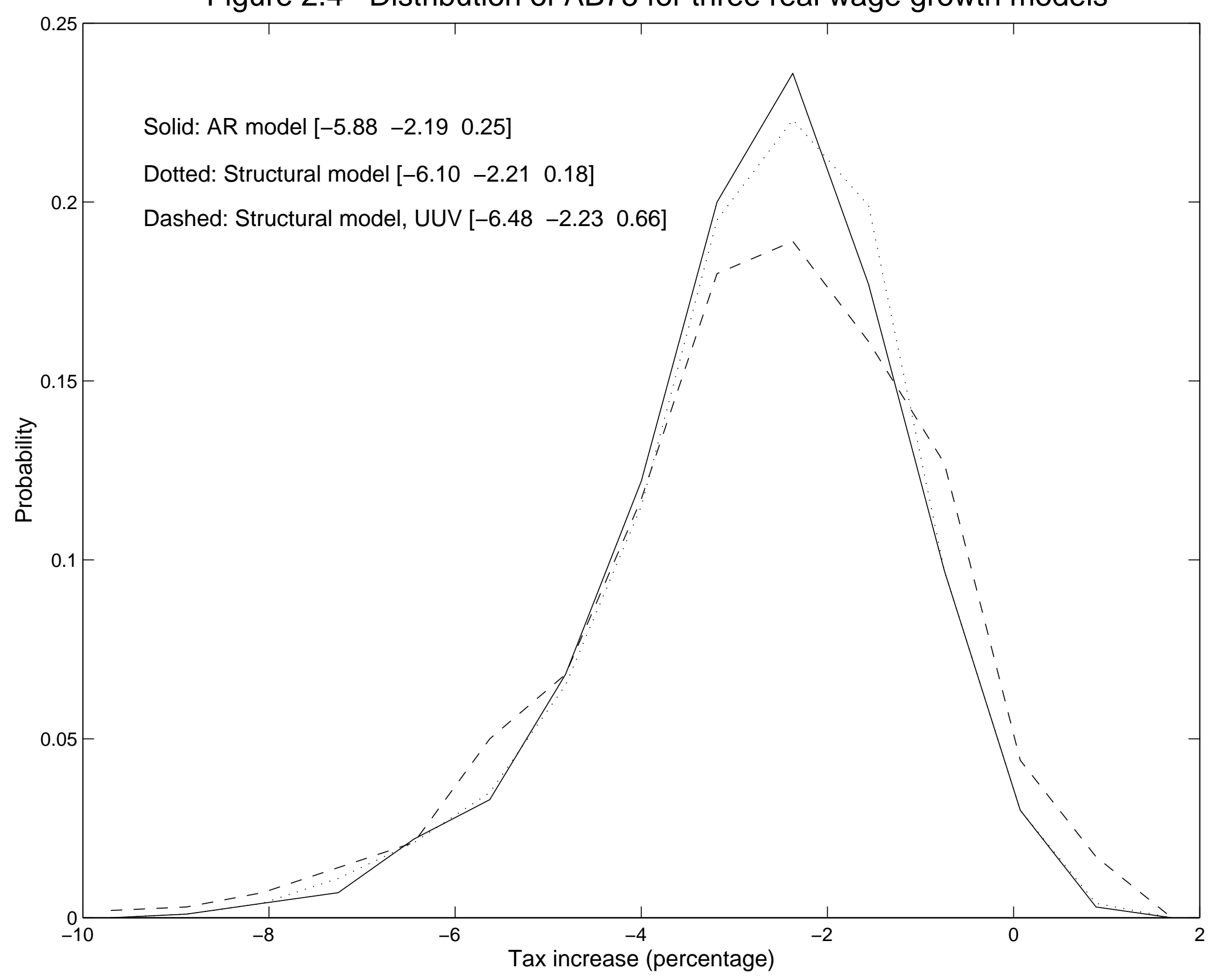

ThreeProdModABHist 12-Aug-2004 11:21:09 
Figure 2.5 Total fertility rate, historical and forecasted with two models

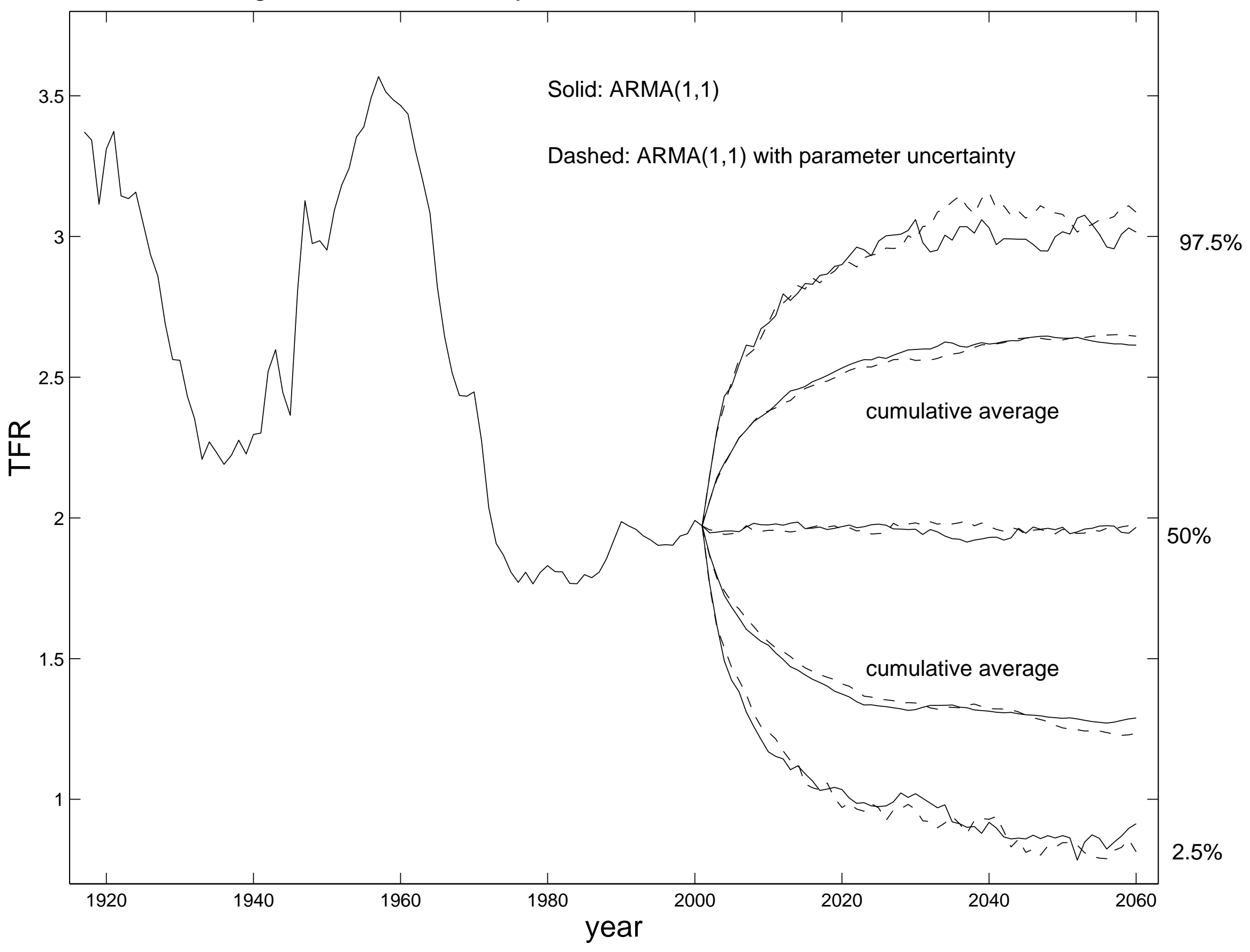


Figure 2.6 Total fertility rate, using $\operatorname{ARMA}(1,1)$ model and Holmer's model

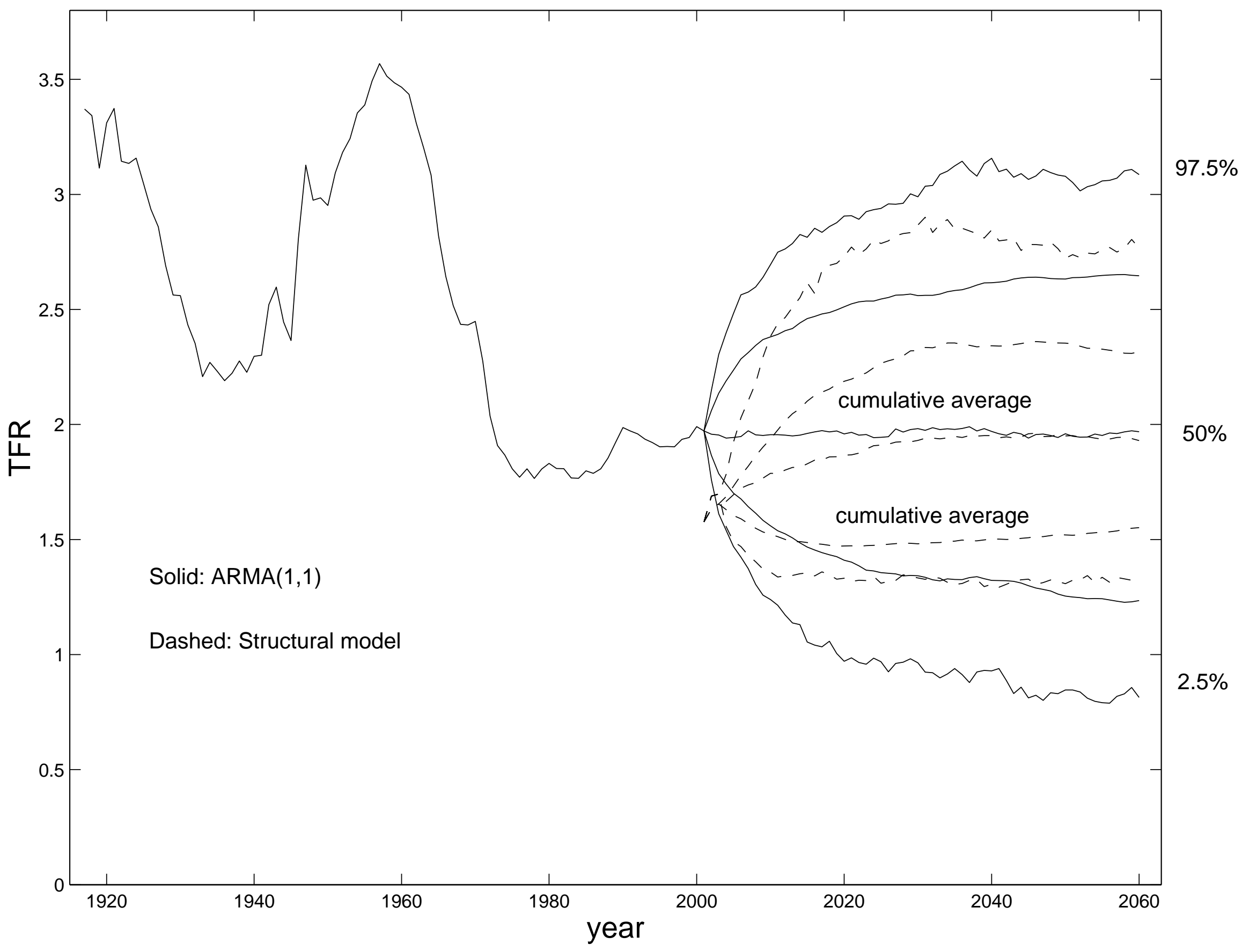


Figure 2.7 Total fertility rate, historical and forecasted with two models

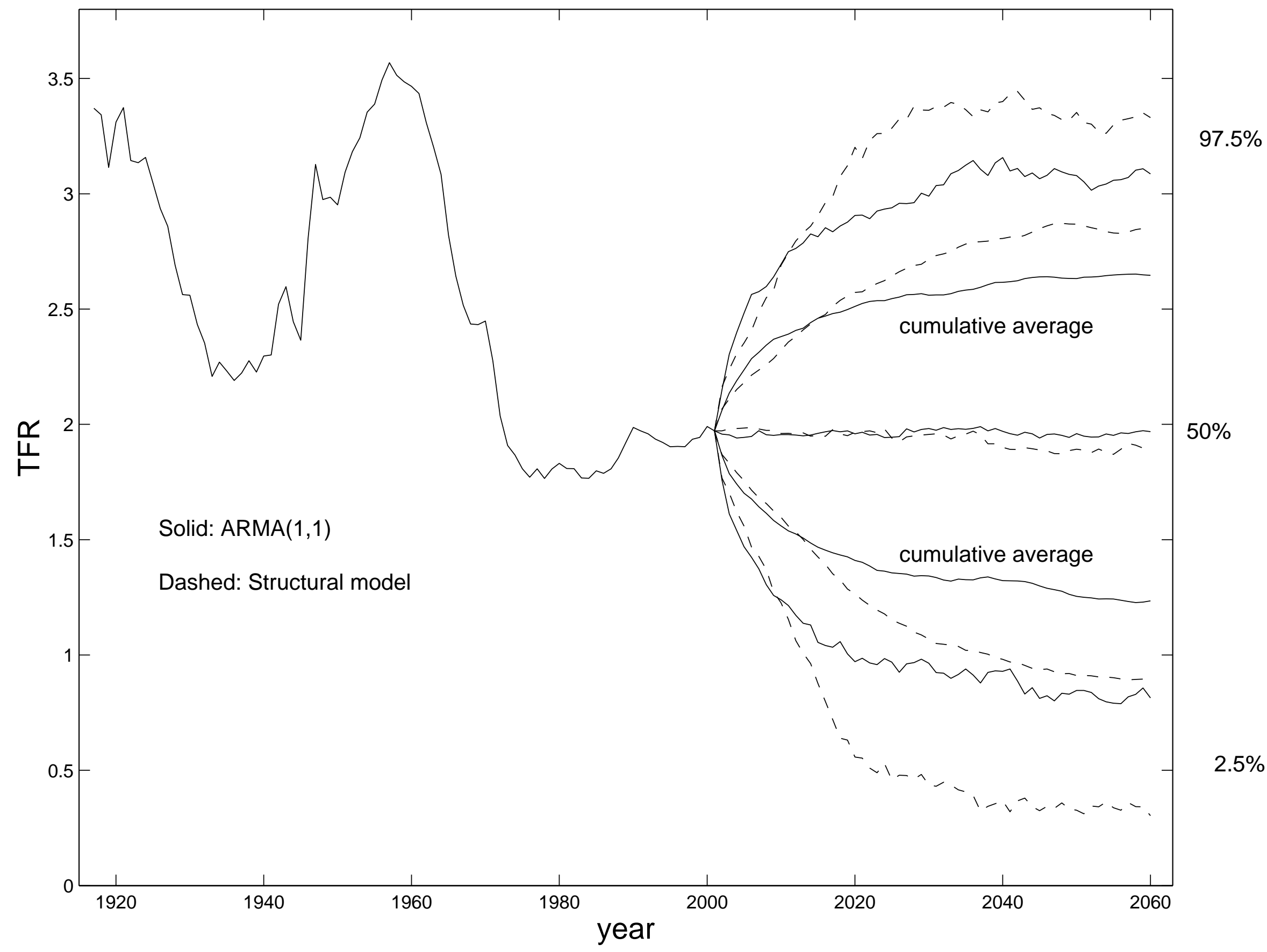

TFRwithTwoModels 17-Aug-2004 13:50:52 
Figure 2.8 Total fertility rate, using ARMA $(1,1)$ model and Holmer's model

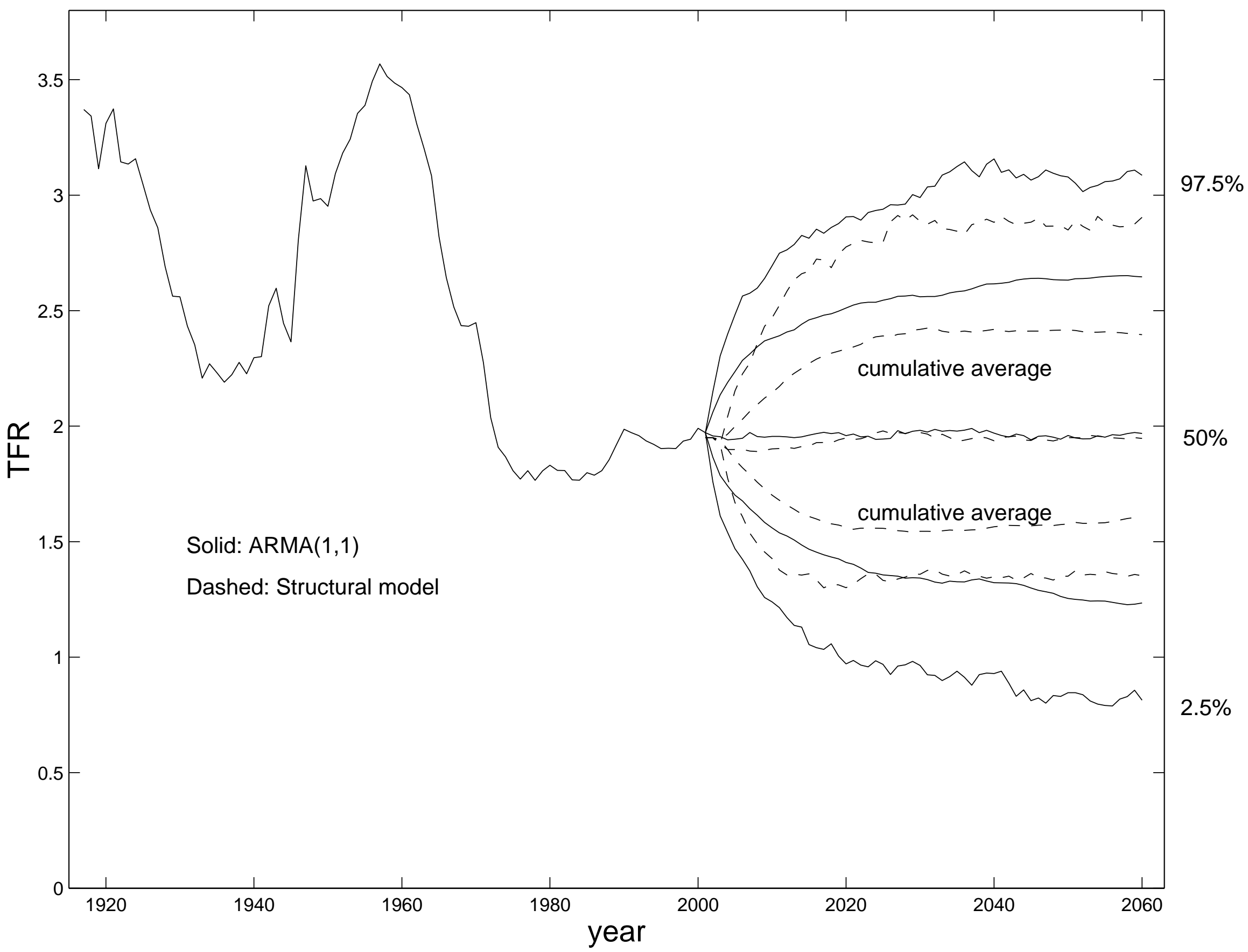

TFRwithHolmerModelRescaled 29-Sep-2004 06:57:17 
Figure 2.9 Distribution of AB75 using Holmer's fertility model versus Lee-Tuljapurkar model

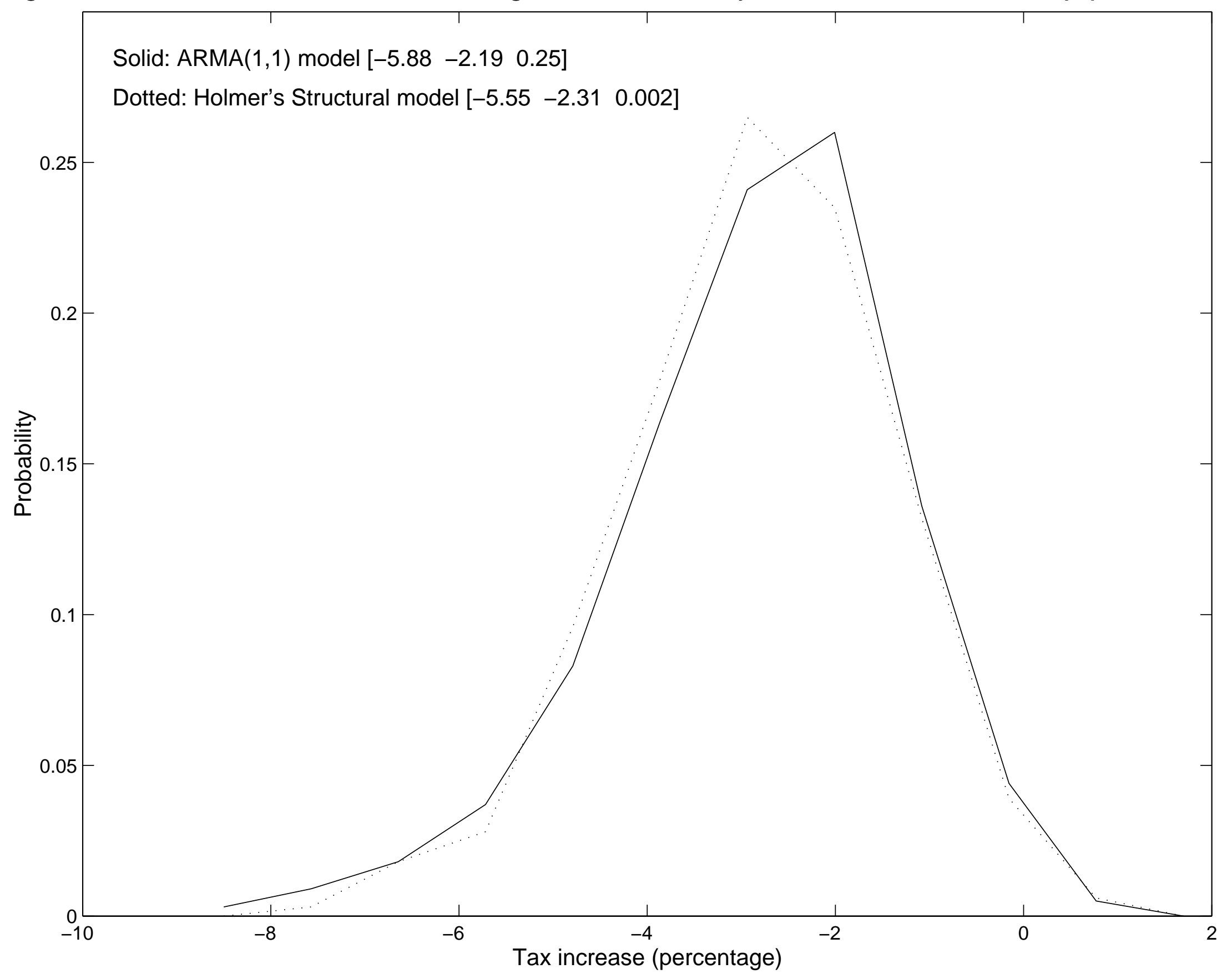

HolmerFertModAB75 03-Oct-2004 11:06:42 


\title{
Report III
}

\section{Stochastic Infinite Horizon Forecasts of Social Security Sustainability}

\author{
Ronald Lee \\ and \\ Michael Anderson \\ Center for the Economics and Demography of Aging \\ University of California at Berkeley \\ 2232 Piedmont Avenue \\ Berkeley, CA 94720-2120 \\ rlee@demog.berkeley.edu
}

October 7, 2004

The research reported herein was performed pursuant to a grant from the US Social Security Administration (SSA) as part of the Retirement Research Consortium. The opinions and conclusions expressed are solely those of the authors and do not represent the opinions or policy of SSA or any agency of the Federal Government. The authors also acknowledge support from Berkeley's NIA-funded Center for the Economics and Demography of Aging. The research funded here builds on basic research funded by NIA grant R37-AG11761. 


\section{Introduction}

Many analysts agree that there are severe problems with the 75-year summary actuarial balance as a measure of the long term fiscal soundness of the system, because it takes no account of what happens after the 75 year horizon, and therefore does not measure what it would cost to put the system on a sustainable footing. For closely related reasons, it is not time-consistent: given exactly the same underlying economic and demographic projections, it will nonetheless deteriorate from one year to the next due to the loss of a good year at the start of the evaluation period and the addition of a bad year at the end.

Lee and Yamagata (2003) developed analytic methods for making infinite horizon projections, and also discuss simpler measures which can be calculated from the standard 75 year projection under certain assumptions about stability, in which case they are equivalent to a certain kind of infinite horizon projection. One of these, that they call the Flat Fund Ratio Tax, is the immediate and permanent tax increase that would leave the ratio of the Trust Fund to Costs constant at the end of the projection horizon, a measure that has also been included in recent Trustees Reports.

Prior to 1965 the Actuaries assessed solvency over an infinite horizon or "in perpetuity" (Myers, 1959). After 1965, the infinite horizon was replaced by a 75-year horizon on the recommendation of the Advisory Council (Goss, 1999). According to Goss this had a relatively small effect on the long-run cost projections at that time, because costs were projected to remain flat in any case, rather than rising exponentially as they do now. Starting in 1973, the projections assumed a changing time path for earnings and benefits, since new legislation linked benefits to past earnings, and consequently use of an infinite horizon might make a considerable difference.

The 2003 Trustees Report included an infinite horizon measure for the first time in many decades, which agreed with the Lee-Yamagata calculations in showing that the budget shortfall was about twice as great relative to payroll as for the 75-Year Summary Actuarial Balance. These estimates were repeated in the 2004 TR. The method is described as follows: "The [infinite horizon] extension assumes that the current-law OASDI program and the demographic and economic trends used for the 75-year projection continue indefinitely." (TR 2004:58, text in brackets is added by us)

It is well known that central forecasts by economists, demographers and actuaries often deviate seriously from actual outcomes even a few years ahead, which is in the nature of the undertaking. Lee and Tuljapurkar (1998a and b, and 2000) and Lee, Anderson and Tuljapurkar (2003) developed probabilistic or stochastic projections of the finances of the Social Security system. Details of the methods are described in the papers cited.

Subsequently, the Congressional Budget Office developed a stochastic projection model, and then in 2003 the Office of the Actuary of the Social Security Administration also developed their own version. The projections of date of fund exhaustion were compared across these three models (Burdick and Manchester, 2003), and agreement was quite close among these three macro-stochastic forecasts. 
These stochastic forecasts indicate a considerable range of uncertainty over a 75 year horizon. Given the substantial uncertainty inherent in long term forecasts, it is questionable how seriously we should take infinite horizon forecasts. Can they really be trusted as the basis for serious policy decisions today? The very phrase "infinite horizon forecast" makes many people snicker, and indeed many serious demographers believe it is pointless and misleading to forecast population beyond 25 years or so. In principle, it would therefore be useful to have probability intervals for the infinite horizon forecasts, giving an idea of how far from the central forecast the actual outcomes might lie. This project will investigate the possibilities of developing probability intervals for infinite horizon forecasts, building on unpublished work by Lee and Yamagata and using the stochastic projection model described earlier. Of course, construction of probability intervals also requires assumptions about the regularity of history, and one need only count back 500 years from the present to a time before Shakespeare to get some idea of how difficult and potentially misleading the whole enterprise might be. Nonetheless, we believe it is worthwhile to make the attempt. However, it should be understood and kept in mind that the we incorporate into our forecasts only uncertainty that arises within the context of assumed structural continuity and homogeneity. This means that we assume that expected or long term average rate of growth of covered wages remains the same over 500 years, as does the expected rate of decline of mortality, the expected level of fertility, and the expected level of real interest rates on government bonds. Random variations about these expected values do occur, but the expected values themselves are constant. Also, we assume that the current program structure remains the same except for already legislated changes in the normal retirement age. Thus the forecasts are conditional on current program structure, as they should be if they are intended to illuminate the extent of need for policy change. We call this kind of forecast uncertainty "routine" or "business as usual" to acknowledge that it excludes deep structural change, and kinds of shocks and trend breaks that were not observed in the past century. Thus the uncertainty we include understates the true amount of uncertainty.

\section{Assumptions, Procedures and Measures}

\section{Basic Methods}

The basic strategy is the same one described above by the Trustees Report. We have a method for making probabilistic forecasts over a horizon of 75 or 100 years, and we just keep going, assuming that the same ultimate levels of fertility, rate of real wage growth, real interest rate, and rate of mortality decline continue, while the structure of Social Security conforms to current law (including the legislated increase in the normal retirement age to 67). We are interested in present values and their ratios over the infinite horizon. Present values involve discounting at the real rate of $3.0 \%$ annually, and given a rate of population growth that tends toward .5\% per year, and a rate of growth in the covered real wage that tends toward $1.1 \%$ per year, the net effect will be that the

discounting dominates, and what happens $\mathrm{S}$ years in the future will count for only $\mathrm{e}^{-.014^{*} \mathrm{~S}}$ relative to the present. After 300 years, outcomes get a weight of only .015 , and after 500 years, a weight of only .0009. In practice, then, we carry out our projections for 500 years, but not beyond. We will confirm below that this is a reasonable practical horizon. 


\section{Stochastic Infinite Horizon Methods}

As described elsewhere (Lee et al, 2003), we impose the TR intermediate assumptions as long term expected values for fertility $(\mathrm{TFR}=1.95)$, real interest rates $(.030)$, and real wage growth (.011). For mortality, we use our own projections based on recent implementations (Lee and Miller, 2001) of the Lee-Carter (1992) model. Other inputs, including immigration, are treated as deterministic in the model used here. The simulation starts with the Trust Fund balance from the 2003 Trustees' Report, which states total assets of \$1.378 trillion at the end of calendar year 2002 .

Of all these variables, only mortality is projected to have a continuing trend. Each age specific death rate is assumed to decline at its own exponential rate (roughly speaking) for 500 years, where the rates of decline are based on historical estimates. Figures 3.1 and 3.2 plot the life expectancies, for males and for females, that result from this procedure, along with the $95 \%$ probability intervals that are generated by the method. Surprisingly (to us, at least) our fitted model predicts that life expectancy will not exceed 100 years until some time between 2400 and 2500, and will only slightly exceed 100 by 2500 . We view these forecasts as too low. There are several reasons why this might be so. First, we fit the model using a weighted Singular Value Decomposition procedure (Wilmoth, 1993) instead of our usual unweighted SVD, and we believe that this leads to lower forecasts even over normal horizons. Second, our procedures constrain survivorship to become zero at age 120. Third, our projections assume that the age pattern of rates of decline remains unchanged. However, it is entirely possible that this age pattern of rate of decline will itself change dramatically in the coming centuries, which could permit much larger increases in life expectancy.

We note that a recent paper by Oeppen and Vaupel (2002) found that record life expectancy among the world's populations with suitable data had been increasing linearly at nearly 2.5 years per decade or 25 years per century. If that trend were to continue, then life expectancy would be roughly 200 years by the year 2500 , or twice our projected level. There are many biologists who believe that life expectancies of 150 or more could be attained in this century. There are also biologists who believe that life expectancy is unlikely to exceed 85 or so. Without necessarily subscribing to any of the views we just mentioned, we nonetheless conclude that our central projection is too low.

The $95 \%$ probability intervals on our projected life expectancies are less than ten years wide, which also strikes us as unrealistically narrow for such a long horizon. Indeed, the span of the interval is not much different than the span of our interval for the forecast only to 2075 . One reason for the narrow uncertainty range is that the rapidly rising age pattern of mortality (death rates double every seven years of age) means that even large variations in the levels of the age specific death rates translate into small variations in life expectancy. As noted above, the age pattern or age specific mortality could change dramatically in the coming centuries, leading to very different mortality trends. This sort of uncertainty is not reflected in our probability intervals. One might say that our probability intervals reflect only a small portion of the true extent of the unknown. 
All these projections or input series assume constant central tendencies. In another section of this report, we discuss structural time series models in which the central tendencies themselves can vary over time, for example as random walks or ARIMA processes (see also Holmer, 2003). Over a 500 year horizon, a random walk would most likely stray implausibly far from its starting value, leading to impossible levels of fertility or interest rate, for example. However, a structural process with a stochastic but equilibrating central tendency could perhaps reflect uncertainty more adequately. In any event, here we will proceed as described, although mindful of the problems with doing so.

\section{Simplified Measures and Rules of Thumb}

Lee and Yamagata (2003) developed two measures of long-run sustainability which do not require actually carrying out detailed projections beyond the standard 75 year horizon. One of these is the Flat Fund Ratio Tax, which was described above. They show that under a strong assumption of stability, that is that revenues and costs grow at equal and constant exponential rates after the end of the projection period, then this Flat Fund Ratio Tax is identical to the infinite horizon summary actuarial balance. Consequently, we will often call it the Stable measure. This simple measure has the virtue that it is easy to explain to policy makers and the public. The idea that the ratio of the Trust Fund to the costs of benefits should not be falling at the end of the projection period is just common sense. In this report, we will investigate the performance of this measure relative to the actual 500 year horizon calculations. It is also possible to calculate the probability distribution of the Flat Fund Ratio Tax in a stochastic projection over the 75 year horizon, provided one smoothes the projected paths a bit near the 75 year horizon, so that changes in the Fund Ratio are not dominated by short term noise.

If we calculate the actual rates of change of revenues and costs from the Trustees' Report, we find that costs are growing more rapidly than revenues, so that the stability assumption is not warranted. Therefore we should expect that the Flat Fund Ratio Tax will underestimate the infinite horizon imbalance. This leads us to a second measure that is slightly more complicated but can also be calculated directly from the 75-year projections regularly published by the Trustees. This measure assumes that costs and revenues continue to change after the 75 year horizon at the same exponential rate that they were changing at the end of the projection period, say between year 74 and year 75 . We called this the "Unstable" measure. Under current conditions (rate of growth of costs exceeding that of revenues) it will indicate a larger infinite horizon imbalance than the Flat Fund Ratio Tax measure. As with the Stable measure, it is possible to calculate a probability distribution for the unstable measure, based on stochastic projections over a 75 year horizon.

Below, we will assess the accuracy and usefulness of these simpler measures, taking the actual 500 year projection as the gold standard.

\section{Results}

For reference purposes, it will be useful to recall that the 2003 Trustees' Report reported an infinite horizon Actuarial Balance of $-3.7 \%$ of payroll, while the 2004 Trustees' 
Report reported $-3.5 \%$, both consistent with Lee and Yamagata (2003) when the Social Security Actuary's mortality projection is used.

\section{The 75-Year Actuarial Balance is not a Sustainability Measure}

The problems with the 75-year Actuarial Balance, or AB75, are illustrated in Figure 3.3 which shows the probability distribution of the projected Trust Fund Ratio, assuming the payroll tax has been raised by $1.92 \%$, which the 2003 AB75 indicated should balance the system. The figure shows that the median ratio crosses zero and turns negative in 2074, falling to -82 in 2200 . The mean ratio crosses zero a bit later, but falls much faster, ending at below -150 by 2200 . The upper $67 \%$ probability bound (that is, at $83.3 \%$ ) also goes increasingly negative soon after 2120 . Clearly, a tax increase of $1.92 \%$ will not put the system on a sustainable footing, even with quite a lot of luck.

\section{Simple Measures of Sustainability}

Based on our stochastic projection of the finances of the system, which consists of 1000 stochastic sample paths, we can calculate the Stable or Flat Fund Ratio measure for each one at a 75 year horizon. This gives us a probability distribution for the measure, which is plotted in Figure 3.4. The median is $4.36 \%$, which suggests that under the stable assumption, the infinite horizon imbalance is $4.36 \%$ of the present value of payroll. Alternatively, an immediate and permanent tax increase of $4.36 \%$ would put the system in sustainable balance. This compares to a similar calculation of $4.2 \%$ reported in Lee and Yamagata (2003). 99\% of the probability distribution for this measure lies between $0 \%$ and $10 \%$.

Similarly, we can find the probability distribution for the Unstable measure of infinite horizon imbalance, as shown in Figure 3.5. First, we note that as expected, the Unstable measure indicates a larger imbalance, with a median equal to $5.21 \%$ of the present value of payroll. Second, we note that the probability interval is extremely wide compared to the that for the stable, with probability mass spread from $-30 \%$ to $+30 \%$. The width of this range is an artifact of the unstable method in the stochastic context, and no importance should be attached to it. We will see below that the correct range is far narrower.

\section{Results of 500 Year Stochastic Projections}

We described above how the infinite horizon projections are carried out. Actuarial Balances can be calculated for different horizons, and the Trustees' Reports generally give them for horizons of 25, 50 and 75 years, as well as for the infinite horizon in recent years. Figure 3.6 plots percentiles of the probability distributions for Actuarial Balances calculated over a continuum of horizons up to 500 years. Thus, for example, the line labeled " $50 \%$ tile" portrays the median $\mathrm{AB}$ as a function of horizon. We see that it drops rapidly to increasingly negative values in the first century, reaching about $-3 \%$ in 2100 , and around $-4 \%$ in 2200 , while dropping more an more slowly thereafter, and approximately leveling off in the fifth century. This is the case for all the other probability percentile lines, which indicates that the probability distribution has stabilized after 500 years and extending the horizon further would add little. To make sure the meaning of these lines is clear, if we pick some particular horizon, such as 200 years, we could say that there is a $2.5 \%$ chance that the true $A B$ is less than $-9 \%$ at this horizon, while there is also a $2.5 \%$ chance that the true $\mathrm{AB}$ is greater than $-1 \%$, with a median of $4 \%$ as noted above. 
Now consider one specific horizon, at 500 years. The percentiles in Figure 3.6 at a horizon of 500 years provide five points on the full probability distribution for the year 2500. Figure 3.7 plots the full probability distribution of Actuarial Balances at the 500 year horizon. Here we see that the median is $-5.15 \%$ of the present value of payroll (which corresponds to the 50\%tile line shown in Figure 3.6 at this horizon), and mean is $5.37 \%$. Much as with the probability distribution for the Flat Fund Ratio measure, the probability mass is almost entirely between $0 \%$ and $-10 \%$, but with a bit more out on the negative tail for the 500 year projection. These various measures are contrasted in the following summary table.

\begin{tabular}{||l|l||}
\hline $\begin{array}{l}\text { INFINITE HORIZON MEASURE OF } \\
\text { ACTUARIAL BALANCE }\end{array}$ & $\begin{array}{l}\text { PERCENT OF PV OF } \\
\text { TAXABLE PAYROLL }\end{array}$ \\
\hline 2003 (2004) Trustees' Report & $-3.7 \quad(3.5)$ \\
\hline Stochastic Projection (median) & -5.15 \\
\hline $\begin{array}{l}\text { Flat Fund Ratio (median of Stochastic } \\
\text { Projection at 75 years) }\end{array}$ & -4.36 \\
\hline $\begin{array}{l}\text { Unstable Measure (median of } \\
\text { Stochastic Projection at 75 years) }\end{array}$ & -5.21 \\
\hline
\end{tabular}

We note that the unstable measure agrees very closely with the 500 year projection, which suggests, but does not establish, that it might be a simple alternative to carrying out the detailed projections over 75 years, at least to obtain a central value. The Flat Fund Ratio measure also does surprisingly well, given its simplicity, and the strong and false assumption on which it rests (rates of growth of revenues and costs are equal and constant after 75 years). We also note that all three of the measures based on our stochastic projections show substantially greater imbalances than does the Trustees' Report. This most likely reflects the difference in the mortality projection, which Lee and Yamagata (2003) found to make about twice as much difference over the infinite horizon (about 1 to $2 \%$ ) as over the 75 year horizon (about .5\%).

The probability interval for the Flat Fund Ratio estimate of the infinite horizon balance appears very similar to the interval for the actual 500 year Actuarial Balance, although the medians are somewhat different. However, any temptation to believe that the Flat Fund Ratio distribution is credible is quashed by inspection of a scatter plot of the stochastic Flat Fund Ratios at the 75 year horizon versus the 500 year outcomes for Actuarial Balance, as shown in Figure 3.8. The correlation is essentially zero, so the Flat Fund Ratio criterion is not identifying trajectories that are headed in particularly costly or particularly inexpensive directions. Rather, the correspondence of the two probability distributions is coincidental. When one thinks about the quite different basis for the two distributions, that is not surprising.

We can conclude that it is best to carry out the full stochastic projection over a long horizon of around 500 years, but that a pretty good approximation of the central tendency may be obtained from the 75 year Unstable measure, at least in the present circumstances. Whether it will be a good approximation in other circumstances as well remains to be 
seen. The Flat Fund Ratio also provides an acceptable measure, although when costs are rising more rapidly than revenues it will underestimate the imbalance.

So far, we have expressed the imbalance relative to the present value of payroll. However, we can also report the distribution of the infinite horizon imbalance in dollars, as is done in Figure 3.9. We see that the median present value of the imbalance is 18 trillion dollars, or about 1.6 times GNP at the start of 2003. This figure of 18 trillion is substantially larger than the 10.5 trillion reported by the 2003 Trustees' Report for the open group infinite horizon obligation, at 3.7\% of payroll. Given our estimate of 5.15\% of payroll, for the same payroll we would get 14.6 trillion; the balance must be due to a higher projection of the present value of payroll, due to lower mortality or to other differences in our projection methodology, including the fact that we are reporting the median of a stochastic outcome, rather than a deterministic projection.

\section{The High Cost of Delay}

Figure 3.6 showed the amount of uncertainty in the 500-year actuarial balance. It is tempting to view this dispersion, and to conclude that the difference between raising payroll taxes by $0 \%$ or $1.92 \%$ or $5.15 \%$ is swamped by uncertainty, and adjustment could easily be made later. If adjustment is made relatively quickly, this might be so. But we must keep in mind that the actuarial imbalances shown in Figure 3.6 are not simple averages of all the imbalances year by year from now over the next 500 years. Rather they are heavily weighted averages, with the weights given by the residual discounting factor, by which we mean the $3 \%$ real rate of interest that is assumed, less the $1.1 \%$ growth rate in covered real wages that is assumed, less the approximate rate of population growth of $.5 \%$, for a residual discount rate of $1.4 \%$ per year. Here are the relative weights that result, showing a decay by half every fifty years.

\begin{tabular}{rr} 
Delay & \multicolumn{2}{c}{ Weight } \\
0 & 1.000 \\
50 & 0.497 \\
100 & 0.247 \\
150 & 0.122 \\
200 & 0.061 \\
250 & 0.030 \\
300 & 0.015
\end{tabular}

A $1 \%$ increase in the payroll tax rate implemented for the first year is worth twice as much as one implemented for the $50^{\text {th }}$ year, and almost 70 times as much as a $1 \%$ increase implemented for the $300^{\text {th }}$ year.

\section{Dates of Insolvency}

These measures are intended to indicate the size of the policy adjustment needed to put the system on a sustainable path. Nonetheless, a probability of insolvency remains, and it would be poor policy indeed to raise taxes or cut benefits to the point where the probability of future insolvency approached zero. It is much more sensible to adjust taxes 
and benefits as the future reveals itself, so as to keep the program on track. The sustainability measures we have discussed and estimated strive to indicate the likely center of the range of policy adjustments that would prove necessary.

If payroll taxes were raised by $5.15 \%$, which is the median Actuarial Balance over the 500 year horizon, then we should expect that the system would nonetheless become insolvent (Trust Fund equal to zero) in less than 500 years about $50 \%$ of the time. This is what is shown in Figure 3.10, which gives the histogram of dates of insolvency under a $5.15 \%$ tax increase (from $12.4 \%$ to $17.55 \%$ ). We see that there is a $10 \%$ chance of insolvency by 2100 despite this hefty tax increase, a $20 \%$ chance by 2125 , and a $28 \%$ chance by 2150 .

Figure 3.11 shows the same for the Flat Fund Ratio Tax increase of $4.36 \%$, or about .8\% less. Here we see a $36 \%$ chance that the system would stay solvent for 500 years, and nearly a $20 \%$ chance that it would become insolvent by 2100 , rising to $35 \%$ by 2125 , and to $43 \%$ by 2050 .

\section{How Big Would the Trust Fund Get?}

It is important to keep clearly distinct the use of these measures of imbalance on the one hand, and prescriptions for correcting these imbalances on the other. Because it is simple and intuitive to present these measures as equal to the size of the immediate and permanent increase in the payroll tax rate that would be necessary to restore the system to balance in the long term, it is easy to slide into viewing immediate and permanent tax increases as the appropriate policy remedy. There are alternatives. One is to reduce benefits, and these measures could just as well (but somewhat less clearly and simply) be couched in terms of necessary benefit reductions. But more to the point in the present context, one could plan a gradual increase in tax rates (or benefit cuts) that would distribute the costs of adjustment in different ways across generations, and that would also make it possible to respond on a regular basis to emerging trends in demography, economy, functional status at older ages, and retirement behavior.

Having said that, in this section we will explore the implications of instituting immediate tax increases corresponding to the measured imbalances. In particular, we will examine the trends in trust fund ratios and in size of trust fund implied by these tax increases.

We begin by looking at median Trust Fund Ratio through 2200, for tax increases equal to the Trustees' 75 year Actuarial Balance measure, 1.92\%; equal to the Flat Fund Ratio Tax, $4.36 \%$; and equal to the Unstable measure, $5.21 \%$ (very close to the infinite horizon Actuarial Balance measure of $5.15 \%$, which will therefore not be shown separately). These are shown in Figure 3.12. We have already noted that the Trust Fund Ratio goes negative in 2074 with the $1.92 \%$ increase, as was shown in Figure 3.3, having peaked in 2019 at 6.4 times Costs. The Trust Fund Ratio for the Flat Fund Ratio Tax is constant in the 2070's by construction, where it peaks at 13.3 times Costs, but it declines steadily thereafter and has become negative before 2200. We have already indicated that it is an underestimate of the adjustment needed for sustainability, but the rapidity of its decline is nonetheless surprising to us. With an increase equal to the Unstable amount (or nearly 
equivalently, to the infinite horizon Actuarial Balance), the Trust Fund Ratio reaches a high near 27 times Costs toward 2200, and appears to have stabilized.

We have just looked at projections for the Trust Fund Balance relative to Costs, which has the advantage of factoring out the scale of the economy. It is also interesting to look at the absolute amount of the Trust Fund Balance. Figure 3.13 plots the median Trust Fund Balance in 2002 dollars under the Flat Fund Ratio Tax increase of $4.36 \%$. We see that it rises to 100 trillion dollars around 2150 , before declining precipitously to -35 trillion by 2200 . These are huge numbers, and difficult to interpret without considering the scale of the economy as a whole, which is greatly expanded by labor force growth and real wage growth.

While dividing by they systems Costs, as with the Trust Fund Ratio, is one convenient way to adjust for the scale of the economy, perhaps the simplest number to interpret is the ratio of the Trust Fund to the level of GDP. Figure 3.14 shows selected percentiles of the probability distribution for this ratio, expressed as a percent, for a tax increase equal to the Flat Fund Ratio Tax increase of $4.36 \%$, through 2080. The median ratio reaches $105 \%$ of GDP in the 2070s. While the median flattens out, and then declines (outside the range of this graph), the mean continues to rise, surpassing $170 \%$ by the end of the plot range, with no end in sight. We also show the $2 / 3$ probability range, with its upper bound (labeled $83.3 \%$ ) asymmetrically high and rising rapidly, reaching above $300 \%$ of GDP by the late $2070 \mathrm{~s}$. The lower $16.7 \%$ bound remains positive throughout, but has dropped below $30 \%$ by the late 2070 s. This great range of outcomes for a policy that is supposed to be sustainable demonstrates the absolute necessity to maintain policy flexibility to adjust to changing circumstances as they unfold.

As we would expect, a similar plot for the infinite horizon Actuarial Balance tax increase of $5.15 \%$ shows an even greater increase of the Trust Fund relative to GDP. The median reaches nearly $150 \%$, and the $83.3 \%$ bound reaches $375 \%$, by the late 2070 s.

Balances of this sort could not be held as government bonds, since that would require that the rest of the government would go in debt to an extent that is not now imaginable. An alternative would be to hold the Trust Fund in equities, in which case it would account for a very sizable portion of the domestic capital stock. But these issues are beyond the scope of this paper.

\section{Conclusions}

1. Many issues surround infinite horizon forecasts, and the whole enterprise can certainly be questioned. Nonetheless, we have found it useful simply to extend the range of the stochastic forecasting models to very distant horizons. We call these "routine" or "business as usual" stochastic forecasts, because their uncertainty does not reflect the possibility of structural shifts. They understate actual uncertainty.

2. Both the Flat Fund Ratio Tax measure and the Unstable measure are useful simple approximations to the deterministic or median infinite horizon open group imbalance measure. The Flat Fund Ratio is the immediate and permanent tax increase that would be needed to hold the ratio of the Trust Fund to Costs constant over the last two years 
of the 75-year projection. It is more intuitive and therefore easier to explain than the Unstable measure, but it underestimates the imbalance, whereas the Unstable measure (explained in the report) gives a very good approximation to the infinite horizon measure, at least under current circumstances.

3. The 2004 Trustees Report indicates an infinite horizon open group imbalance equal to $3.5 \%$ of payroll, consistent with Lee and Yamagata (2003) when the Actuary's mortality projection is used. Based on our 500-year projection, we estimate it to be $5.15 \%$, substantially larger. Our two simple methods, based on our 75 year projections, indicate levels of $4.36 \%$ for the Flat Fund Ratio measure, and $5.21 \%$ for the Unstable measure.

4. Good estimates of the uncertainty of the simple measures cannot be derived from stochastic forecasts over the 75 year horizon, at least using the methods we have attempted. Therefore the simple measures are useful only for central tendency.

5. The "routine" uncertainty surrounding the infinite horizon estimates of Summary Actuarial Balance is about $40 \%$ greater than the uncertainty of the 75 year projections: the $95 \%$ probability interval is $9 \%$ wide versus $6.5 \%$ for the 75 -year horizon.

6. Raising tax rates immediately by an amount intended to achieve sustainability would imply substantial chances of huge Trust Fund accumulations that neither could nor should be realized in practice, at least not through holdings of government bonds. Adaptive policies that maintain the Trust Fund ratio at a desirable level seem more attractive, but have not yet been explored. 


\section{References}

Burdick, Clark and Joyce Manchester (2003) "Stochastic Models of the Social Security Trust Funds" Research and Statistics Note, posted on the web site of the Office of the Actuary.

Congressional Budget Office (2001) Uncertainty in Social Security's Long-Term Finances: A Stochastic Analysis, a paper posted on the $\mathrm{CBO}$ web site, www.cbo.gov; December.

Lee, Ronald, Michael W. Anderson, and Shripad Tuljapurkar (2003) "Stochastic Forecasts of the Social Security Trust Fund" Report for the Social Security Administration (January)

Lee, Ronald and Lawrence Carter (1992) "Modeling and Forecasting U.S. Mortality," Journal of the American Statistical Association v.87 n.419 (September 1992), pp.659-671, and "Rejoinder," same issue, pp.674-675.

Lee, Ronald and Shripad Tuljapurkar (1998a) "Stochastic Forecasts for Social Security," in David Wise, ed., Frontiers in the Economics of Aging. Chicago: University of Chicago Press, pp. 393-420.

Lee, Ronald and Shripad Tuljapurkar (1998b) "Uncertain Demographic Futures and Social Security Finances" American Economic Review: Papers and Proceedings (May) pp. 237-241.

Lee, Ronald and Shripad Tuljapurkar (2000) "Population Forecasting for Fiscal Planning: Issues and Innovations" in Alan Auerbach and Ronald Lee, eds., Demography and Fiscal Policy, Cambridge: Cambridge University Press.

Lee, Ronald and Hisashi Yamagata (2003) "Sustainable Social Security: What Would It Cost?" National Tax Journal, v. 56, n. 1, part 1, pp. 27-43.

Tuljapurkar, S and R. Lee, (2000) "Demographic uncertainty and the United States OASDI fund," in Sharing the Wealth: Demographic Change and Economic Transfers between Generations, in A. Mason. and. G. Tapinos, Eds. Oxford University Press.

Wilmoth, J.R. (1993) "Computational methods for fitting and extrapolating the LeeCarter model of mortality change." Technical report, Department of Demography, University of California, Berkeley LINK. 
Figure 3.1 Male e0, historical and $500-y r$ forecast w/95\% Cl

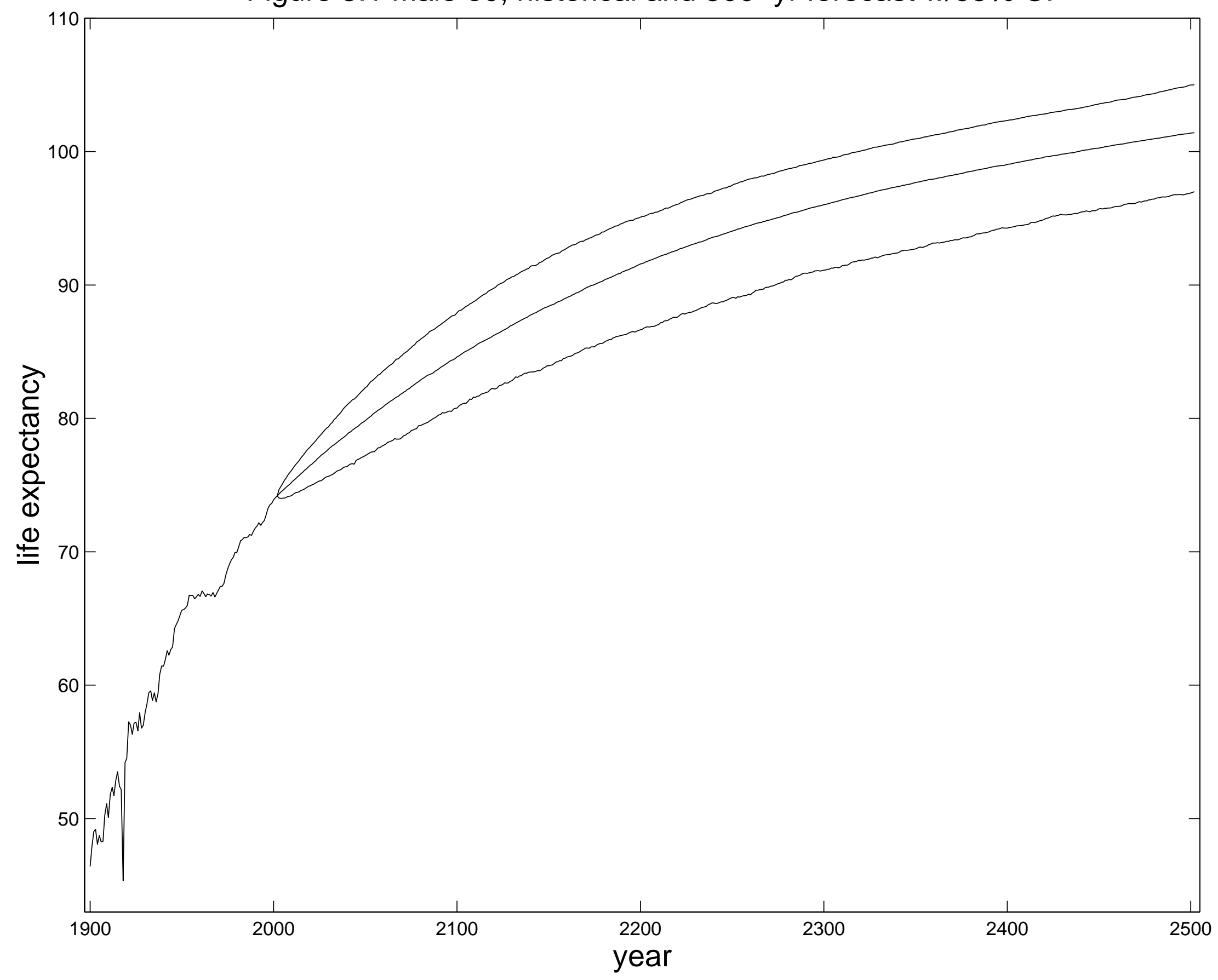


Figure 3.2 Female e0, historical and 500-yr forecast w/95\% Cl

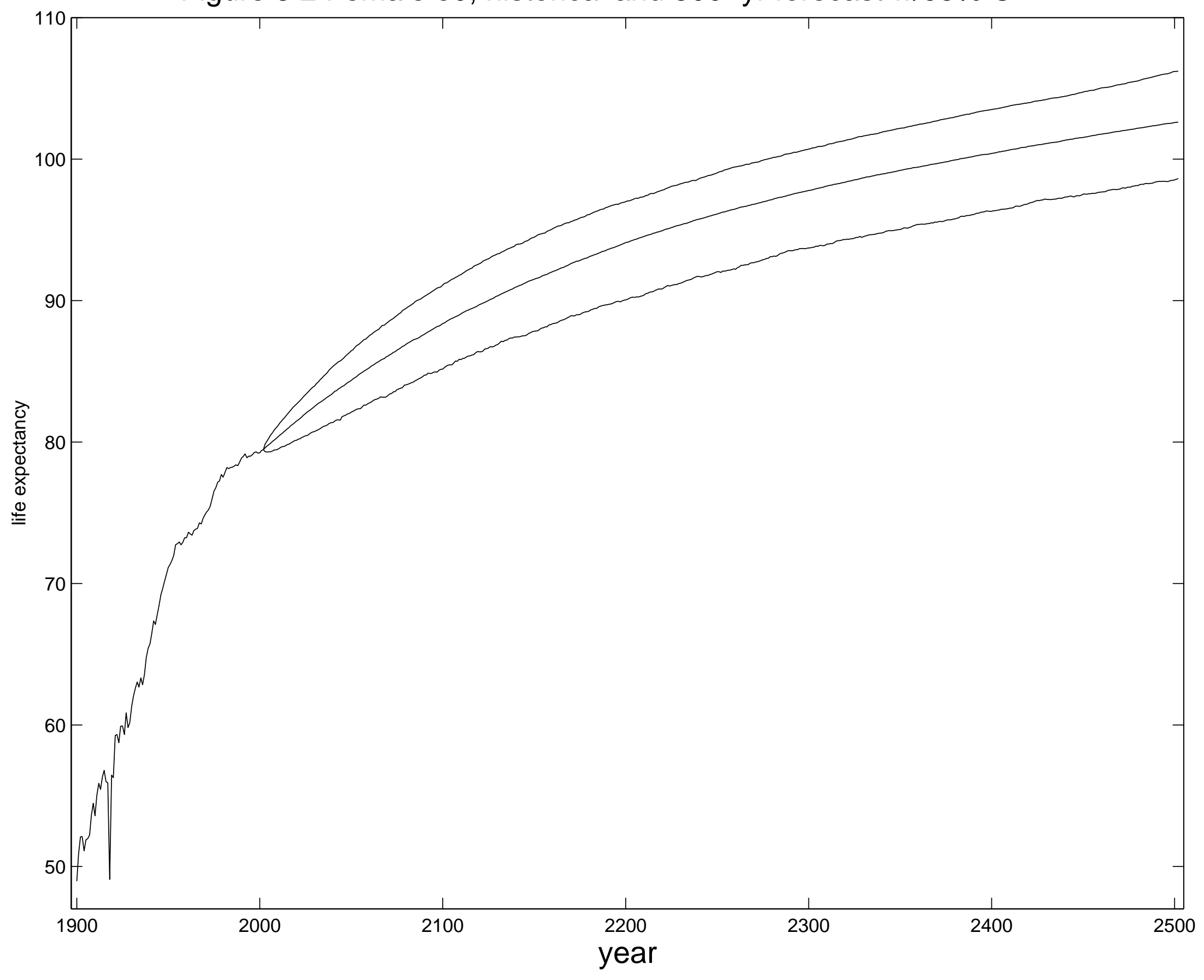


Figure 3.3 Trust fund ratio with $1.92 \%$ tax increase (SSA's AB75)

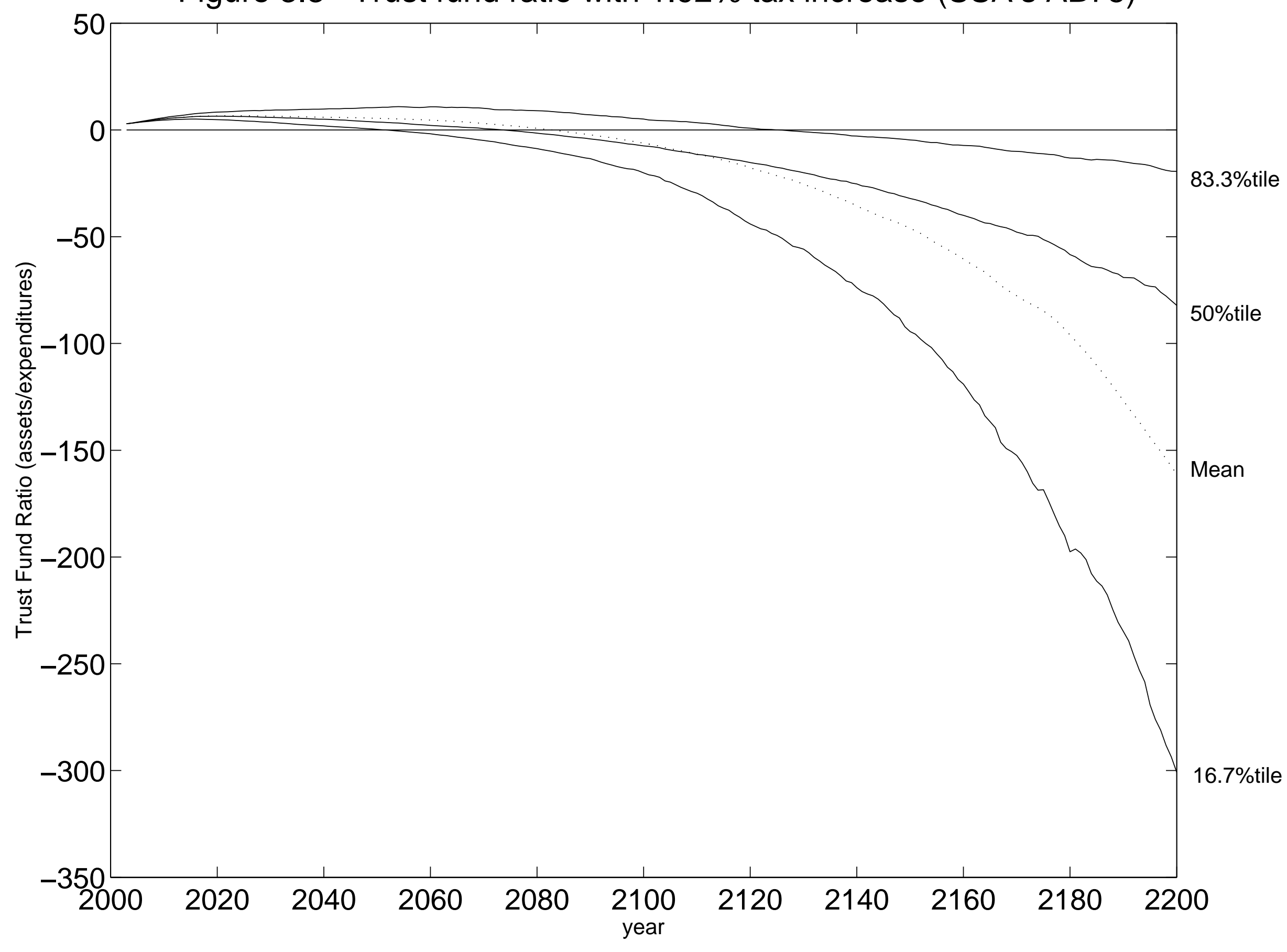


Figure 3.4 Sustainable tax rate increase under stable assumption

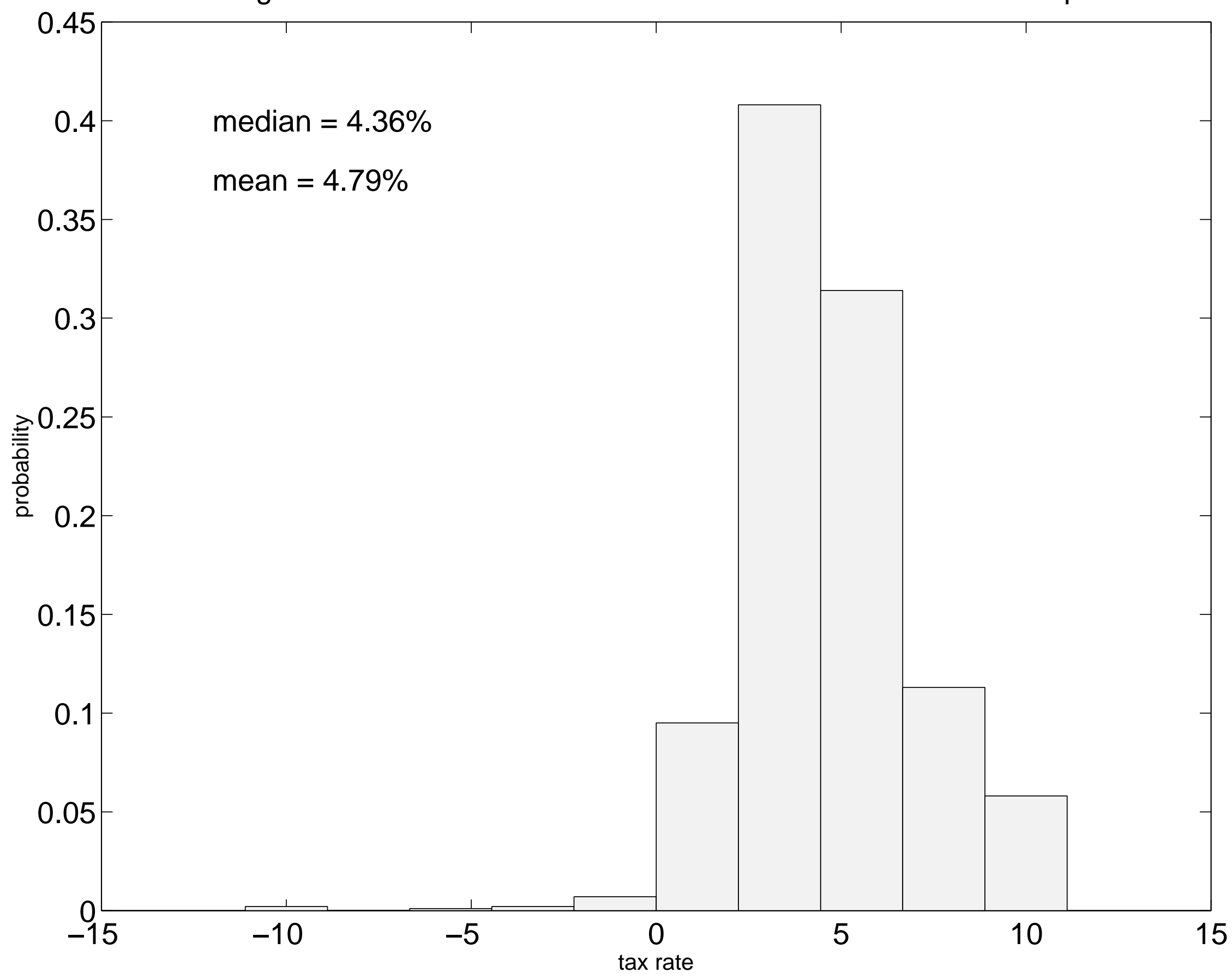

SustainableTaxStable 03-Jul-2004 14:23:39 


\section{Figure 3.5 Distribution of sustainable tax rate under unstable assumption}

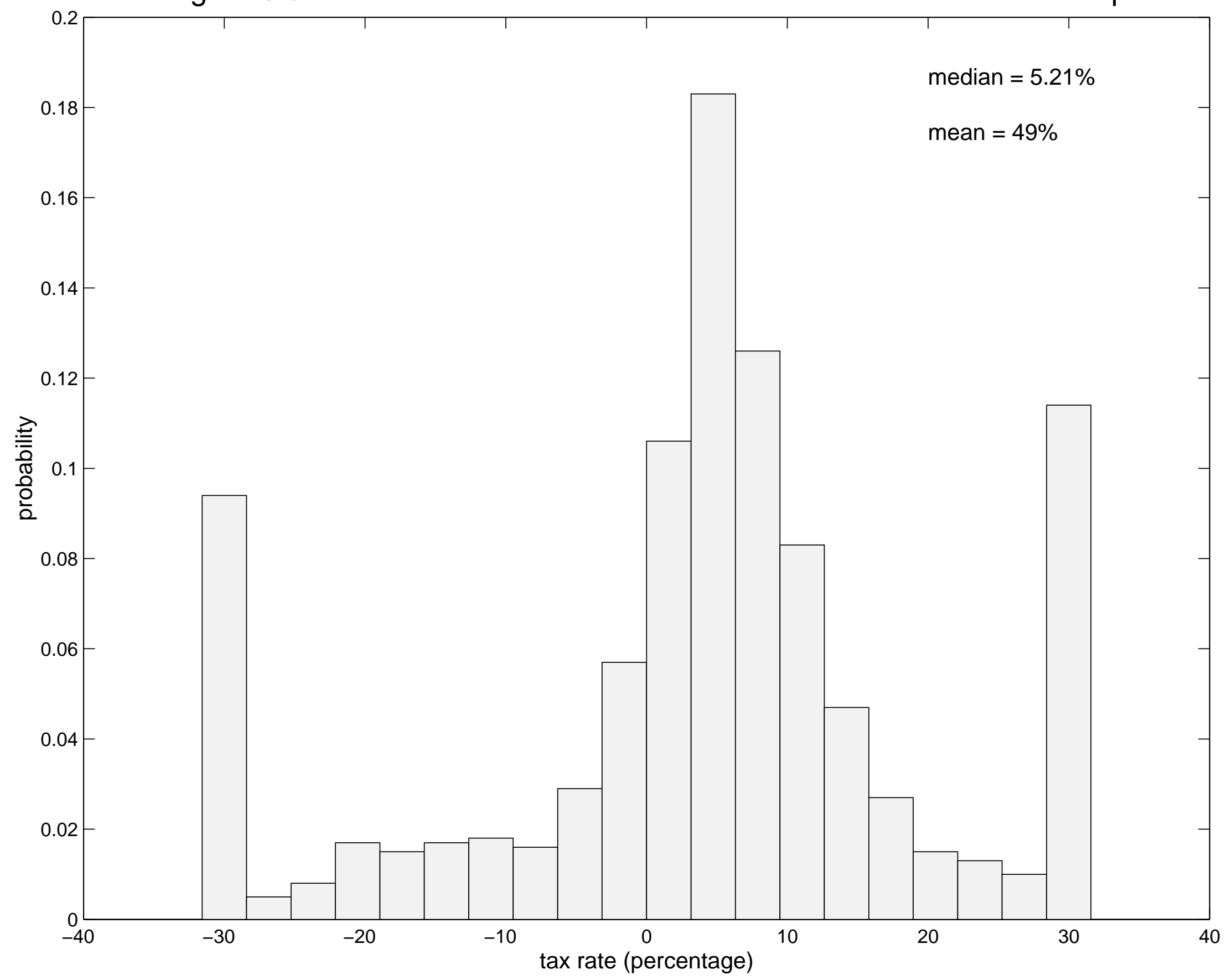

SusTaxUnstable 04-Jul-2004 15:51:18 
Figure 3.6 Summarized actuarial balance by horizon

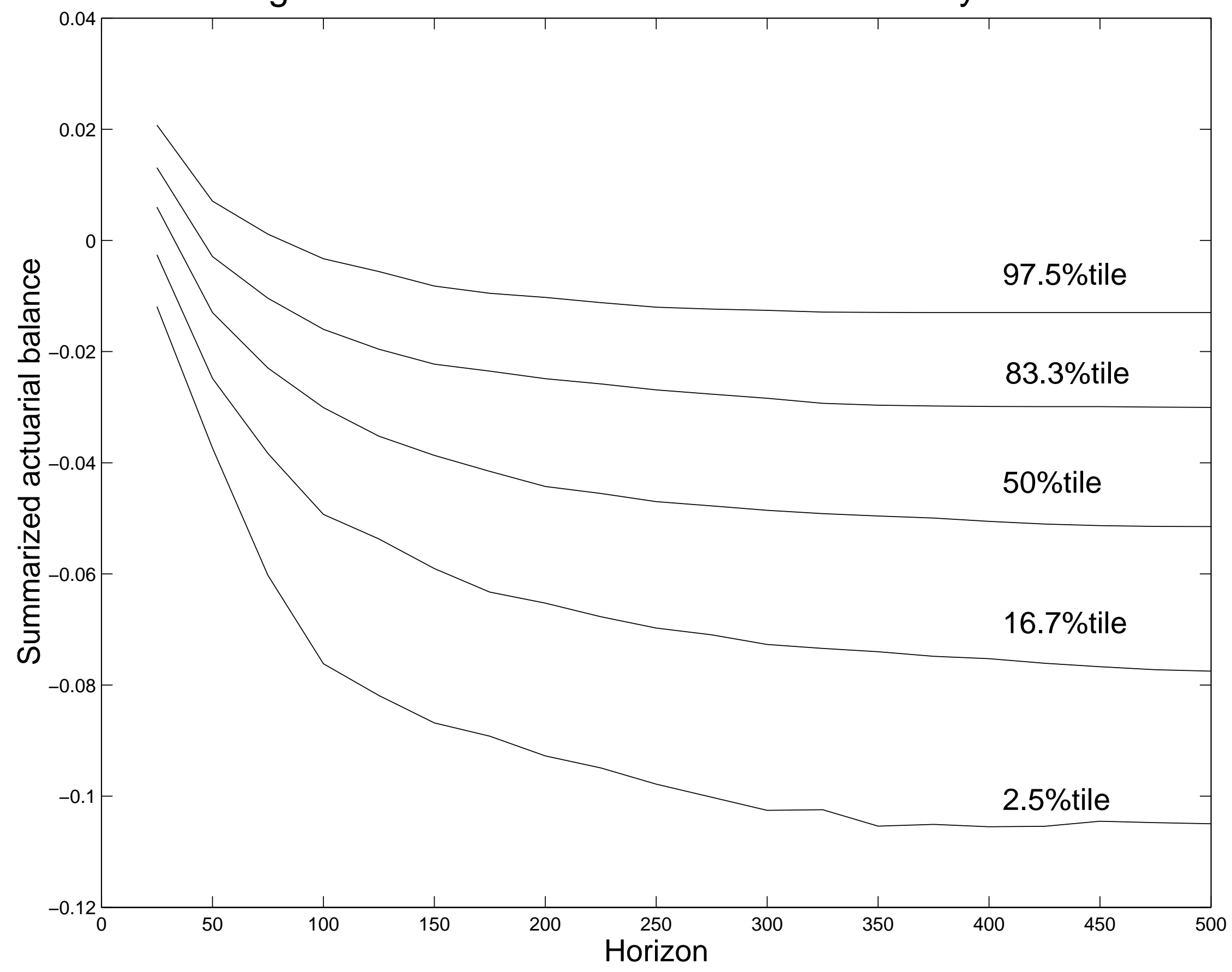


Figure 3.7 Distribution of 500-year summarized actuarial balance

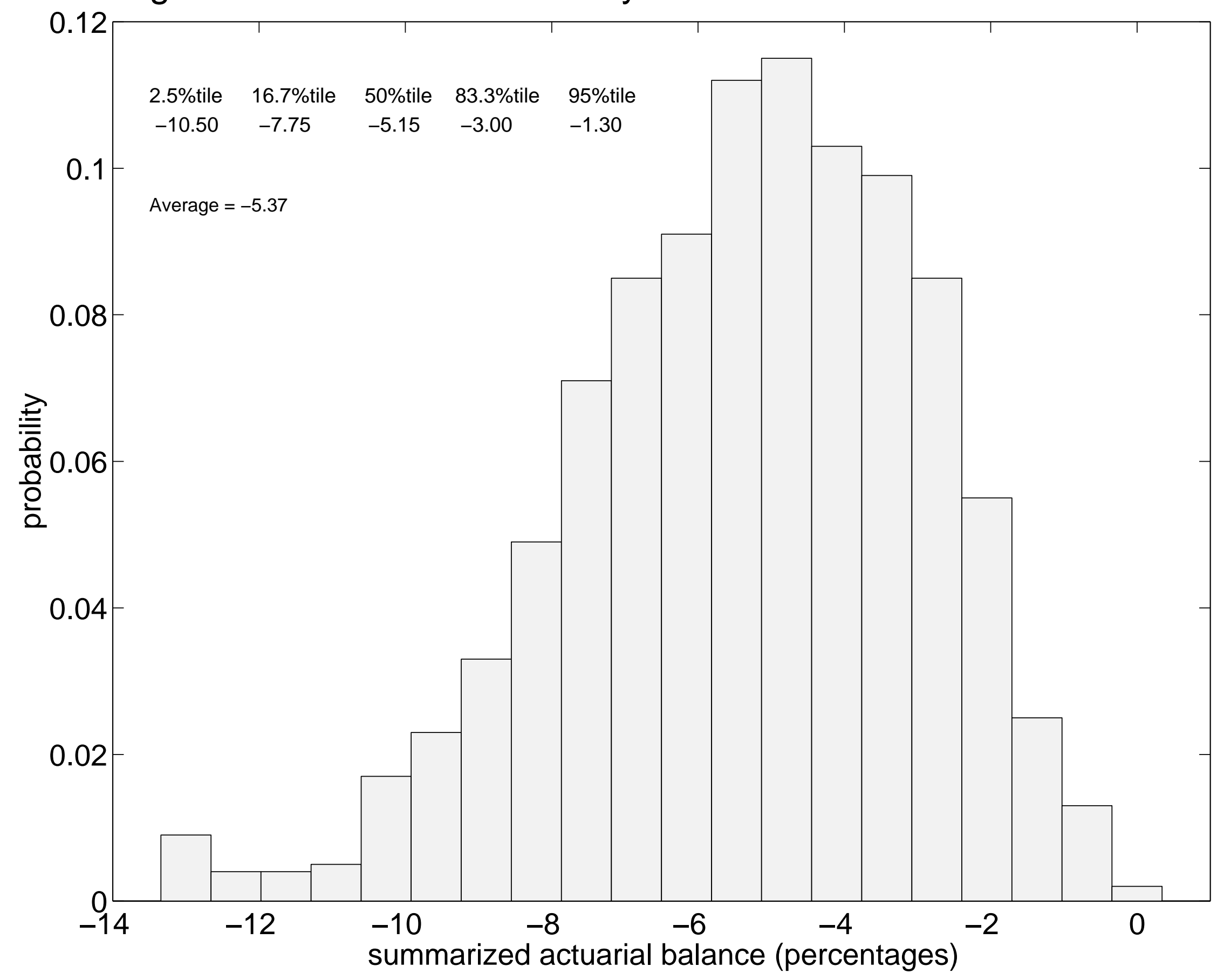


Figure 3.8 Sustainable tax rate under stable assumption by 500 -year actuarial balance

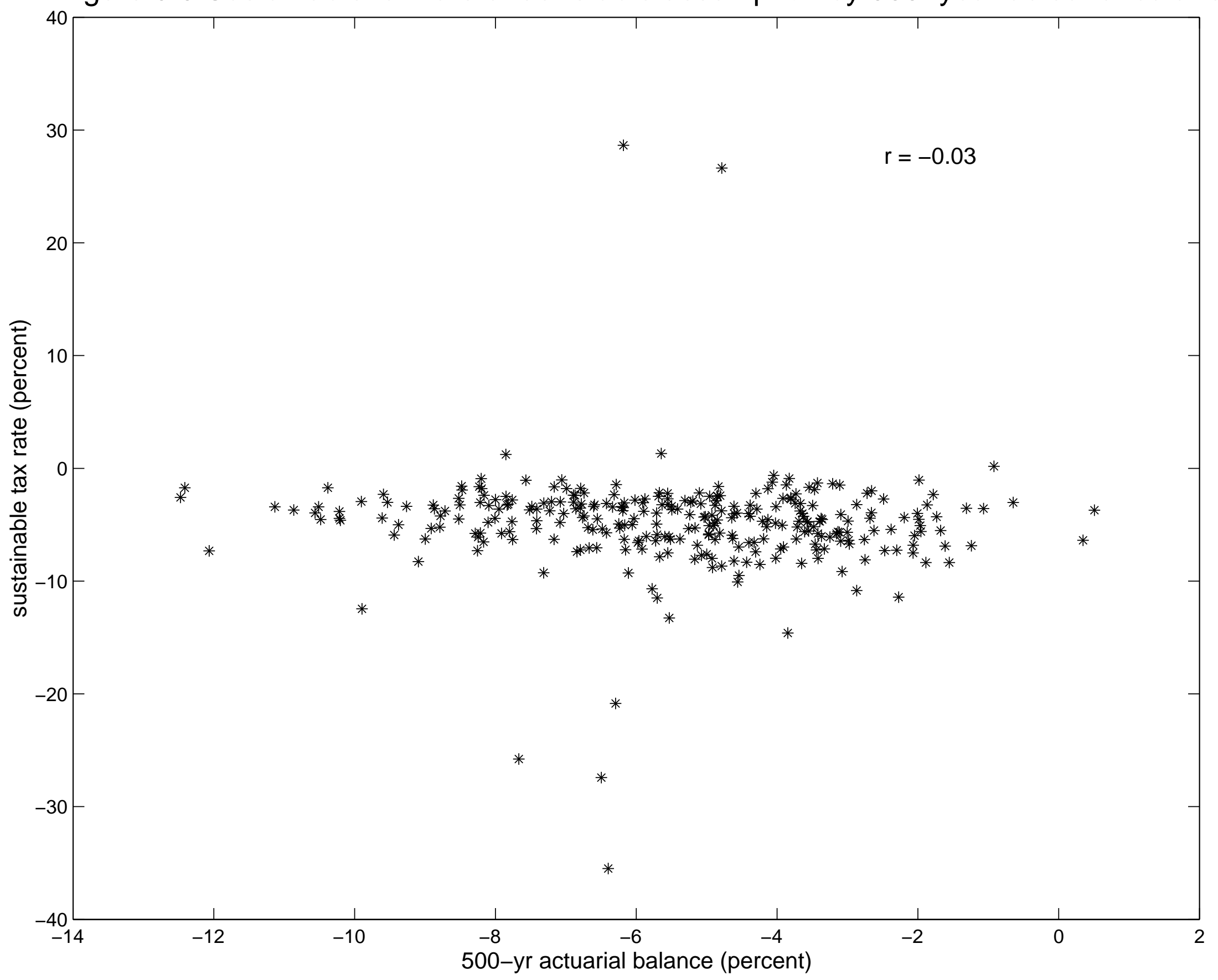

SusRateByActBal $\quad$ 04-Jul-2004 15:10:51 
Figure 3.9 Distribution of 500-year open group actuarial deficit

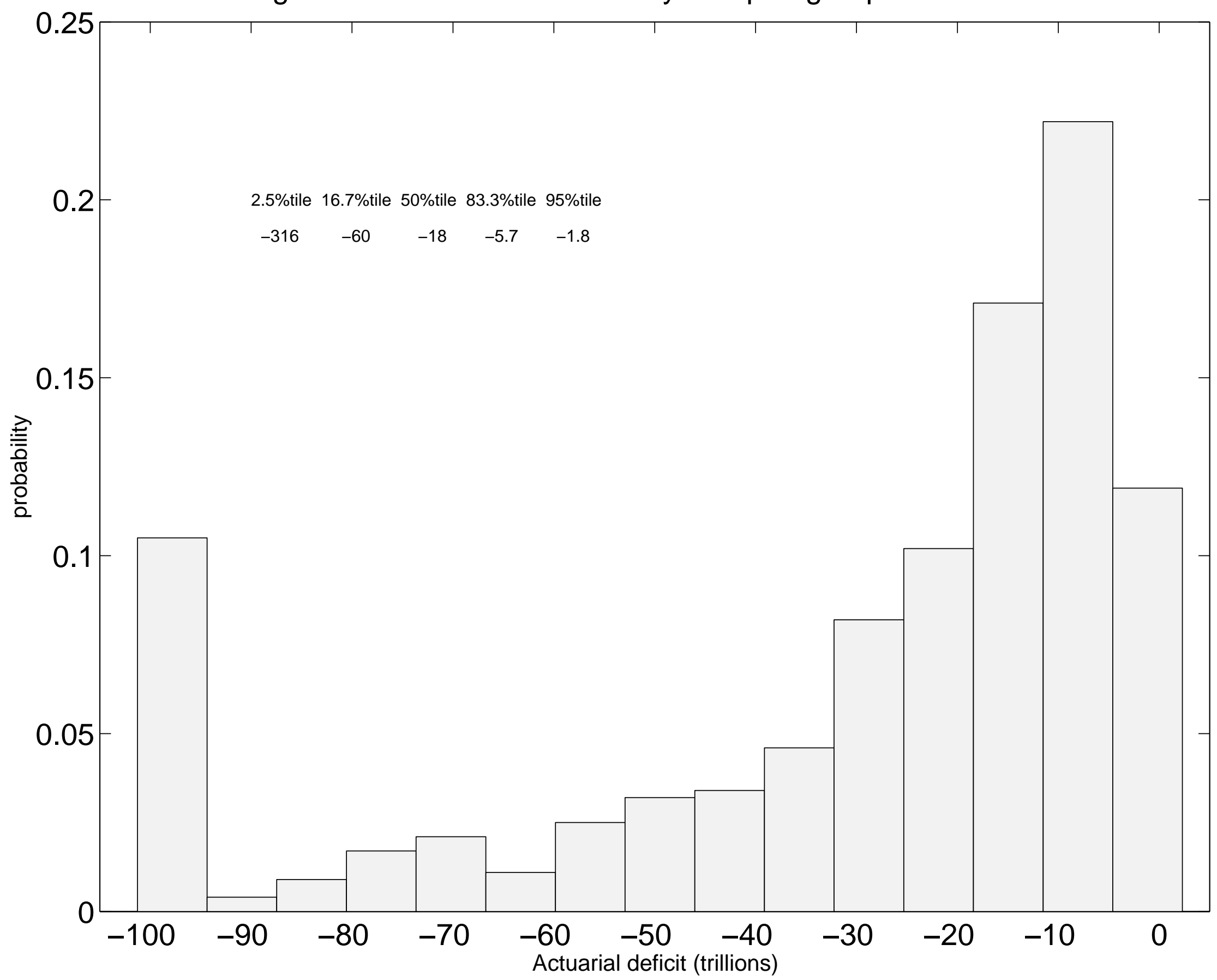

OpenActuarialDeficit $\quad$ 03-Oct-2004 12:41:52 
Figure 3.10 Distribution of date of insolvency with 5.147 tax increase

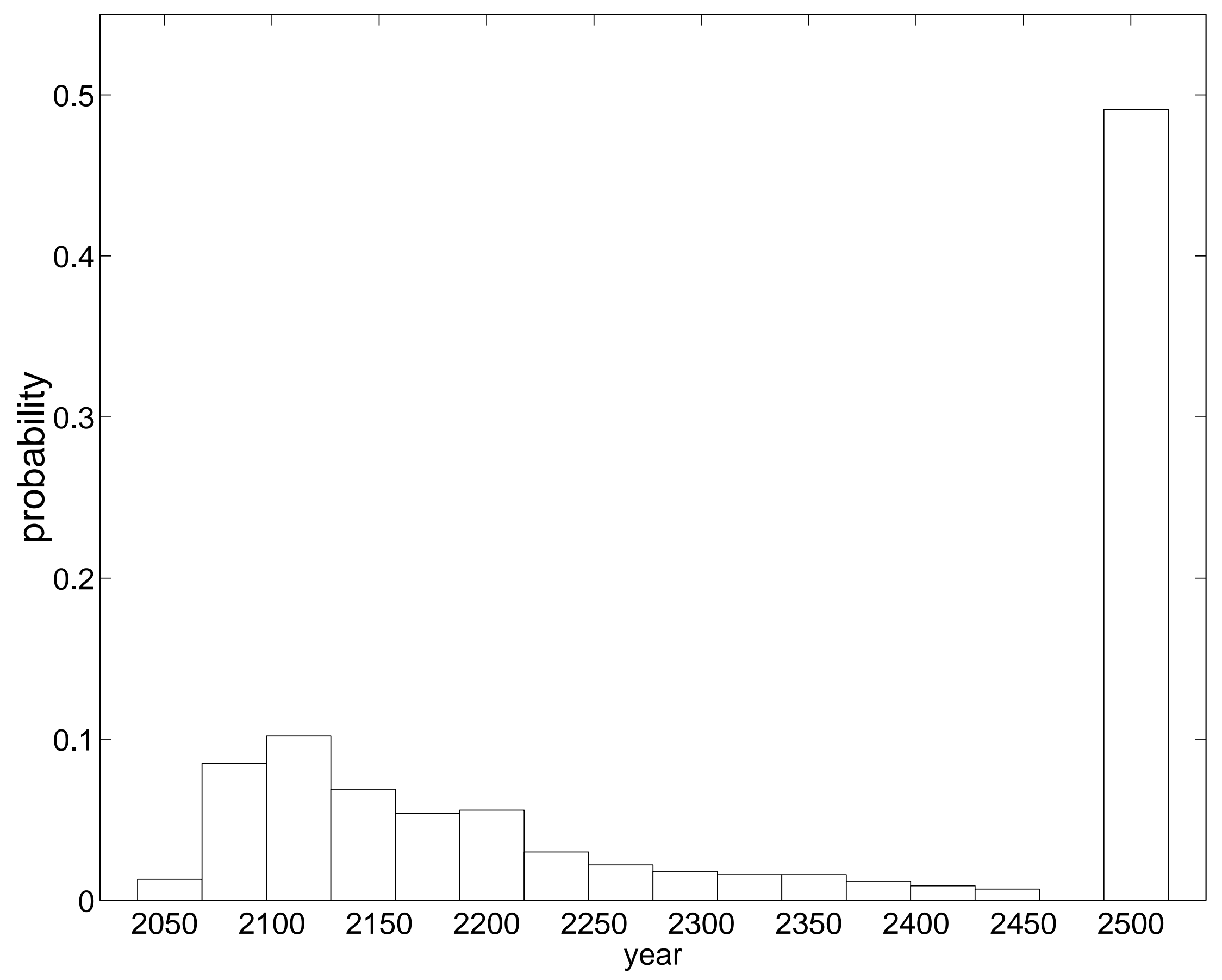


Figure 3.11 Distribution of date of insolvency with $4.36 \%$ tax increase

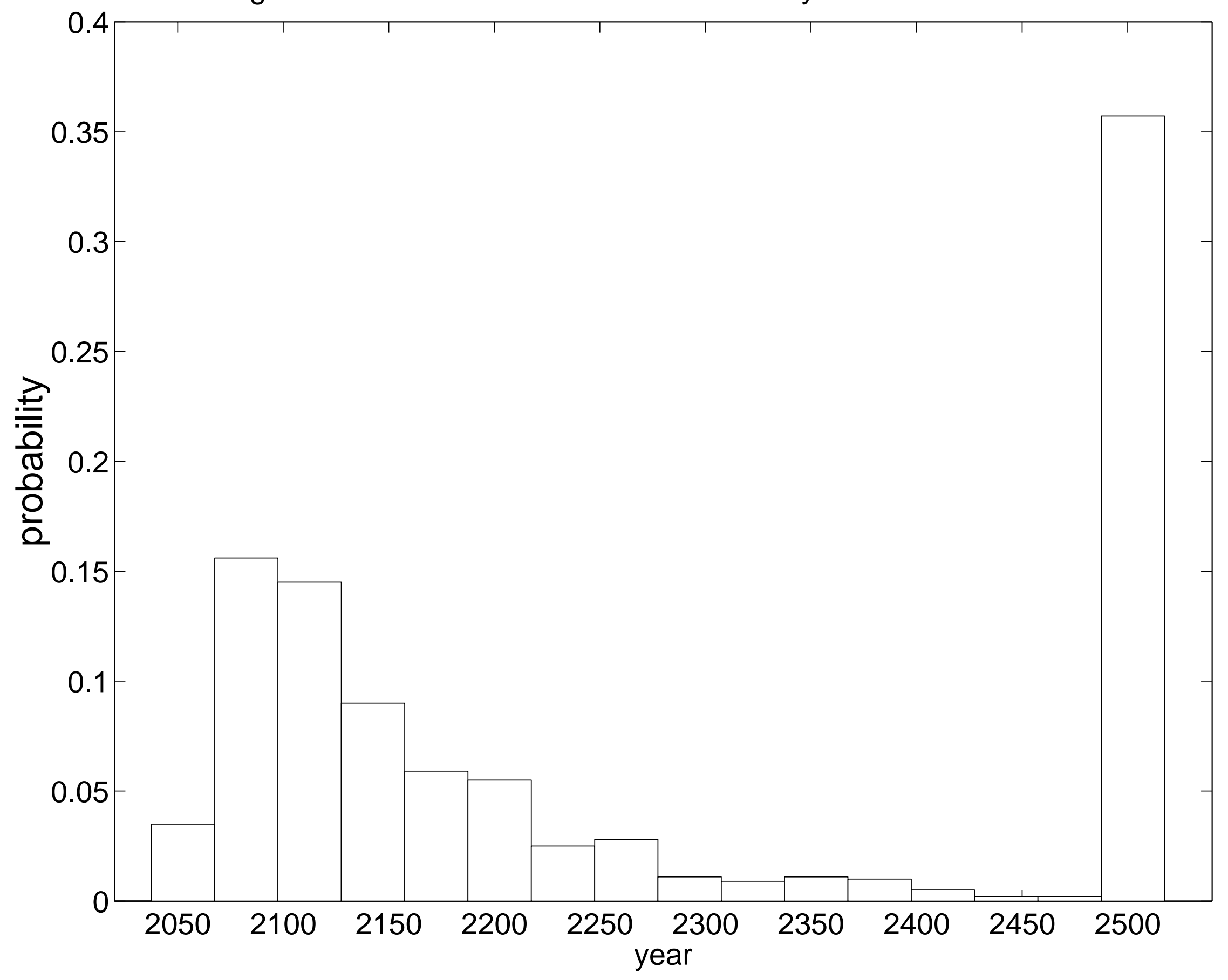


Figure 3.12 Median trust fund ratio with three tax increases

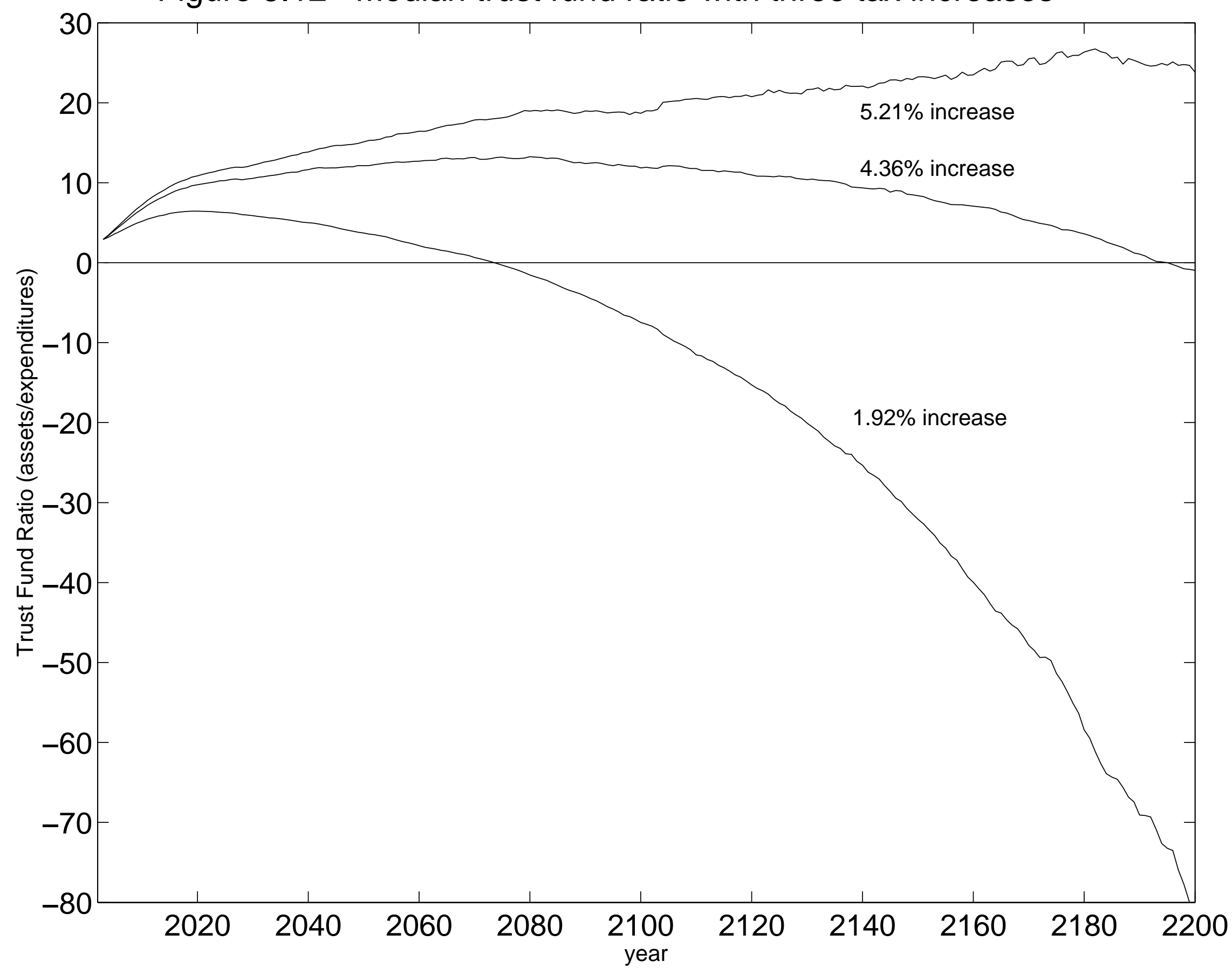

TFRtaxinc 14-Jul-2004 00:11:48 
Figure 3.13 Median trust fund balance, 2002-2200, with $4.36 \%$ tax increase

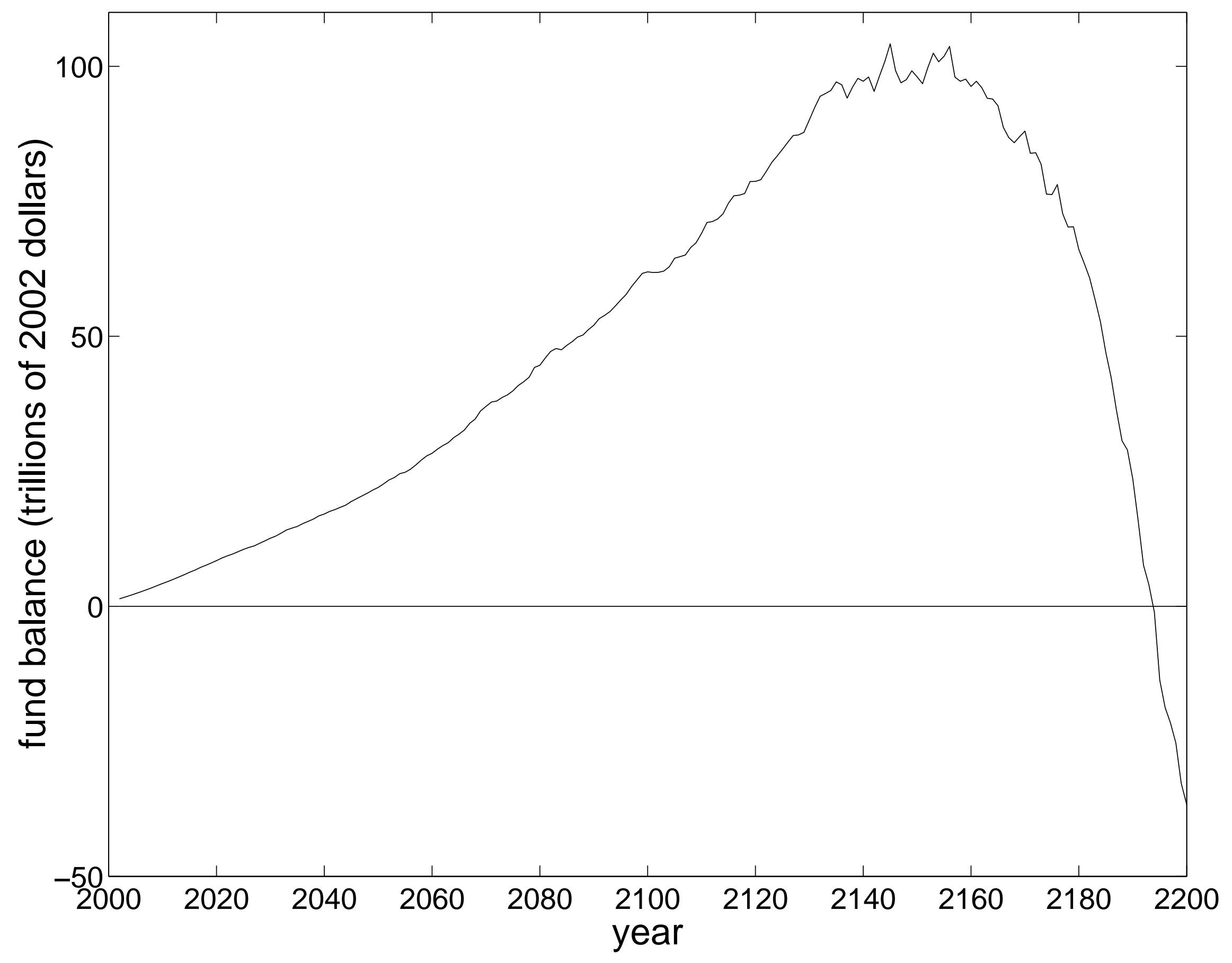


Figure 3.14 Trust fund balance as a percentage of GDP, initial tax increase of $4.36 \%$

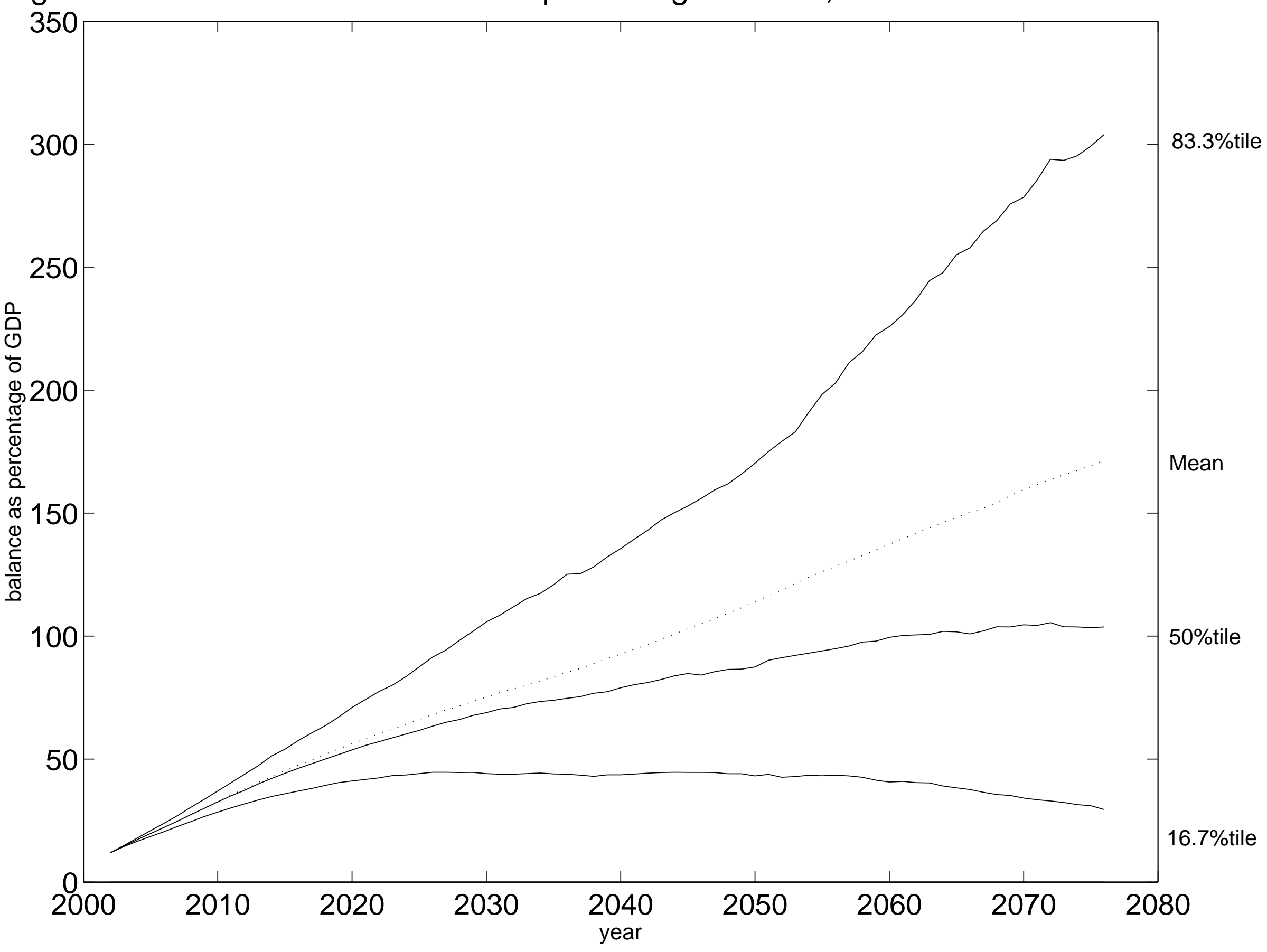

BalanceToGDP4p36 05-Jul-2004 22:13:31 
Figure 3.15 Trust fund balance as a percentage of GDP, initial tax increase of 5.15\%

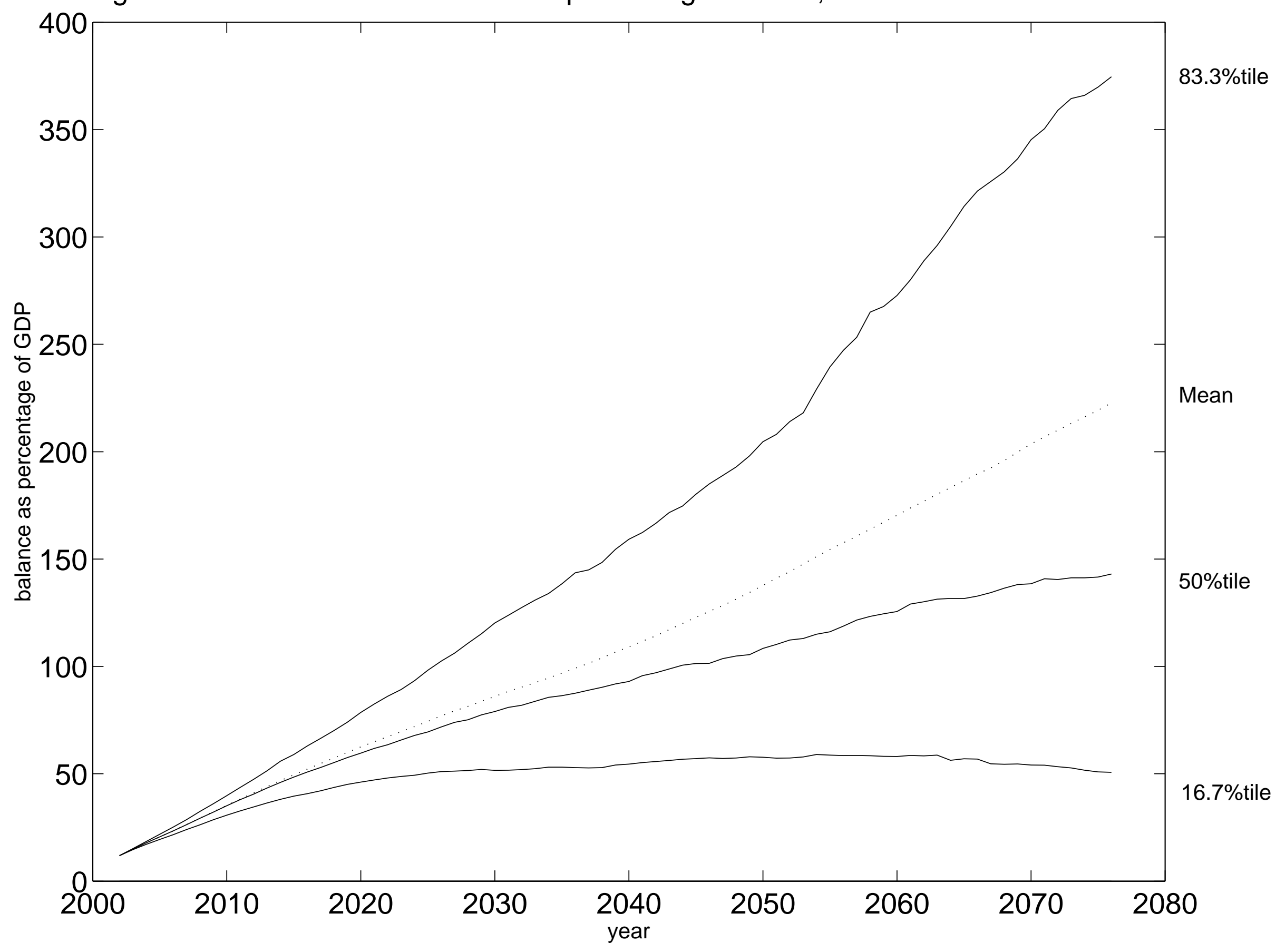

BalanceToGDP5p15 05-Jul-2004 22:10:26 
Figure 3.16 Trust fund ratio with $4.36 \%$ tax increase (sustainable FFRT)

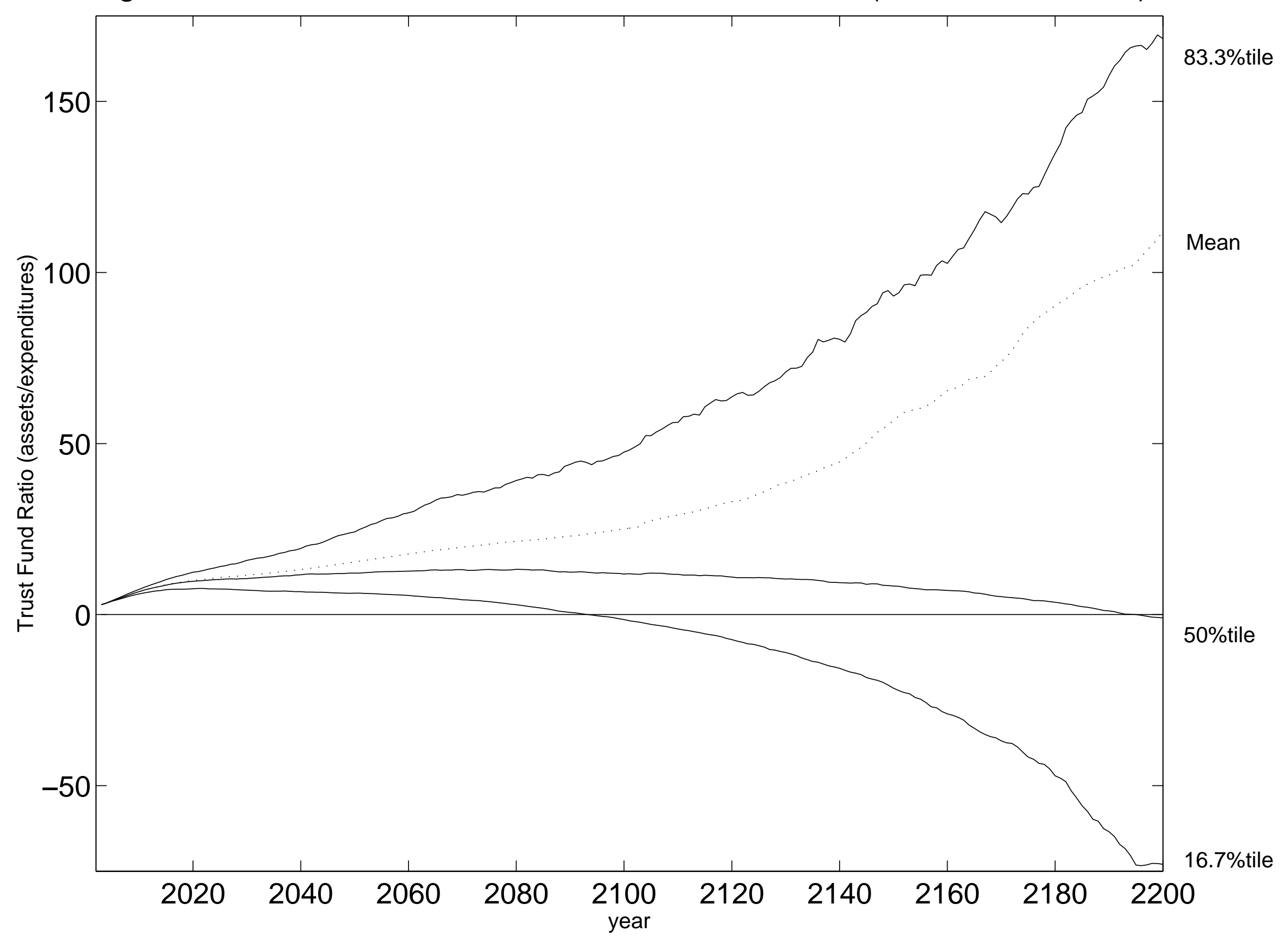


Figure 3.17 Trust fund ratio with $5.21 \%$ tax increase (sustainable FFRT, unstable assumption)

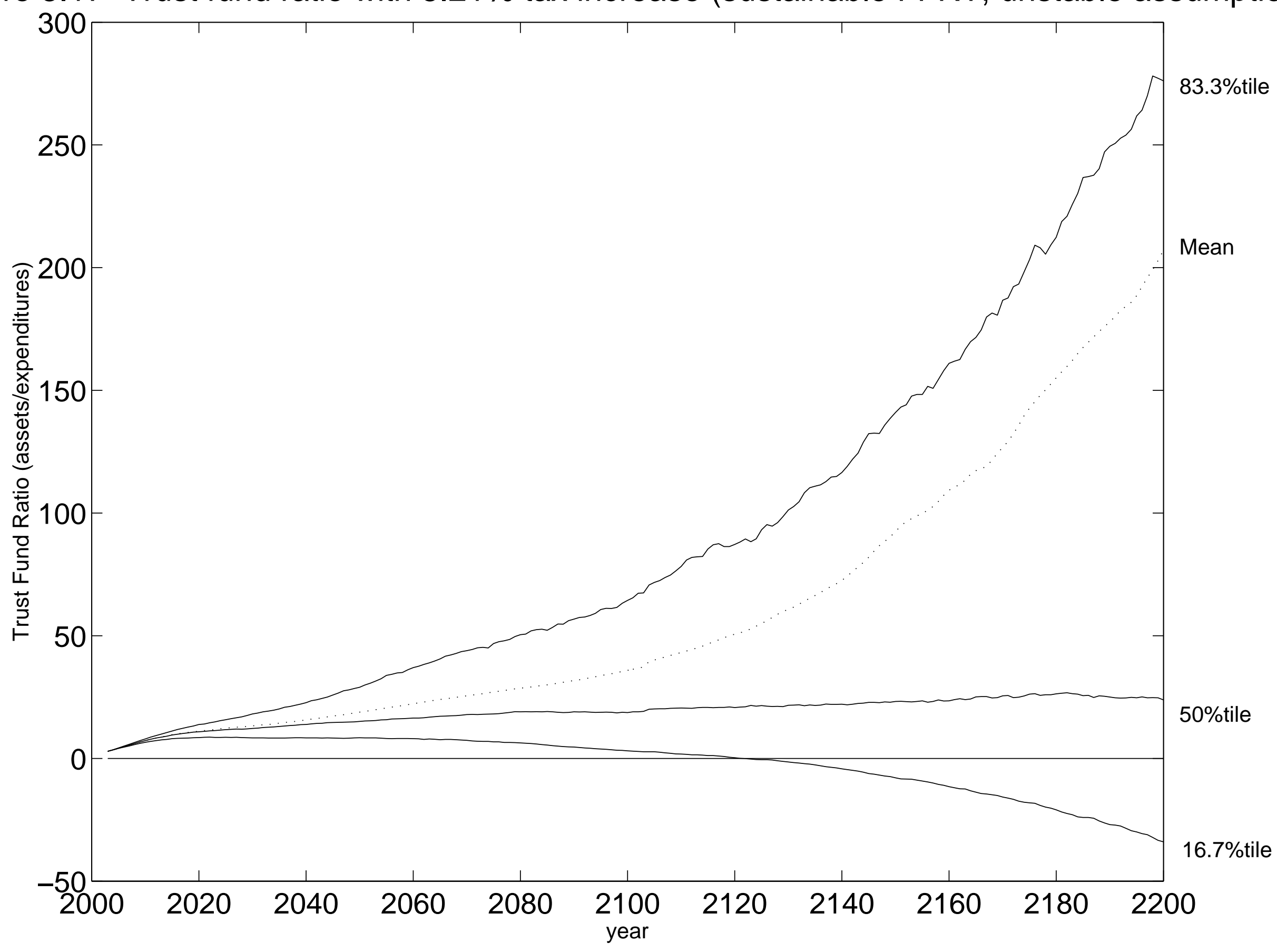

